\title{
CUA GUIDELINE
}

\section{CUA guideline on adult overactive bladder}

Jacques Corcos, MD, FRCSC'; Mikolaj Przydacz, MD'; Lysanne Campeau, MD, PhD, FRCSC'; Jonathan Witten, MD'; Duane Hickling, MD, MSCl, FRCSC ${ }^{3}$; Christiane Honeine, RN, BN';

Sidney B. Radomski, MD, FRCSC4; Lynn Stothers, MD, MHSc, FRCSC';

Adrian Wagg, MD, FRCP (Lond), FRCP (Edin), FHEA ${ }^{6}$

'Department of Urology, Jewish General Hospital, McGill University, Montreal, QC; ${ }^{2}$ Northern Alberta Urology Centre, Edmonton, AB; ${ }^{3}$ Division of Urology, Department of Surgery, The Ottawa Hospital,

Ottawa, ON; ${ }^{4}$ Division of Urology, Toronto Western Hospital, University of Toronto, University Health Network, Toronto, ON; ${ }^{5}$ Department of Urological Sciences, University of British Columbia, Vancouver, $B C$; ${ }^{D}$ Department of Medicine, University of Alberta, Edmonton, AB; Canada

Cite as: Can Urol Assoc J 2017;11(5):E142-73. http://dx.doi.org/10.5489/cuaj.4586

Published online May 9, 2017

\section{Table of contents}

Introduction.

J.Corcos

Definitions and epidemiology

S. Radomski

Impact on psychosocial life and patients' quality of life

L. Stothers (adults), A. Wagg (elderly)

Diagnosis

J. Corcos, M. Przydacz

Treatment

I. First-line treatment (behavioural therapies and lifestyle changes)

S. Radomski, C. Honeine (patient education)

II. Second-line treatment (pharmacological management)

L. Campeau L (adults), A. Wagg (elderly)

III. Third-line treatment (onabotulinumtoxinA)

D. Hickling

IV. Third-line treatment (PTNS, SNM)

$$
\text { G. Gray }
$$

V. Additional treatment (indwelling catheters, augmentation cystoplasty, urinary diversion)

$$
\text { G. Gray }
$$

Followup

D. Hickling

Required research, future trends, and conclusion

J.Corcos, et al 


\section{Introduction}

The overactive bladder (OAB) picture has dramatically changed in the last 20 years. A quarter century ago, this symptom complex did not even exist. Bladder hyperactivity and urgency incontinence were separate entities poorly understood and treated only with the first-generation antimuscarinic medications, propantheline and oxybutynin. Only in early 2000 came the concept of this syndrome made of four intimately linked symptoms that we today call OAB. With this concept, new pharmacological agents were launched. These new agents may have not dramatically improved symptoms in comparison with older agents, but undeniably have a more tolerable side effect profile, leading to better compliance and adherence. Neuromodulation was introduced a few years later, giving hope to the worst $O A B$ cases, but with a limited applicability due to its cost. A real revolution occurred around 2010 with the demonstration of onabotulinumtoxinA's efficacy in controlling the symptoms of OAB. Several years passed before it proved its place in the treatment algorithm for $\mathrm{OAB}$. It is definitely time for the Canadian Urological Association (CUA) to produce guidelines to help Canadian urologists better integrate a sequence of investigation, diagnosis, and treatment, which has become more complex over the years.

To do so, the CUA gave a group of experts, Canadian physicians and nurses, the difficult task of putting together a comprehensive document to guide all interested professionals in the management of this interesting and common syndrome, which has so much impact on our patients' quality of life.

An executive summary of the CUA guideline on OAB is available as an Appendix at www.cuaj.ca.

\section{Methodology}

A comprehensive review of OAB studies was performed using PubMed, MEDLINE, and the Cochrane Library databases. In addition, the bibliographies of all relevant articles were searched to avoid exclusion of significant articles. Focus was on systematic reviews, meta-analyses, and evidence-based recommendations, when available. Data from the latest consensus of the International Continence Society (ICS), the American Urological Association (AUA), the European Association of Urology (EAU), the National Institute for Health and Care Excellence (NICE) were incorporated. All articles were reviewed using the evidence-based medicine levels, with the Oxford grading system for recommendations. ${ }^{1}$ Where the literature was inconsistent or scarce, a consensus expert opinion was generated to provide appropriate guidelines.

\section{Definitions and epidemiology}

In presenting the epidemiology of $\mathrm{OAB}$, it should be noted that no level 1, grade $A$ data exist since most studies incorporate only surveys in large numbers.

\section{Definitions}

According to the ICS definition, OAB consists of urinary urgency with or without urgency urinary incontinence (UUI), often accompanied by frequency and nocturia, in the absence of urinary tract infection (UTI) or other obvious pathology. 2,3 The primary urodynamic abnormality underlying $O A B$ is detrusor overactivity (DO). Lower urinary tract storage symptoms include OAB symptoms (urgency, urgency incontinence, frequency, and nocturia) and stress incontinence. Voiding symptoms include slow and/or interrupted stream, terminal dribble, hesitancy, and straining. The ICS defines urinary frequency as the patient complaint of urinating too often during the daytime., ${ }^{2,3}$ The ICS definition of nocturia is one or more voids per night, preceded and followed by sleep. Urgency is the complaint of a sudden, compelling desire to pass urine that is difficult to defer. Urgency incontinence is the involuntary leakage of urine accompanied or immediately preceded by urgency. These standard definitions are, in places, controversial. Frequency has conventionally been considered as voiding $\geq 8$ times per 24 hours. ${ }^{4}$ Many clinical trials assessing the success of $\mathrm{OAB}$ medications have used this definition. Some of the epidemiological data presented below also have examined this definition. Along the same lines, many experts believe that one episode of nocturia per night may be considered normal. ${ }^{5}$ As a result, nocturia of two or more times may be a more realistic determinant of significant symptoms and bother. The data presented below will incorporate both definitions.

\section{Epidemiology}

Although the overall prevalence of $\mathrm{OAB}$ is similar between men and women, there are sex-specific differences in the prevalence of various symptoms within the OAB complex. ${ }^{6,7}$ Anatomical and physiological differences in the lower urinary tract of males and females may help to explain these variations. ${ }^{7}$ Overall, OAB prevalence rates in large population-based studies range from $7-27 \%$ in men and $9-43 \%$ in women. ${ }^{8-15}$ Interestingly, a proportion of OAB cases $(37-39 \%)$ remit during a given year, but the majority of patients have persistent symptoms. ${ }^{16,17}$

The EPIC study is one of the largest population-based surveys that examined the prevalence of lower urinary tract symptoms (LUTS) and OAB. The study had over 19000 participants and showed an overall OAB prevalence of $11.8 \%$ (10.8\% in men and $12.8 \%$ in women) using ICS definitions. ${ }^{12}$ 
The National Overactive Bladder Evaluation (NOBLE) study estimated the prevalence of $O A B$, including the influence of sex on $\mathrm{OAB}$ and its symptoms, again using ICS definitions. ${ }^{13}$ Furthermore, it focused on the impact of $O A B$ on quality of life, sleep, and general mental health. Out of over 17000 households that were contacted, 5204 participants completed the interview. The NOBLE study showed an overall OAB prevalence of approximately $16 \%$, with no significant differences between the two sexes $16 \%$ in men, $16.9 \%$ in women). The Epidemiology of Lower Urinary Tract Symptoms (EpiLUTS) survey was a population-based, cross-sectional survey conducted to evaluate the prevalence and bother of $\mathrm{OAB}$, as well as to update the results of the NOBLE survey done in $2003 .{ }^{10}$ In contrast to the EPIC and NOBLE studies, the EpiLUTS survey used symptoms that were defined as "sometimes." Using this definition, the study found the overall prevalence of OAB was $35.6 \%$. When defined as "often," the overall prevalence decreased to $24.7 \%$. Milsom et al also conducted a population-based study using specific definitions of symptoms of $\mathrm{OAB}$, as well as stress incontinence and prostatic obstruction (these were not ICS definitions)..$^{15}$ Similar to the NOBLE study, Milsom's group found an overall prevalence of OAB symptoms of $16.6 \%$. The overall prevalence of $\mathrm{OAB}$ in a Canadian population was estimated to be $18.1 \%$ ( $14.8 \%$ in men, $21.2 \%$ in women) by Corcos and Schick. ${ }^{9}$ More recently, Herschorn et al reported OAB symptoms in $13.9 \%$ of respondents $(13.1 \%$ of men, $14.7 \%$ of women) in a Canadian population-based study. ${ }^{14}$

The prevalence of OAB symptoms increases with age in both sexes. ${ }^{12,13,16}$ The EPIC study showed that among participants aged $40-59$ years, $51 \%$ of men and $56 \%$ of women experienced storage symptoms. ${ }^{12}$ Thirty eight percent of men and $49 \%$ of women under 39 years of age also experienced storage symptoms. In the NOBLE study, UUI increased with age in both sexes, increasing from $2 \%$ to $19 \%$ in women after the age of 44 years and $0.3 \%$ to $9 \%$ in men, with a marked increase after 64 years. ${ }^{13}$ While there is a steady increase with age of $\mathrm{OAB}$ with $\mathrm{UUI}$ in women throughout their lifetime, the main increase in the prevalence of $O A B$ with UUI in men only occurs after the age of 65 years. In contrast, the prevalence of OAB without UUI has a statistically significantly steeper age-related increase in men than in women. This increased in men from $8.5 \%$ in those less than 45 years of age to $21.8 \%$ in men after 55 years. In women, $\mathrm{OAB}$ without UUI increased gradually and reached a plateau after the age of 44 years. Similarly, the prevalence of $\mathrm{OAB}$ symptoms in men increased slowly until the age of 70 , but then had a sharp increase after 75 years of age, with a slight fall in prevalence between the ages of 70-75 years. ${ }^{15}$ In women, there was also a gradual increase seen until the age of 60 , with a leveling off seen between 60 and 70 years of age and a gradual increase in prevalence thereafter. In the Canadian study by Herschorn et al, OAB symptoms were also more common with increasing age $(23.8 \%$ for $>60$ years old vs. $12.2 \%$ for $<60$ years old.). ${ }^{14}$

The NOBLE study found that while the prevalence of OAB with and without UUI in women was similar $(9.3 \%$ and $7.6 \%)$, in men the prevalence of OAB with UUI (2.6\%) was much lower than the prevalence of $\mathrm{OAB}$ without UUI $(13.4 \%) .{ }^{13}$ Both the EpiLUTS and Milsom studies reported UUI to be more prevalent in women. ${ }^{10,15}$ Nevertheless, these surveys largely excluded older persons living in institutions.

When examining individual symptoms, the prevalence may vary depending on the OAB definition used. In the EPIC study, using the ICS definition of nocturia as one or more voids per night, the general prevalence of nocturia was $48.6 \%$ in men and $54.5 \%$ in women. ${ }^{5}$ In the same study, when nocturia was defined as two or more voids per night, the prevalence decreased to $20.9 \%$ in men and $24.0 \%$ in women.

Most patients have a combination of OAB symptoms. In the EPIC study, approximately $50 \%$ of OAB patients had a combination of two symptoms and approximately one-third of patients reported a combination of three OAB symptoms. ${ }^{5}$ The EpiLUTS study also found that isolated symptoms were rare in OAB. At the other end of the spectrum, urgency, UUI, frequency, and nocturia together were found in $16 \%$ of men and $20 \%$ of women in the study. ${ }^{10}$

Several studies have shown an association between $O A B$ and bladder outlet obstruction (BOO) due to benign prostatic hyperplasia (BPH) recognizing them as common comorbid conditions (Level of evidence $\mathbf{1 b}$, Grade B).$^{18}$ Up to $50 \%$ of men with $\mathrm{BOO}$ are estimated to have OAB symptoms. ${ }^{19,20}$ Some studies have noted that $50 \%$ of men with LUTS and urodynamically confirmed BOO have DO. ${ }^{21}$ OAB symptoms may develop secondary to BOO..$^{22}$ Men younger than 50 years of age with $\mathrm{OAB}$ symptoms are less likely to have significant BOO. ${ }^{20}$ De Nunzio et al examined 255 patients with symptomatic $\mathrm{BOO}$ who underwent urodynamic testing both at baseline and at a mean of two years of followup. ${ }^{23}$ In general, DO was highly prevalent in patients with $\mathrm{BOO}$. Overall, $52 \%$ and $40 \%$ of patients with $\mathrm{BOO}$ demonstrated DO at baseline and followup, respectively. ${ }^{23}$ Lee et al studied 144 patients with LUTS in a prospective analysis, ${ }^{19} 47 \%$ of patients had BOO and DO (DO was based on the absence or presence of involuntary detrusor contractions on cystometry).

Summary and recommendations: $O A B$ is a symptom syndrome consisting of urinary urgency with or without urgency incontinence, often accompanied by frequency and nocturia, in the absence of UTI or other obvious pathology. $O A B$ is common in both sexes, with increasing prevalence with age. The overall prevalence of $O A B$ in a Canadian population is estimated at 14-18\%. Most patients have a combination of $O A B$ symptoms. In men with $B P H, O A B$ and $B O O$ often coexist (Evidence strength Grade B). 


\section{Impact on psychosocial life and patients' quality of life}

Recent advances in the methods used to measure well-being and quality of life (QOL) have led to a greater understanding of the impact of bladder disease on the various facets of day-to-day life. Understanding how urinary incontinence (UI) influences changes in health status, including physical, emotional, social, and mental functioning is critical because of the chronic nature of the condition and the fact that these changes can be lifelong. ${ }^{24}$

It is important for both clinical and research purposes that $\mathrm{OAB}$ is accurately diagnosed and symptom severity classified. ${ }^{25}$ Usually, a distinction is made between QOL and well-being in those patients with incontinence (OAB-wet) and those without (OAB-dry). A large array of specific tools are available to evaluate individual aspects of $\mathrm{QOL}$, from the accomplishment of daily activities to sexual satisfaction. ${ }^{26}$ QOL assessment should incorporate self-noted symptoms and patients' perceptions of their impact, and re-evaluation should occur following interventions. ${ }^{27}$ In this way, the full impact of $\mathrm{OAB}$ and any resulting incontinence on daily life, social, and sexual activities is comprehensively quantified.

Individuals who develop UI have their QOL affected in multiple ways; much depends on how the symptoms encountered and the complications they cause result in social and psychological restrictions like isolation, loss of confidence, depression, the avoidance of one's sexual partner, and reduced contact with family members. ${ }^{28,29}$ Besides these biopsychological aspects of UI, some complications, like chronic irritation and infection, directly threaten health; UI interferes with work, as well as social activities, hence the economic impact of UI must also be considered. ${ }^{30}$

The assessment of QOL in health outcomes research is important. The National Audit of Continence Care from the U. K. investigated assessment of QOL in individuals with incontinence and concluded that it is underevaluated. ${ }^{24}$

\section{Domains affected by overactive bladder with or without incontinence}

\section{Daily life}

As numerous factors affect the overall quality of daily life of patients with UI, it is a difficult parameter to measure; the severity of incontinence, type of work, household duties, and requirement for taking care of personal hygiene during working hours are key issues. ${ }^{31}$

\section{Recreational life}

In industrialized societies, QOL is dictated to a large degree by the ability to include recreational activities, such as sports, hobbies, and travel. Women who experience UI often indi- cate that while their general health is satisfactory, their QOL is affected because they are no longer able to participate in their sport of choice or to engage fully in social activities they previously enjoyed. ${ }^{32}$

\section{Psychological concerns}

Numerous authors have reported a direct correlation between $\mathrm{UI}$ and depression. ${ }^{33-35}$ Thirty percent of patients with $\mathrm{OAB}$ have depression; those who are depressed record more severe UI symptoms, greater disturbance to their daily living, and more adverse impact on their QOL compared to those without depression. Nygard et al reported that $80 \%$ of women with severe UI are likely to develop depression compared with $40 \%$ of those with mild incontinence. ${ }^{36}$ Depression often manifests as a lack of self-motivation; behavioural therapies tend to have a limited effect in these patients. ${ }^{37}$

\section{Isolation}

$\mathrm{OAB}$ patients commonly report anxiety and constant worry about reaching a toilet in time to avoid UI. ${ }^{38}$ For some, such anxiety induces feelings of hopelessness and depression that leads to social isolation. Nocturia-induced sleep disturbance also predisposes $\mathrm{OAB}$ patients to daytime fatigue and exhaustion that may exacerbate feelings of depression resulting from self-induced isolation. ${ }^{38}$

\section{Sexuality}

OAB has a broad adverse impact on female sexuality in sexually active women. Incontinent patients have a much higher prevalence of sexual dysfunction than those who are not incontinent. ${ }^{39}$ Many studies report that dysfunction is the major, albeit multifaceted, issue that negatively impacts QOL. ${ }^{40}$ Contributing factors include the occurrence of dermatitis caused by urine leakage and depression and a lower libido that may result from fear and embarrassment about experiencing UI during sexual intercourse. ${ }^{39}$

\section{Work productivity}

OAB generates substantial difficulties in the context of employment; work productivity questionnaires allow this to be evaluated. ${ }^{41}$ Use of the Work Productivity and Activity Impairment questionnaire found that men and women with $\mathrm{OAB}$ were more likely to not be able to work and to have lower productivity when they did work when compared with those without OAB. ${ }^{27} \mathrm{~A}$ comparable effect was found in the U.S. using a modified Work Limitations Questionnaire. ${ }^{42}$

Comparison suggests that the impairment on work in those with $\mathrm{OAB}$ is close to that reported in other chronic 
conditions, including rheumatoid arthritis and asthma. These findings highlight the economic burden due to decreased productivity related to $\mathrm{OAB}$; cost-benefit analyses in future research could estimate the impact of treatment results from an economic perspective. ${ }^{41}$

\section{QOL questionnaires}

In the context of the impact on $\mathrm{OAB} / \mathrm{UI}$ on $\mathrm{QOL}$, national and international guidelines identify questionnaires that can evaluate the type, severity, and impact of $\mathrm{OAB} / \mathrm{UI}$ symptoms. These instruments are important measures in both a clinical and research context. They allow healthcare providers to quantify impact on QOL, aid understanding of patients experience and what their needs are, and evaluate the effects of medical and surgical treatment. ${ }^{26}$ Shared with patients, the information derived from questionnaires also enables a better appreciation of how their symptoms affect their daily living. ${ }^{43}$ Current questionnaires related to $\mathrm{OAB}$ with its impact on QOL, both with and without UI, cover different domains, and vary in terms of the number of question incorporated and how the score is applied (Table 1).

\section{Special consideration for older persons}

The absolute number of older people with LUTS and UI will increase as greater numbers of people survive into later life, something common to both the developed and the developing world. Currently, UI constitutes a problem that affects the lives of an estimated 400 million persons worldwide. ${ }^{44-49}$ In Canada, data on the prevalence of LUTS/ UI in persons over 65 years of age are sparse, but appear to follow the pattern observed in large, multinational stud- ies. ${ }^{12,14} \mathrm{UUI}$ and $\mathrm{OAB}$ are the commonest underlying causes of incontinence in older persons. ${ }^{3,12} \mathrm{OAB}$ is also likely to be a marker of frailty in older persons; a case-control study of nursing home residents in the U.S. found that those with $\mathrm{UI}$ or OAB exhibited higher rates of cognitive impairment, mobility impairment, and higher numbers of comorbidities than those without..$^{50}$

While UI and LUTS are often seen as benign, they are stigmatizing conditions, which are often underreported and undertreated, particularly in older individuals. ${ }^{51-53} \mathrm{~A}$ recent review has identified that relative severity, attitudes to normal aging, self-care, and coping, along with limited knowledge of available treatments and relationships with care providers account for the majority of reasons of either not seeking help or delaying healthcare-seeking. ${ }^{54}$ There is also a significant increase in the likelihood of institutionalization, ${ }^{48}$ particularly when associated with a dementia diagnosis, ${ }^{55}$ although this evidence is inconsistent. ${ }^{56}$

While there is a large body of evidence concerning the psychosocial impact of UI on community dwelling adults, , $^{57-61}$ its impact on psychosocial well-being and QOL in older people has been seldom researched. ${ }^{62}$ Specifically, the impact of OAB on older people with significant comorbidity has been the subject of little if any systematic research; a study of 252 men and women from Austria of mean age 75 concluded that individuals with pure urgency or mixed UI reported more moderate to severe impairment in QOL than those with pure stress UI (35\% vs. $20 \%$ ), like findings in the adult population. However, QOL impairment caused by UI was moderate: only $6.5 \%$ of men and $15 \%$ of women experienced a moderate to severe QOL impairment because of UI. ${ }^{63}$

Residents of institutional care are often excluded from research because of either significant physical or cognitive

\begin{tabular}{|c|c|c|c|c|c|c|c|c|c|c|}
\hline & $\begin{array}{c}\text { Sexually } \\
\text { active }\end{array}$ & $\begin{array}{c}\text { Physically } \\
\text { active }\end{array}$ & $\begin{array}{c}\text { Socially } \\
\text { active }\end{array}$ & $\begin{array}{c}\text { Social } \\
\text { isolation }\end{array}$ & Depression & Emotion & $\begin{array}{c}\text { General } \\
\text { health }\end{array}$ & Sleep & $\begin{array}{l}\text { Physical } \\
\text { limitation }\end{array}$ & UI \\
\hline $\mathrm{ICIO}$ & $x$ & & & & & $x$ & & & & \\
\hline I-QOL & & $x$ & $x$ & $x$ & & & & & & \\
\hline $\mathrm{KHO}$ & $x$ & $x$ & & $x$ & & $x$ & $x$ & $x$ & $x$ & $\mathrm{x}$ \\
\hline FSFI & $x$ & & & & & & & & & \\
\hline PFIQ & & $x$ & $x$ & & & $x$ & & & & \\
\hline PISQ & $x$ & & & & & & & & & \\
\hline SF-36 & & $x$ & $x$ & & & $x$ & $x$ & & $x$ & \\
\hline OBA-q & & & $x$ & & & & & $x$ & & \\
\hline UIQ-7 & & $x$ & $x$ & & $x$ & $x$ & & & & $\mathrm{x}$ \\
\hline CES-D & & & & & $x$ & & & & & \\
\hline MOS sleep & & & & & & & & $x$ & & \\
\hline IIQ & & $X$ & & & & $x$ & & & & $\mathrm{X}$ \\
\hline
\end{tabular}

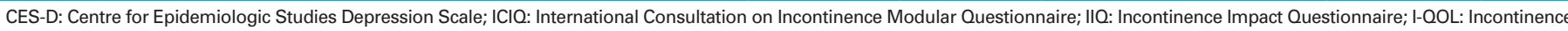
Quality-of-Life Questionnaire; FSFI: Female Sexual Function Index; KHO: King's Health Questionnaire; MOS sleep: Medical Outcomes Study sleep scale; OAB-q: Overactive Bladder

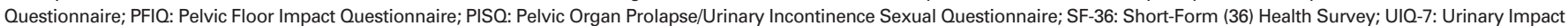
Questionnaire; Ul: urinary incontinence. 
impairment and thus there are even fewer data from this group. In one of the few studies from nursing homes, the impact of UI from 133111 residents was examined in the Minimum Data Set Resident Assessment Instrument and a statistically significant association between UI and poorer QOL in residents with moderate cognitive and functional impairment was found. Moreover, new or worsening UI was second only to cognitive and functional decline in predicting poor QOL. ${ }^{64} \mathrm{~A}$ single Canadian study using semistructured interviews conducted with six elderly women from two nursing homes noted a loss of dignity, inability to remain active, feelings of regression, dependence on others, and embarrassment, which affected their self-esteem. The women's embarrassment and belief that UI was untreatable led to secrecy about their UI, and they tended to socially isolate themselves. ${ }^{65}$ Notwithstanding these qualitative studies, no validated assessment tool for QOL in the frail older person with UI exists, although one is under development under the auspices of the International Consultation on Incontinence.

Social isolation is often a consequence of incontinence, with a well-described association between $\mathrm{UI}$ and the restriction of social activities. ${ }^{66}$ Whilst there is little published evidence of the specific influence of $O A B$, social isolation, and particularly loneliness, is of particular concern for the wellbeing of the elderly, having been implicated in intellectual decline and as a risk factor for the diagnosis of dementia. ${ }^{67}$

The association between depression and $\mathrm{OAB}$ has been reported by many investigators. ${ }^{33,35,59,68} \mathrm{~A}$ single cross-sectional study of 153 Japanese people aged 70 years or older showed a significant association between $\mathrm{OAB}$ and depressive symptoms in univariate regression. Multivariate analysis showed that the risk of having $\mathrm{OAB}$ was significantly higher in subjects with depressive symptoms, with an odds ratio of 2.37 (95\% confidence interval [CI] 1.60-3.52) (Level of evidence $3 \boldsymbol{b}$, Grade C). ${ }^{69}$ However, no study has specifically addressed those with multimorbidity or frailty, who might otherwise be considered "geriatric."

Summary and recommendations: Since $O A B$ is not lifethreatening, its impact on QOL plays a major role in the decision to treat patients. The significant negative impact that $O A B$ has on daily activities, mental health, sexual function, and marital satisfaction has been highlighted by a number of studies. Furthermore, $O A B$ symptoms are linked to depressive illness. Usually distinction is made between $Q O L$ and well-being in those patients with incontinence $(O A B$-wet) and those without (OAB-dry). Individuals who develop UI have worse QOL. There is limited evidence concerning the psychosocial impact of $O A B$ in either frail or multimorbid older persons; however, currently available data suggest that it is a serious concern.

\section{Diagnosis}

\section{Medical history and physical examination}

There is a universal agreement that taking a history should be the first step in the assessment of OAB patients (Level of evidence $2 \boldsymbol{b}$, Grade B)..$^{70-76}$ The symptom history is both an important summary of patient's problems, as well as a useful guide for physical examination and further diagnostic procedures. Clinicians should document symptoms and signs that characterize $\mathrm{OAB}$ and exclude other disorders that could be the cause of the patient's symptoms. Furthermore, the interview should elicit information regarding the rapidity of onset, duration of symptoms, and baseline symptom levels. Questions about urinary symptoms associated with $\mathrm{OAB}$ should be subdivided into storage problems (frequency, urgency, nocturia, incontinence), voiding symptoms (hesitancy, straining, poor and intermittent flow), post-micturition symptoms (sensation of incomplete emptying, post-micturition dribble), and other symptoms (nocturnal enuresis, dysuria). Of note, clinicians should be aware that the symptoms of lower urinary tract pathology are subjective and perception of their severity is influenced by many physical and sociocultural factors.

The clinician should also assess the severity of bladder symptoms and their influence on patient's QOL and day-today activities. Severity can be assessed by asking about pad usage, including pad weight, size, number of used pads, and number of urinary incontinence episodes per day.

Amount and type of fluid intake can affect the bladder function. Excessive or inadequate fluid intake can produce or exacerbate some of the OAB symptoms. Therefore, fluid intake habits should be investigated. Patients should be asked how much fluid they drink each day, what type of fluids they prefer (with a special consideration for caffeine intake as an exacerbating factor for urgency and frequency), and how many times they void over a 24 -hour period. ${ }^{77} \mathrm{~A}$ voiding diary is an important tool helping the physician to differentiate between real small volume frequency (pollakiuria) and polyuria. Assessment of other potential bladder irritants (alcohol, carbonated drinks) is also important and provide an opportunity to educate the patients about modifiable habits..$^{78-81}$

A wide variety of comorbidities may produce or worsen OAB symptoms. Possible related comorbidities include neurological diseases (i.e., stroke, Parkinson's disease, multiple sclerosis, spinal cord injury), endocrine disorders (i.e., complicated and uncontrolled diabetes, diabetes insipidus), urological conditions (i.e., BPH, urolithiasis, recurrent urogenital infections, bladder/prostate cancer), respiratory dysfunctions with chronic cough (i.e., chronic obstructive pulmonary disease), fecal motility disorders (constipation or 
fecal incontinence), chronic pelvic pain, mobility deficits, prior pelvic surgeries, pelvic cancers, and pelvic radiation. Special consideration should be taken in regards to urogenital infections, as the associated irritative bladder symptoms can overlap with those of OAB. Careful assessment of painless hematuria and acute symptom onset should be conducted to rule out underlying pathology, such as malignancy or urolithiasis. In women, a thorough obstetric and gynecological history may help to understand the underlying cause and identify factors that may influence treatment decisions. Pelvic organ prolapse or previous surgery for both prolapse and incontinence may influence the success of future treatment. ${ }^{82} \mathrm{~A}$ general obstetric history with labour duration, mode of delivery, birth weights of children, year of delivery, intrapartum complications (e.g., obstetric anal sphincter injury, peri-urethral lacerations, wound breakdown), as well as de novo post-partum urinary symptoms (e.g., urinary retention requiring prolonged catheterization or stress UI), which may be precipitated by caesarean section, epidural block, or prolonged labour, may be necessary for evaluation. ${ }^{83-86}$ Clinicians should also be aware that psychiatric disorders such as depression, dementia and anxiety can contribute to abnormal voiding patterns.$^{87}$

A carefully conducted medical history is important to ensure that there are no contraindications or risk factors for potential complications with the introduction of $\mathrm{OAB}$ pharmacotherapy. Conditions to consider include cardiac history, in particular a prolonged QT interval, uncontrolled hypertension, functional gastrointestinal pathology, myasthenia gravis, and uncontrolled narrow angle glaucoma, as well as renal and liver impairment.

The patient should also be asked for the details of current medications, both prescribed and over-the-counter, as these may precipitate or worsen OAB symptoms. Diuretics and sympathomimetics can cause urgency, frequency, and urgency incontinence. ${ }^{88}$

The prevalence and severity of $\mathrm{OAB}$ symptoms increase with age. ${ }^{58}$ Thus, special attention should be paid to elderly patients. This population often has higher medication needs and a lower physiological reserve to deal with diagnostic investigations and adverse effects of treatment. ${ }^{89}$ Elderly patients with possible risk factors, especially with cognitive dysfunction, reduced mobility, weakness, glaucoma, constipation, and individuals on polypharmacy should be identified during the diagnostic evaluation. An assessment of depressive symptoms, using validated screening tools (e.g., Geriatric Depression Scale, Centre for Epidemiologic Studies Depression Scale - revised) should be considered for older people presenting with $\mathrm{OAB}$ and mood disorder.

Clinical examination should be part of $\mathrm{OAB}$ assessment (Expert opinion). It should begin with a general evaluation of mental status, cognitive impairment, obesity, physical dexterity, and mobility. Abdominal examination should be routinely performed. Pelvic examination should assess tissue quality and sensation, urethra, pelvic floor supports/pelvic organ prolapse, and stress incontinence (cough test). Digital examination of the rectum and/or vagina should also be performed. ${ }^{82,90-92}$ Neurological examination with a special attention to the sacral neuronal pathways from S1 to S4 with the assessment of perineal sensation, bulbocavernosus reflex, rectal sphincter tone, and ability to contract the anal sphincter should be performed in the presence of any neurological symptoms.

\section{Questionnaires and voiding diaries}

Patient self-completed questionnaires are the most suitable method for assessing the patient's perspective of bothersome symptoms and impact on patients' QOL (Level of evidence 2b, Grade B). ${ }^{93,94}$ Questionnaires should have been validated for use in either English or French. The rationale for use of validated questionnaires is to establish baseline measurements and to quantitate patients' responses to $\mathrm{OAB}$ treatment. The International Consultation on Incontinence has evaluated specific criteria for currently used questionnaires and developed a recommendation grading system. ${ }^{95}$ Questionnaires with a Grade A recommendation (highly recommended) should be used in clinical practice. Among them are the Overactive Bladder Questionnaire (OAB-q), the Overactive Bladder Satisfaction Questionnaire (OABS), the Overactive Bladder Symptom Scores Questionnaire (OABSS), the Incontinence Impact Questionnaire (II-Q), and the Urogenital Distress Inventory (UDI). Each questionnaire can be used alone or in combination with other questionnaires to improve assessment or monitoring of treatment outcomes. ${ }^{96}$ There is no evidence to indicate whether use of QOL or condition-specific questionnaires has an impact on outcomes from treatment.

Measurement of micturition frequency and fluid intake habits is an important step in the evaluation and management of lower urinary tract dysfunction, including OAB. Voiding diaries are a semi-objective method of quantifying fluid intake and urological symptoms, such as frequency and possible episodes of urinary incontinence (Level of evidence $\mathbf{2 b}$, Grade $\boldsymbol{B}$ ). Voiding diaries variants (micturition time charts, frequency/volume charts) can also be used. They should document the time, type, and volume of fluid intake, urine volume voided, urgency episodes, and incontinence episodes. Accurate record of these variables can allow for estimation of functional bladder capacity and calculation of 24-hour and nocturnal total urine volume. ${ }^{97}$ Divergence between diary recordings and the patient rating of symptoms can be useful in patient counselling. ${ }^{98-101}$ Diaries can also be used to monitor treatment response and are widely used in clinical trials. The reproducibility of data obtained from voiding diaries has been demonstrated. ${ }^{102,103}$ However, there 
is considerable variability of diary data within a 24-hour period. ${ }^{4,104} \mathrm{~A}$ voiding diary observation with $3-7$ days duration is therefore recommended. ${ }^{102} \mathrm{~A}$ number of observational studies have demonstrated a close correlation between data obtained from voiding diaries and standard symptom evaluation. ${ }^{70,105-109}$ In voiding diaries, OAB patients are usually characterized by small and frequent voids with possible incidences of UI. Bladder diaries are especially useful in behavioural therapies and bladder training programs. Moreover, they can be used for patient monitoring, both by clinicians and patients themselves.

\section{Urinalysis and urine culture}

Urinalysis may indicate UTI, proteinuria, glycosuria, or hematuria and require further assessment. Negative results for nitrite and leucocyte esterase in reagent strip ('dipstick') analysis or absence of pyuria/bacteriuria on microscopic examination reliably exclude UTI in people without additional risk factors for infections of uncommon etiology and should be included in the evaluation of all patients with suspected OAB (Level of evidence $3 \boldsymbol{b}$, Grade $\boldsymbol{C}$ ). ${ }^{110} \mathrm{OAB}$ symptoms may occur during symptomatic UTI ${ }^{111}$ and existing symptoms may worsen during UTI. ${ }^{112}$ If evidence of infection is detected, a urine culture should be performed and the infection treated appropriately. After recovering from infection, OAB patient evaluation should be again performed. Low count bacteriuria $\left(10^{3}-10^{5} \mathrm{CFU} / \mathrm{ml}\right)$ might be associated with a wide range of LUTS and thus should be treated in patients with OAB symptoms. ${ }^{113}$ Of note, asymptomatic bacteriuria $\left(>10^{5} \mathrm{CFU} / \mathrm{ml}\right)$, highly prevalent in older persons, diabetic and catheterized patients, or in those with neurogenic lower urinary tract dysfunction, should not be routinely treated except in pregnant women (Level of evidence 1a, Grade $\boldsymbol{B}$ ) and before urological procedures within the urinary tract (Level of evidence $3 \boldsymbol{b}$, Grade B). ${ }^{14-116}$ Urine cytology is not recommended in the routine evaluation of patients with uncomplicated OAB (Level of evidence 5, Grade D).

\section{Post-voiding residual volume}

Post-voiding residual (PVR) volume indicates poor voiding efficiency. It may worsen symptoms and increase the risk of UTI, upper urinary tract dilatation, and renal insufficiency. ${ }^{117}$ Elevated PVR has a multifactorial etiology, but is usually caused by $\mathrm{BOO}$ or detrusor underactivity. Measurement of $P V R$ is not mandatory for uncomplicated $O A B$ patients with no risk factors or history of urinary retention (Level of evidence $3 \boldsymbol{b}$, Grade $\boldsymbol{B}) .{ }^{118,119}$ However, PVR should be evaluated in patients with obstructive symptoms, neurological diagnoses, and history of either prostatic or incontinence surgery. In these patients, PVR should be measured prior to starting antimuscarinic treatment. In patients already treated with antimuscarinics, especially those with existing risk factors for urinary retention, PVR may be elevated. ${ }^{120}$ Ultrasound measurement of PVR is preferable to catheterization. ${ }^{121-125}$ PVR $>250-300 \mathrm{ml}$ warrants special attention if antimuscarinic treatment is intended and consideration should be made as to the existence of other possible pathologies. ${ }^{126}$

\section{Bladder/renal ultrasound, cystoscopy, other imaging techniques}

Bladder/renal ultrasound, cystoscopy, computed tomography $(\mathrm{CT})$, and magnetic resonance imaging (MRI) are not recommended in the initial assessment of uncomplicated OAB patients (Level of evidence 4, Grade C). For patients who have failed multiple OAB treatments, the use of additional diagnostic testing should be based on patient history and symptoms. Special consideration should be taken for neurological causes of bladder overactivity and should include renal ultrasound for upper urinary tract surveillance. Cystoscopy may be used to exclude other causes for the symptoms associated with $\mathrm{OAB}$ (bladder tumour, carcinoma in-situ, ulcers, bladder stones, foreign bodies, cystitis) and is recommended in patients with recurrent UTI, persistent pyuria, hematuria, bladder pain, a history of stress incontinence or pelvic surgery, those with suspected fistula, urethral diverticulum, or urinary tract malformation. Cystoscopy should also be considered in patients with possible obstructive pathology. Neurological evaluation with spine imaging (CT, MRI) may also be considered for patients with associated neurological symptoms.

As OAB pathophysiology has been associated with DO, it has been hypothesised that frequent detrusor contractions may increase detrusor/bladder wall thickness (DWT/BWT). Recently published data suggest that routine clinical assessment of BWT for monitoring the effects of OAB/DO treatment is not clinically useful (Level of evidence $\mathbf{1 b}$, Grade A). ${ }^{127,128}$ Furthermore, standardization of the technique is lacking. ${ }^{129}$ No consensus regarding the relationship between $\mathrm{OAB}$ and increased BWT/DWT exists. ${ }^{130}$ DWT/BWT is not currently recommended for diagnosis or monitoring of patients.

\section{Urodynamics}

OAB cannot be precisely and directly measured by the cystometric urodynamic study (UDS). Thus, it is not recommended in the initial patient assessment (Level of evidence $\mathbf{1 b}$, Grade A). ${ }^{131,132}$ However, UDS is indicated when the diagnosis remains uncertain after history and physical examination, when the symptoms do not correlate with physical findings, or after failed previous treatment. ${ }^{133-135}$ UDS should be taken into consideration in initial diagnosis of patients with neurogenic voiding dysfunction, a history of radical pelvic surgery and pelvic radiation, and those at risk of upper urinary tract deterioration. ${ }^{136}$ Obtained data 
can help in the management of patients with $O A B$ symptoms, even in the absence of DO. ${ }^{137}$ Patients suffering from refractory urgency incontinence may have concomitant urodynamic stress $\mathrm{UI}$ or BOO. Correction of these associated conditions may greatly improve symptoms related to urinary urgency; however, these tests may not precisely predict outcomes of treatment. ${ }^{138}$ Successful responses to non-surgical and surgical interventions for $\mathrm{OAB}$ do not correlate with a pre-intervention finding of DO on UDS. ${ }^{131,132,139}$ There is only low-grade evidence for the added value of imaging to UDS. ${ }^{140}$ Thus, the role of videourodynamics in OAB has not been determined and this technique is not currently recommended (Level of evidence 5, Grade D).

Summary and recommendations: Patients with $O A B$ require comprehensive assessment. There is universal agreement that taking a history should be the first step in the assessment of $O A B$ patients (Evidence strength Grade $B)$. Clinical examination should be part of assessment of people with $O A B$ (Expert opinion). Patient self-completed questionnaires are the most suitable method for assessing the patient's perspective of bothering symptoms and further implications on patients' QOL(Evidence strength Grade B). Questionnaires should be validated for use in English or French. Measurement of micturition frequency and fluid intake habits should be performed with voiding diaries (Evidence strength Grade B). A voiding diary observation with 3-7 days duration is recommended. As OAB symptoms may occur during symptomatic UTI, urinalysis should be included in the initial evaluation of all patients suspected of OAB (Evidence strength Grade C). PVR volume measurement (Evidence strength Grade B), bladder/renal ultrasound (Evidence strength Grade C), cystoscopy (Evidence strength Grade C), CT/MRI (Evidence strength Grade C), and UDS (Evidence strength Grade $A$ ) are not recommended in the initial assessment of the uncomplicated $O A B$ patient. Additional tests are indicated when the diagnosis remains uncertain after history and physical examination, when the symptoms do not correlate with physical findings, or after failed previous treatment (Expert opinion).

\section{Treatment}

First-line treatment (behavioural therapies and lifestyle changes, patient education)

Since $O A B$ is not a life-threatening condition, all patients who desire treatment should start with some form of behavioural therapy and/or lifestyle changes, as they are non-invasive and reversible; however, these forms of therapy require a significant time commitment and effort on the patient's part, with regular followup to achieve success. ${ }^{141}$ Furthermore, behavioural therapies and lifestyle changes can easily be combined with other $\mathrm{OAB}$ treatments and should form part of any treatment plan. The main difficulty in assessing the success of behavioural therapies and lifestyle changes is due to the tremendous variability in how each is performed, with little consistency from study to study. As a result, there are few Level 1, Grade A studies to compare. In the end, because these treatments have little to no morbidity associated with them, recommendations to use them are generally warranted.

\section{Behavioural therapy}

This form of therapy includes two main treatments, bladder training (BT) and pelvic floor muscle therapy (PFMT). BT includes the use of bladder diaries, bladder control strategies, timed voiding, prompted or scheduled voiding, or delayed voiding. These are all used to alter patient voiding patterns. PFMT may also include urgency suppression, control strategies, and biofeedback. ${ }^{142}$ In general, there is good literature to support the use of BT and PFMT in patients with OAB (Level of evidence 1b, Grade B). ${ }^{143-145}$ One important factor, as mentioned above, is although there have been a number of randomized controlled trials (RCTs) using PFMT, there is no consistency between them, which makes it difficult to compare studies. Often in regards to PFMT, the mode of delivery, intensity, duration of treatment, and exact techniques used are different between studies. Significant improvement in urinary frequency using BT has been shown in both men and women (Level of evidence 1b, Grade B). ${ }^{143,146-148}$ Wyman et al compared PFMT to BT and to PFMT + BT. They found at three month followup that all three groups had similar improvement in incontinence reductions and QOL scores (Level of evidence $\mathbf{1 b}$, Grade B). ${ }^{149}$ When behavioural treatments were compared to medications, they either were equivalent to or superior to medications in regards to reducing incontinence episodes, improvement in frequency, nocturia, and QOL (Level of evidence 1b, Grade B). ${ }^{144-148,150-153}$ The use of BT in the elderly, who require a caregiver, can be challenging. Flanagan et al reviewed all the RCTs looking at prompted voiding in patients that had incontinence. ${ }^{154}$ They showed that prompted voiding had a positive effect on continence outcomes (Level of evidence 1b, Grade A).

\section{Lifestyle changes}

Lifestyle changes include fluid and caffeine intake, diet management, and weight loss. Subak et al demonstrated that weight loss in obese women reduced overall incontinence episodes per week by $47 \%$ and urgency incontinence episodes by $42 \%$ compared to $28 \%$ and $26 \%$ in controls, respectively (Level of evidence $\mathbf{1} \boldsymbol{b}$, Grade $\boldsymbol{B}$ ). ${ }^{155}$ Hashim and Abrams showed that a $25 \%$ reduction in fluid intake reduced frequency and urgency significantly (Level of evidence 1c, Grade B). ${ }^{156}$ In a RCT Bryant et al showed that there was a 
$35 \%$ reduction in voids/day and $61 \%$ reduction in occasions of urgency symptoms (but not incontinence) after one month of caffeine reduction, which was statistically significant (Level of evidence 1 b, Grade B). ${ }^{157}$ Gleason et al examined data from the National Health and Nutritional Examination Surveys (NHANES) specifically looking at caffeine and UI in U.S. women. ${ }^{158}$ They found that caffeine intake $\geq 204 \mathrm{mg} /$ day was associated with any UI, but not with moderate/severe UI (Level of evidence 1c, Grade B).

Management/treatment of other medical conditions (i.e., diabetes, congestive heart failure, obstructive sleep apnea syndrome, etc.) may improve $\mathrm{OAB}$ and incontinence; however, the best study published demonstrated that improved diabetic control did not improve UI (Level of evidence 3a, Grade B). ${ }^{159}$ The EAU guidelines on incontinence published in 2014 felt this paper was the best available, with Level 3 evidence. ${ }^{160}$ Chiu et al assessed urological symptoms in patients with chronic heart failure (CHF). ${ }^{161}$ They found that patients with CHF had more storage urinary symptoms suggestive of $O A B$ than did age-matched controls. Furthermore, they found that greater NYHA class heart function was significantly associated with OAB and LUTS (Level of evidence $\mathbf{3 a}$, Grade B). The relationship between obstructive sleep apnea (OSA) and OAB is still unclear and studies present rather conflicting results (Level of evidence $2 \boldsymbol{b}$, Grade B). ${ }^{162}$ Nevertheless, a prospective study of 53 patients with moderate to severe OSA conducted by Miyazato et al showed improvement of nocturia with continuous positive airway pressure treatment. ${ }^{163}$ The concurrent results were presented by Miyauchi et $\mathrm{al}^{164}$ There are a number of studies that have shown an association between constipation, UI, and OAB (Level of evidence 3a, Grade B); ${ }^{159,165-168}$ however, the evidence supporting improvement in $\mathrm{UI}$ and other $\mathrm{OAB}$ symptoms when constipation is treated is scarce. Charach et al, in a small prospective cohort study, did show that treatment of constipation improved urgency and frequency (Level of evidence 4, Grade C). ${ }^{169}$ Despite this, the EAU guidelines on incontinence recommend that for adults with UI, co-existing constipation should be treated. ${ }^{160}$ This would seem a logical recommendation since treatment of constipation is relatively non-invasive and would benefit patients overall health.

Summary and recommendations: Behavioural therapies and lifestyle changes should be the first-line therapy in all patients because of the non-invasive nature of the treatment. $B T$ and PFMT may be effective methods of treatment in certain cases (Evidence strength Grade B). Lifestyle changes involving modifications of fluids/caffeine intake, weight control, dietary modifications, management of bowel regularity, and optimization of other comorbidities (i.e., diabetes, $\mathrm{CHF}$, OSA) can be effective (Evidence strength Grade B/C).

\section{Patient education}

Patient education is an important principle in OAB. Education empowers patients to engage and participate in their treatment. Active participation on the part of a willing patient is necessary when interventions are related to behavioural and lifestyle changes. The patient's understanding can affect their motivation and adherence, which can influence the effect and outcome of treatment. To facilitate the conversations, patient education should be modified to fit the patient's needs and level of understanding. Normal lower urinary tract function should be explained in terms that the patient understands. Thus treatment planning should be based on the patient's desired outcome; higher satisfaction is achieved when the patient understands that voiding is a manageable behaviour (Level of evidence 5, grade D). ${ }^{142}$

If advanced age and/or cognitive impairment are present, a caregiver or family member willing to assist in the interventions must be involved in the education. ${ }^{142,170}$

The foundation of behavioural treatment is patient education and counselling, which can be provided by different clinicians, such as the physician, the nurse and, in some cases, the physiotherapist specialized in pelvic floor physiotherapy. Treatment goals should be aimed at symptom control, aiming to improve QOL. ${ }^{171-174}$ To optimize treatment, the clinicians should incorporate education to promote bladder health into routine visits. A report on the challenges of managing $O A B$ found that one of the recurring challenges was the lack of patient education due to time and resource constraints on the healthcare provider. ${ }^{175}$ Patient education is a key factor in the success of behavioural treatments, but it also requires patients to make significant changes in their habits and daily activities. To allow for compliance and adherence to the treatment, patients must include these changes in their daily life to increase success rate. ${ }^{176} \mathrm{An}$ appropriate duration of 8-12 weeks of therapies is necessary for full evaluation of effects. ${ }^{142} \mathrm{~A}$ minimum of six weeks of therapy is recommended, as per the NICE guidelines (Level of evidence 5, Grade D). ${ }^{177}$

\section{Weight control}

Obesity is an associated a risk factor for $\mathrm{UI}$ in many studies. A patient with a body mass index greater than $30 \mathrm{~kg} / \mathrm{m}^{2}$ is at increased risk for the onset of OAB symptoms. ${ }^{170,176,178,179}$ Thus, some patients may require specialized nutrition counselling provided by a dietitian. Weight loss has been shown to improve OAB symptoms, even when it is only moderate loss in overweight women ${ }^{155,176,180-182}$ (Level of evidence $1 \boldsymbol{B}$, Grade $\boldsymbol{B}$ ). 
Corcos et al.

\section{Management of fluid intake}

Individualized fluid intake management restrictions should be promoted, but they must be based on the patient's 24-hour intake and subsequent 24-hour urinary output. Thirst must be avoided and an appropriate level of fluid must be maintained. ${ }^{170,176}$ The physician should take into consideration the patient's comorbidities, such as renal or cardiac disease. Restricting fluid intake 2-4 hours before bedtime, or after 6 pm decreases nocturia and night time incontinence ${ }^{171,176,183}$ (Level of evidence $2 B$, Grade $B$ ).

\section{Dietary modifications}

The reduction or elimination of caffeinated and alcoholic beverages, as well as aspartame from the diet may improve symptoms. ${ }^{171}$ These items can act like a diuretic or worsen OAB symptoms; ${ }^{176}$ however, in view of inconsistent results, ${ }^{157,184}$ the best approach would be an individualized one, where patients reduce these items from their diet and a continuous evaluation is completed in parallel to assess symptom management (Level of evidence $2 \boldsymbol{B}$, Grade $\boldsymbol{C}$ ).

\section{Management of bowel regularity}

Constipation is regularly found in men and women with OAB. ${ }^{176,185,186}$ Patients should be provided with strategies to avoid constipation, such as increasing fibre in their diet ${ }^{176}$ (Level of evidence $3 B$, grade $B$ ).

Physical exercise

Regular physical activity is shown to strengthen the pelvic floor muscles, which can decrease OAB symptoms. ${ }^{170}$ Increasing physical activity can reduce OAB symptoms, but strenuous exercise can also worsen symptoms. ${ }^{187-190}$ The association between physical activity and lower level of incontinence was observed in women who did moderate exercise; ${ }^{191,192}$ however, it should be noted that moderate physical activity could also assist the patient in a weight loss program, which is a recommended lifestyle modification (Level of evidence 3B, Grade C).

\section{Smoking cessation}

Nicotine has been shown to irritate the bladder detrusor, causing increased activity and OAB symptoms. ${ }^{171}$ There is also an association between increased intra-abdominal pressure from recurrent coughing in smokers causing urinary leakage. ${ }^{171,193}$ Smoking cessation is a recommendation even though a Cochrane review described the effect of nicotine on $\mathrm{OAB}$ as uncertain. ${ }^{194}$ Smoking cessation remains a gen- eral public health intervention. ${ }^{195}$ (Level of evidence $3 \boldsymbol{B}$, Grade D).

Timed voiding

To encourage an appropriate voiding frequency, caregivers use the timed voiding technique. Instead of waiting for the patient to voice an urge to void, the patient is prompted to toilet at regular intervals or based on a schedule. In two systematic reviews, this technique has shown beneficial results in comparison to standard care. ${ }^{154,170,196}$ A Cochrane review has demonstrated inconsistencies in the results in cognitively impaired adults. ${ }^{197}$ Timed voiding can still be recommended, considering it has no negative impact on the patient (Level of evidence 2A, Grade C).

\section{Urgency control and suppression techniques}

This technique involves teaching the patient to control urgency by performing general relaxation, such as slow, deep breathing. This can decrease the intensity and urgency, therefore delaying the voiding process. ${ }^{176}$ They can also use selfdetermination and self-motivational statements for encouragement. ${ }^{176,198}$ They can also perform 6-10 quick pelvic floor muscle (PFM) contractions, which prevent the sphincter from relaxing when the urge is present. These contractions need to be well timed to provide increased benefit. ${ }^{176,199}$ (Level of evidence $3 B$, grade $B$ ).

\section{BT}

BT involves the use of different strategies to restore normal bladder function. The main strategy is implementing a voiding schedule and lengthening the intervals between voids until a normal pattern is established. Techniques for urgency control and suppression must be used in conjunction. The voiding intervals are determined on an individual basis, depending on baseline pattern. They are increased by 15-30 minutes each week, depending on patient compliance and tolerance, until a voiding interval of 3-4 hours is achieved. ${ }^{176,198}$ Different studies demonstrate that BT is more effective in symptom control than not providing physical behavioural therapy ${ }^{145,170,177,194,200}$ (Level of evidence $1 B$, Grade B).

\section{PFMT}

PFMT strengthens and improves the function of the pelvic floor. It has also shown improvement in urethral stability, which in return decreases OAB symptoms. ${ }^{170,201}$ This technique is only effective if the patient tightens the PFM correctly; it should result in a closing and lifting sensation without tensing the leg, buttock, or abdominal muscles. To 
facilitate teaching, the patient can be asked to imagine the passing of gas without tensing any of the previously mentioned muscles. This helps the patient isolate the proper PFM. The PFMT regimen consists of repeating the contraction for 10 seconds, 15 times in a row with equal breaks of 10 seconds a total of time times a day, totalling 45 PFM contractions in a day. ${ }^{176,202}$ The PFMT should be incorporated into the activities of daily life to promote compliance and adherence. It should be done in different positions, such as sitting, standing, and lying down. ${ }^{176,203}$ Continuous training is needed to maintain the gained strength of PFMs. ${ }^{176}$ A meta-analysis demonstrated that PFMT improves QOL and decreases symptoms. A Cochrane review of 21 RCTs concluded that increased intensity of PFMT demonstrated better outcomes and that there was no difference between individualized therapy or group therapy settings ${ }^{170,204}$ (Level of evidence 1B, Grade B).

Summary and recommendations: Patient education empowers patients and engages them in their treatment plan. First-line treatments for $O A B$ strongly rely on patient compliance and adherence. Patients with $O A B$ and UI have an improved $Q O L$ when they have a comprehensive knowledge of their medical problem and seek to develop an avoidance-oriented stress-coping lifestyle that promotes social contact, thus, emphasizing the importance of patient education (Expert opinion). Lifestyle changes and physical therapies should be incorporated in the activities of daily life to facilitate compliance and adherence to the program.

\section{Second-line treatment (pharmacological management)}

Pharmacological management of $\mathrm{OAB}$ aims to control and alleviate bothersome symptoms of urgency, frequency, and urinary incontinence. The current available literature includes individual studies and systematic reviews for antimuscarinic agents and beta-3 adrenoceptor agonist (primarily mirabegron).

The goals of pharmacological treatment are therefore mainly to improve QOL of patients suffering from $\mathrm{OAB}$ by decreasing their symptoms. The preferable option should be safe, efficacious, tolerable, and allow long-term adherence for patients. Therefore, each treatment options will be assessed for these characteristics. Most studies report on efficacy, based on changes in number of micturitions, incontinence, urgency, or UUI episodes. Safety and tolerability outcomes are also reported by identifying the number of patients with certain side effects, with limited data on adherence.

\section{Antimuscarinics}

The antimuscarinic agents (AM) available for the treatment of $\mathrm{OAB}$ in Canada are oxybutynin (immediate release [IR], extended release $[E R]$, transdermal), tolterodine (IR, ER), darifenacin, trospium (IR), solifenacin, propiverine, and fesoterodine. They have an antagonistic action on muscarinic receptors throughout the body, but improve OAB symptoms by blocking the $\mathrm{M} 2$ and $\mathrm{M} 3$ receptors in the bladder and urothelium, and therefore affect both involuntary detrusor contraction and increased sensory afferent signalling.

\section{Efficacy}

The latest Cochrane review reported a meta-analysis of RCTs comparing one AM vs. another or different doses, using QOL as a primary outcome measure. Tolterodine-IR had similar efficacy vs. oxybutynin-IR, but with less withdrawal due to adverse events and less dry mouth. Similarly, tolterodine-ER had less risk of dry mouth compared to oxybutynin-ER. It was found that ER preparations of oxybutynin or tolterodine provided similar improvement, while having less risk of dry mouth compared to IR. Transdermal oxybutynin and tolterodine-ER had similar rates of dry mouth, but the transdermal patch was associated with a higher withdrawal rate due to skin reactions. Therefore, tolterodine-ER would be a first choice compared to other formulations of tolterodine and oxybutynin (Level of evidence 1a, Grade A). The highest of the two doses for both solifenacin and fesoterodine (10 mg and $8 \mathrm{mg}$, respectively) had better clinical efficacy, but with higher rates of dry mouth than the lowest doses at 12 weeks ( $5 \mathrm{mg}$ and $4 \mathrm{mg}$, respectively) (Level of evidence 1a, grade A). Solifenacin had better clinical efficacy and less dry mouth rates compared to tolterodine-IR (Level of evidence 1a, Grade A). Fesoterodine had favourable clinical outcomes compared to tolterodine-ER, but higher rates of withdrawal due to adverse events and risk of dry mouth (Level of evidence 1a, Grade A). All included trials were of 12 weeks duration with the exception of one-year studies on trospium and oxybutynin. ${ }^{205}$

A meta-analysis on the effects of AM on health-related QOL measures in patients with OAB reported that active treatment with four different AM formulations (oxybutynin-TDS, tolterodine-IR, tolterodine-ER, trospium) had a significant difference for mean change of score compared to placebo (Level of evidence 1a, Grade A). There were no significant differences between the different interventions when comparing active-controlled trials (Level of evidence 1a, Grade A). ${ }^{206}$

An update of a systematic review of the tolerability, safety, and efficacy of seven drugs (darifenacin, fesoterodine, oxybutynin, propiverine, solifenacin, tolterodine, and trospium) in $O A B$ by Chapple et al found that active treatment had higher efficacy in reducing the number of incontinence episodes, urgency episodes, micturition frequency, and return to continence compared to placebo (Level of evidence 1a, Grade A) ${ }^{207}$ Combining different AMs has limited clinical improvement with much higher adverse events (Level of evidence $\mathbf{2 b}$, Grade $\boldsymbol{C}$ ). ${ }^{208}$ A network meta-analysis with 
complete assessment across different drugs by Buser et al performed an efficacy and adverse events analysis, along with a trade-off analysis between these two components. The longest duration of treatment for all trials included was 12 weeks. It was found that trospium $40 \mathrm{mg}$, oxybutynin topical gel $100 \mathrm{mg} / \mathrm{g}$, and fesoterodine $4 \mathrm{mg}$ had the most favourable efficacy/adverse events relationship, while higher doses of oral oxybutynin and propiverine had the least favourable (Level of evidence 1a, Grade A). ${ }^{209}$

\section{Safety, tolerability, and persistence}

The most common adverse events reported in a meta-analysis was dry mouth $(29.6 \%$ and $7.9 \%$ of active treatment and placebo arm patients) followed by pruritus (Level of evidence 1a, Grade A). ${ }^{207}$ The most commonly adverse events reported groups are gastrointestinal, followed by neurological, ocular, and renal/genitourinary (Level of evidence 1a, Grade A). ${ }^{209}$ A network meta-analysis comparing adverse events of AMs identified 82 reports, with most of them being parallel and placebo-controlled. They found that the overall adverse event profile was comparable for darifenacin, fesoterodine, transdermal oxybutynin, propiverine, solifenacin, tolterodine, and trospium. However oral oxybutynin, in doses of or exceeding $10 \mathrm{mg} /$ day was associated with the worst adverse event profile (Level of evidence 1a, Grade A). ${ }^{210}$

Although drug persistence is generally low in chronic diseases, AM have an overall poor adherence profile, with $17-35 \%$ of patients still taking their prescribed drug at one year. ${ }^{211-213} \mathrm{~A}$ better tolerability profile may increase rates for long-term treatment of $\mathrm{OAB}$.

AMs are contraindicated in patients with uncontrolled narrow-angle glaucoma due to their antagonistic actions on M3 and M5 receptors in the eye. The anticholinergic action can induce or precipitate acute angle-closure glaucoma. ${ }^{214}$ AMs contribute to the overall anticholinergic burden. Anticholinergic burden has been linked to cognitive dysfunction (Level of evidence $\mathbf{1 b}$, Grade B), ${ }^{215}$ but also with increased mortality and cardiovascular risk (Level of evidence 1b, Grade B). ${ }^{216}$ These effects should be considered in the potential use of a medication for a prolonged duration of time. There are limited long-term data on the use of AM and their effect in different patient populations, particularly the elderly.

\section{Beta-3 adrenoceptor agonist}

The only commercially available agent, mirabegron, is approved in Canada for the treatment of OAB. It activates beta-3 adrenoceptors, allowing bladder relaxation, improving bladder filling and storage of urine. A starting dose of 25 $\mathrm{mg}$, and increasing to $50 \mathrm{mg}$ is recommended. The lowest dose is also recommended for renal and hepatic impairment.
Efficacy

A meta-analysis of four phase 3 RCTs found that mirabegron was more effective than placebo in treating OAB by decreasing the mean number of incontinence episodes, mean number of micturition, mean volume voided per micturition, and mean number of urgency episodes per 24 hours (Level of evidence 1a, Grade A). ${ }^{217}$ The trials, SCORPIO, ${ }^{218}$ ARIES, ${ }^{219}$ CAPRICORN, ${ }^{220}$ and $178-C L-048^{221}$ were all of 12 weeks duration. The overall treatment-emergent adverse events (TEAEs) of hypertension, cardiac arrhythmias, and urinary retention, and discontinuation rates were similar between mirabegron and placebo. A pooled efficacy analysis of these trials also found that mirabegron 50 and $100 \mathrm{mg}$ decreased the number of incontinence episodes and micturitions per 24 hours compared to placebo (Level of evidence 1a, Grade A). ${ }^{222}$ The NICE 2013 report also indicates that mirabegron $50 \mathrm{mg}$ has a significant improvement in urinary frequency and incontinence episodes compared to placebo (Level of evidence 1a, Grade A). ${ }^{223}$ A post-hoc responder analysis of pooled data from three phase 3 RCT showed that patient reported outcomes (PROs) were significantly improved compared to placebo (Level of evidence 1a, Grade A). ${ }^{224}$

In an incontinent population at baseline, a post-hoc analysis of pooled data from three randomized phase 3 trials found that mirabegron $50 \mathrm{mg}$ statistically significantly reduced the mean number of incontinence episodes, micturitions, and urgency episodes per 24 hours, and improved mean volume voided per micturition. The treatment effect was positively correlated with increasing severity of incontinence at baseline (Level of evidence 1a, Grade A). ${ }^{75}$ A post-hoc analysis of SCORPIO showed similar efficacy in subgroups of patients who were AM-naïve and those with prior use of AM (Level of evidence $\mathbf{1 b}$, Grade B). ${ }^{225}$

There were two phase 3 trials that included a tolterodine $4 \mathrm{mg}$ active treatment arm. The SCORPIO study compared tolterodine to placebo, but did not make any direct comparison between mirabegron and tolterodine. ${ }^{218}$ Yamaguchi et al randomized $\mathrm{OAB}$ patients to placebo, mirabegron 50 $\mathrm{mg}$, and tolterodine $4 \mathrm{mg}$, but did not test for non-inferiority of efficacy and safety. ${ }^{226}$

The 12-month safety and efficacy was evaluated in a randomized, double-blind, active controlled phase 3 study. Patients received either mirabegron 50 or 100 mg or tolterodine $4 \mathrm{mg}$. Although there was no placebo arm, efficacy was maintained in each treatment group throughout 12 months, as determined by the change from baseline in number of micturitions per 24 hours, mean number of incontinence episodes per 24 hours, and improvements in mean volume voided per micturition (Level of evidence $\mathbf{1 b}$, Grade $\boldsymbol{B}$ ). ${ }^{227}$ 
The SYMPHONY trial was a 12-week placebo- and monotherapy-controlled phase 2 trial looking at combination treatment of mirabegron and solifenacin for OAB. Combining mirabegron 25/50 mg with solifenacin 5/10 mg significantly improved PROs and micturition frequency compared with placebo or solifenacin $5 \mathrm{mg}$ (Level of evidence 1b, Grade B). ${ }^{228}$ The BESIDE study was a phase 3 b 12 -week trial where OAB patients, still incontinent after four weeks of solifenacin $5 \mathrm{mg}$, were randomized to a combination of mirabegron with solifenacin 5 or $10 \mathrm{mg}$. Mirabegron could be increased from 25 to $50 \mathrm{mg}$ after four weeks. Combination treatment improved daily micturitions compared to solifenacin 5 and $10 \mathrm{mg}$, and daily incontinence compared to solifenacin 5 $\mathrm{mg}$. A higher percentage of patients were dry with combination treatment $(46 \%)$ vs. solifenacin 5 or $10 \mathrm{mg}(37.9 \%$ and $40.2 \%)$, and the safety profile was similar across the different groups (Level of evidence $\mathbf{1 b}$, Grade B). ${ }^{229}$

\section{Safety, tolerability, and persistence}

A prospective pooled analysis of three 12-week randomized phase 3 trials and of a one-year randomized phase 3 trial looked at the rates of adverse events, serious AE (SAE), and TEAEs. The most common TEAEs for mirabegron were hypertension, nasopharyngitis, and UTI in the pooled 12-week studies. Headache and back pain also occurred in the oneyear study. Tolerability profile was not clinically significantly different between age groups (cutoffs of 65 and 75 years old), sex, or race to warrant special precautions. The adverse event profile was similar across mirabegron, tolterodine, and placebo, except for dry mouth, which was fivefold more frequent in the tolterodine group. The incidence of SAEs was low and they were not directly related to the study drug (Level of evidence 1a, Grade A). ${ }^{230}$

Persistence data from retrospective claims in Canada showed that overall persistence rates at 12 months were greatest with mirabegron $(31.7 \%)$, and lowest with oxybutynin IR (13.8\%). Persistence for the treatment experienced group at 12 months was 39\% for mirabegron vs. $14-35 \%$ for antimuscarinics. For the naïve group, the persistence for mirabegron was $30 \%$ vs. $14-21 \%$ for antimuscarinics. Adherence was higher in treatment-experienced patients compared to treatment-naïve patients, regardless of treatment (Level of evidence $2 \boldsymbol{b}$, Grade C) ${ }^{231}$ In a small, prospective, randomized study, the 12-month persistence rates were similar between mirabegron and solifenacin, but the reasons for discontinuation were different: side effects for solifenacin, and lack of efficacy for mirabegron (Level of evidence $2 \boldsymbol{b}$, Grade C). ${ }^{232}$
In a Bayesian mixed treatment comparison analysis by Maman et al, mirabegron $50 \mathrm{mg}$ had a similar efficacy in decreasing the number of micturition frequency, UUI episodes, and overall incontinence episodes, compared to all AM except for solifenacin. Only solifenacin $10 \mathrm{mg}$ had a higher efficacy than mirabegron $50 \mathrm{mg}$ in the improvement of micturition frequency and UUI episodes (Level of evidence 1a, Grade A). Mirabegron $50 \mathrm{mg}$ had a similar rate of dry mouth and constipation compared to placebo. For dry mouth, all other AMs had higher rates than mirabegron $50 \mathrm{mg}$; for constipation, darifenacin $15 \mathrm{mg}$, fesoterodine $8 \mathrm{mg}$, solifenacin $5 \mathrm{mg}$, solifenacin $10 \mathrm{mg}$, and trospium $60 \mathrm{mg}$ had higher rates than mirabegron $50 \mathrm{mg}$ (Level of evidence 1a, Grade A). ${ }^{233}$

Although there is no direct comparison, mirabegron appears to have similar clinical effectiveness compared to most AMs, but has a different sideffect profile. There is limited data on cost-effectiveness, persistence, or effect of long-term treatment with the medication.

Summary and recommendations: Second-line treatment of $O A B$ should include the use of oral AMs, transdermal oxybutynin or oral beta-3 adrenoceptor agonist (Evidence strength Grade A). The lowest recommended dose should first be prescribed, followed by dose increases in order to obtain the best clinical improvement while monitoring for adverse events (Evidence strength Grade B). If the initial selected drug is not tolerated or does not provide adequate symptom relief, patients should be offered an alternative medication, preferably with a different mechanism of action (Expert opinion). The adverse event profile and possible contraindications should be considered when prescribing the drug of choice as second-line treatment (Expert opinion). Immediate release formulations of AMs should be avoided if other formulations are available (Evidence strength Grade A). Patients who remain incontinent after the initial treatment with an AM could be offered combination treatment with solifenacin and mirabegron (Evidence strength Grade C). Recommended doses of drugs are presented in Table 2.

\section{Special considerations in frail older people}

\section{Age-related changes in pharmacology}

Specific age-related changes in pharmacokinetics, alteration in drug absorption, distribution, metabolism, and clearance, and their potential effect on UI drugs, are shown in Table 3. The numerous factors potentially affecting drug clearance in older, frail patients, as well as previous and/or crossover compounds, may confound observed drug effects. 


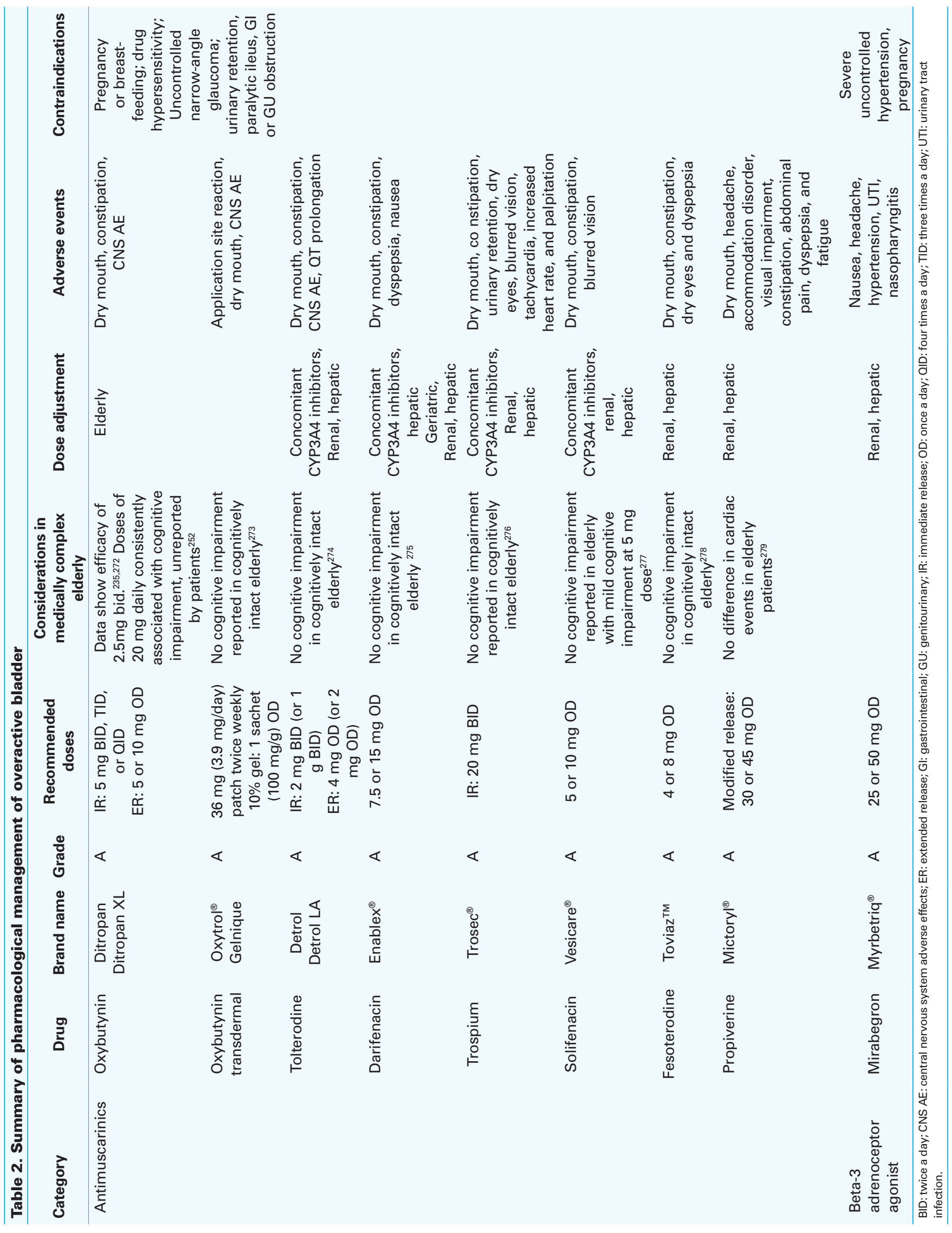




\begin{tabular}{|c|c|c|}
\hline Parameter & Age-associated changes & UI drugs potentially affected \\
\hline \multirow[t]{2}{*}{ Absorption } & $\begin{array}{l}\text { Minimal quantitative change despite } \downarrow \text { gastric motility, yet } \\
\text { little known regarding effect on slow-release agents }\end{array}$ & Extended-release preparations \\
\hline & $\downarrow$ Skin thickness & Transdermal preparations \\
\hline \multirow{2}{*}{ Distribution } & $\begin{array}{c}\text { Decrease in lean body mass leads to } \downarrow \mathrm{Vd} / \downarrow \mathrm{T}^{1} 1 / 2 \text { for } \\
\text { hydrophilic drugs and } \mathrm{Vd} / \mathrm{T} 1 / 2 \text { for lipophilic agents }\end{array}$ & Lipophilic agents, tricyclic antidepressants \\
\hline & $\begin{array}{l}\text { Decreased protein binding in frail patients with low albumin, } \\
\text { leading to higher concentration of free drug }\end{array}$ & Tolterodine \\
\hline \multirow{5}{*}{$\begin{array}{l}\text { Hepatic } \\
\text { metabolism }\end{array}$} & $\downarrow$ Phase I reactions (oxidation/reduction) & Tricyclic antidepressants \\
\hline & No change in phase II reactions (glycosylation) & \\
\hline & $\begin{array}{c}\downarrow \text { Hepatic blood flow and } \downarrow \text { hepatic mass, leading to reduced } \\
\text { clearance for agents with first-pass metabolism }\end{array}$ & Oxybutynin, tolterodine, solifenacin, darifenacin \\
\hline & Stereoselective selectivity in metabolism (hypothetical) & Enantiomers \\
\hline & Cytochrome P450 & $\begin{array}{l}\text { Oxybutynin, tolterodine, solifenacin, darifenacin, } \\
\text { mirabegron, 5-hydroxymethyl tolterodine (clearance only) }\end{array}$ \\
\hline Clearance & Decrease in renal clearance & Tolterodine fesoterodine (5-hydroxymethyl tolterodine) \\
\hline
\end{tabular}

\section{Availability of low-dose agents}

One effect of the underrepresentation (if not exclusion) of frail older persons in UI drug studies is a lack of knowledge regarding minimal effective drug doses for this population. The age-related changes in pharmacology suggest that some UI drugs may be effective at lower than standard doses in frail older persons with concomitant decreased adverse effects. ${ }^{234}$ There are some data supporting the effective use of low-dose oxybutynin in older persons (Level of evidence 2b, Grade C). ${ }^{235,236}$ A single study has assessed low standard doses of trospium chloride and solifenacin in combination in older persons (not frail) of average age 69 years in comparison to higher doses, showing higher efficacy of combination lower-dose therapy (Level of evidence $2 \boldsymbol{b}$, Grade B). ${ }^{237}$

\section{Polypharmacy}

Approximately $60 \%$ of people over age 65 take at least one prescribed medication and about one-third take more than five prescribed drugs. In addition, many older persons take over-the-counter, naturopathic, or herbal agents and dietary supplements, with the rate of use varying across countries and cultures. In 2010-2011, approximately $15.1 \%$ of older adults were at risk for a potential major drug-drug interaction compared with an estimated $8.4 \%$ in 2005-2006 $(p<0.001) .{ }^{238}$ The likelihood of adverse drug reactions (ADEs) and drug interactions rises exponentially as the number of medications increases. Changes to existing drug regimens should be considered in the management of UI in all frail older people (Level of evidence 3, Grade B).

\section{ADE}

ADEs are extremely common in older persons, ${ }^{239}$ with rates up to $35 \%$ among community-dwelling persons aged $>65$ in the US. Factors associated with higher ADEs in older persons are higher drug doses, age-related pharmacological changes, polypharmacy, comorbid conditions and the interactions between them, and female sex. ${ }^{240,241}$ Older people are at higher risk of ADEs from AMs because of age, and comorbidityrelated changes in muscarinic receptor number and distribution, blood-brain barrier transport, and drug metabolism. ${ }^{242}$ Whereas AM ADEs in younger persons are bothersome, in the frail elderly they can result in serious morbidity, such as sedation, heat intolerance, delirium, and falls. Xerostomia is common in older people. ${ }^{243}$ In general, older people, women, and those taking multiple medications are more likely to report the symptom. A subcut analysis of a Canadian randomized controlled trial of solifenacin $5 \mathrm{mg} /$ day vs. oxybutynin $5 \mathrm{mg}$ three times daily, examined the tolerability of both drugs in subjects under and over the age of 65 years. The study found that dry mouth was no more common amongst those over the age of 65 , but was more common and more severe with oxybutynin (Level of evidence $\mathbf{1 b}$, Grade B). ${ }^{244}$ In those over 75 years of age treated with $8 \mathrm{mg}$ vs. $4 \mathrm{mg}$ of fesoterodine from a pooled analysis of data from registration trials, dry mouth was more common in the older sample; this finding was duplicated in a prospective trial of fesoterodine in older patients (Level of evidence $\mathbf{1 b}$, Grade B). ${ }^{245,246}$ Another AM ADE to which the frail elderly may be predisposed is decreased visual accommodation, yet this has been specifically evaluated only in young, healthy volunteers ${ }^{247}$ and a single prospective cohort including patients up to the age of 60 years. ${ }^{248}$ Drug trials typically report only "blurred vision," without further characterization. 


\section{Anticholinergic medication and cognitive impairment}

There have been a number of reports linking anticholinergic medication to cognitive impairment, an increase in incident dementia diagnosis, and a possible increase in mortality. ${ }^{215,249,250}$ Older persons commonly use medications with anticholinergic properties. As much as there is a reported increase in overall medication prescribing for older persons, temporal trends also reveal an increase in anticholinergic medication prescribing for older persons. ${ }^{251}$ Due to the nature of the cohorts of persons studied, data on medications used for $\mathrm{OAB}$ and $U \mathrm{UI}$ are limited to identifying immediate-release oxybutynin as a consistent significant factor in exposure. In the study of Gray, over 10 years, those with the highest cumulative burden of oxybutynin exposure had a significant association with cognitive impairment (Level of evidence $2 \boldsymbol{b}$, Grade $\boldsymbol{B}){ }^{215}$ Cognitive effects may be underdetected because they are clinically subtle, neither asked about nor reported by the patient, or mistaken for age-related diseases and ageing. ${ }^{252,253}$ It is clear that duration of exposure and extent of exposure to medications with anticholinergic properties are significant factors in the observed associations with cognition. Persons with pre-existing cognitive impairment (especially from conditions known to affect central cholinergic pathways) may be at greater risk for cognitive impairment, although there are also some data to suggest that those with established dementia may not experience cognitive decline following therapy with anticholinergic agents. ${ }^{254}$

\section{Drug interactions}

Because frail older people take higher numbers of drugs and usually have several comorbid conditions, drug interactions are more common. ${ }^{255}$ Drug-drug interactions for oxybutynin, solifenacin, darifenacin, and tolterodine include potent CYP3A4 inhibitors (azole antifungals, macrolide antibiotics, cyclosporin, and vinblastine). Fesoterodine, a pro-drug that is converted to tolterodine by non-specific esterases, is also dependent upon $\mathrm{CY} 3 \mathrm{~A} 4$ for its excretion. There is one case report of interaction between tolterodine and warfarin in two older patients, which has not been seen in healthy volunteers (Level of evidence 4, Grade C). ${ }^{256}$ Naturopathic/ herbal preparations should also be considered for potential interactions, especially in areas where these agents are frequently used. Evidence regarding the co-prescription of bladder AM agents and cholinesterase inhibitors (CEIs) used for dementia are of poor- to moderate-quality. There is evidence CEls can cause or worsen UI (Level of evidence $\mathbf{3} \boldsymbol{b}$, Grade C), ${ }^{257,258}$ but this finding has not been replicated in a large Dutch dataset analysis (Level of evidence $2 \boldsymbol{b}$, Grade C). ${ }^{259}$ Concomitant use of AMs and CEls in nursing home residents was associated with a decline in ADL function in the most functionally able residents, but there was no worsening of cognition in one study. ${ }^{260}$ In a study of trospium chloride in older people with dementia treated with galantamine, no effect on cognition or activities of daily living was detected (Level of evidence $2 \boldsymbol{b}$, Grade C). ${ }^{261}$ A small study reported some positive effect of the treatment of UI with propiverine in subjects with probable AD taking CEls (Level of evidence $2 \boldsymbol{b}$, Grade C). ${ }^{262}$ Although intuitively illogical, given the opposing pharmacological actions, there seems to be no reason not to use bladder AMs for older people with dementia, ensuring that the CEI is warranted and effective, that the incontinence is sufficiently bothersome to warrant treatment, and that the patient (where possible) and the caregiver are fully informed.

\section{Potentially inappropriate drugs for older persons}

A revised Beers criteria was introduced in $2015 .{ }^{263}$ These guidelines focus on drugs with lower risk-benefit ratios and higher potential for drug-drug and drug-disease interactions, and are used for nursing home regulation and quality performance measurement. More recently, a system for prescribing appropriate medications for older persons, the Fit fOr The Aged (FORTA) criteria have been published with respect to drugs for LUTS. ${ }^{264}$

\section{Special issues unique to frail older men}

Frail older men are under-represented in UI treatment trials, whether behavioural, pharmacological, or surgical. Results from treatment trials in frail women cannot be directly extrapolated to men for several reasons:

- Differences in comorbidity: Frail older women have higher rates of functional impairment and chronic disease and geriatric syndromes, which may mean that frail men may be more likely to respond to behavioural intervention. ${ }^{265}$

- Benign prostate disease: The prevalence of histological $\mathrm{BPH}, \mathrm{BPE}$, and $\mathrm{BOO}$ increases with age, and is associated with LUTS, UI, and DO. In a UDS of older persons, $29 \%$ of men had $\mathrm{BOO}$ and $59 \%$ had $\mathrm{DO}$ as the predominant cause of UI vs. $4 \% \mathrm{BOO}$ and $61 \%$ DO in women. ${ }^{266}$

- Differences in device usage: A nationally representative survey of adults in the U.S. showed that older men were nearly three times less likely than older women to use pads to contain leakage (15\% vs. $45 \%) .{ }^{267}$ In a survey of patients recruited from family practice clinics in the Netherlands, the gender difference for pad usage by older adults with UI was even higher, with four out of five women using pads vs. one of nine men. ${ }^{268}$ Men are also more likely to be users of indwelling catheters, both in the long-term care setting ${ }^{269}$ and in the community. ${ }^{270}$ 
- Differences in medical treatments: The interactions of $\mathrm{UI}$ and other conditions with regards to orthostatic hypotension and risk of falls merits attention. In a German registry of 3414 patients with Parkinson's disease, for those with UI $(716 ; 21 \%)$, orthostatic hypotension was reported for $14 \%$ of the men, yet only $9 \%$ of the women. ${ }^{271}$

Special considerations of pharmacological management in medically complex elderly are included in Table 2. ${ }^{235,252,272-279}$

Summary and recommendations: Age-related changes in pharmacokinetics affect AM drugs for UI and these factors should be incorporated into treatment planning (Evidence strength Grade B). Drugs may be effective at lower doses in frailer compared with healthier older persons (Evidence strength Grade C). Polypharmacy increases the chance of adverse reactions to drug therapy, which are more common in the frail elderly (Evidence strength Grade A). Furthermore, drug-drug and drug-disease interactions are common in frail older persons (Evidence strength Grade $A / B)$. AMs for treatment of $O A B$ remain as potentially inappropriate medications for frail older people (Evidence strength Grade $B / C$ ). CEI treatment is associated with either precipitation or worsening of OAB symptoms (Evidence Strength Grade C).

\section{Third-line treatment: OnabotulinumtoxinA}

Strong, Level 1 (Grade A) evidence supports intradetrusor onabotulinumtoxinA $100 \mathrm{U}$ as an effective, safe, and longterm treatment option for $O A B$ with $U U I$ refractory to second-line OAB pharmacotherapies.

\section{Efficacy and safety}

There are two 24-week, phase 3, randomized, double-blind, placebo-controlled multicentre trials, which demonstrate that onabotulinumtoxinA $100 \mathrm{U}$ is both effective and safe when compared to placebo in patients with refractory idiopathic OAB.

Nitti et al randomized 557 patients with idiopathic OAB inadequately treated with or intolerant to anticholinergic therapy to receive onabotulinumtoxinA $100 \cup$ or placebo (Level of evidence $\mathbf{1 b}$, Grade A). Treatment was administered as 20 evenly distributed intradetrusor injections of $0.5 \mathrm{ml}$ per injection site using flexible or rigid cystoscopy and sparing the trigone. ${ }^{280}$ Followup visits occurred at two, five, and 12 weeks, and every six weeks thereafter until study exit at 24 weeks. Patients completed a three-day bladder diary before each study visit to collect information on OAB symptoms and volume per void. Perception of treatment benefit was assessed using the treatment benefit scale (TBS) and health-related QOL was assessed at Week 12 using validated patient questionnaires, including the Incontinence Quality of Life (I-QOL) instrument and King's Health Questionnaire (KHQ). Co-primary efficacy variables were defined as: 1) the change from baseline in daily average frequency of UI episodes; and 2) the proportion of patients with a positive treatment response on treatment benefit scale (TBS) at Week 12. Secondary efficacy variables were the change from baseline in daily average frequency of micturition and urgency episodes, the I-QOL total summary score, and two KHQ multi-item domain scores. Other efficacy variables were change in nocturia, volume per void, and proportion of patients achieving $50 \%$ or greater or $100 \%$ reduction in UI episodes. Adverse events, PVR, and clean intermittent catheterization $(\mathrm{CIC})$ were evaluated at two, six, and 12 weeks or at any other time if needed. Urinary retention was defined as PVR $>200 \mathrm{ml}$ or greater that required CIC. UTI was defined as a positive urine culture $>10^{5} \mathrm{CFU} / \mathrm{ml}$ together with leukocyturia greater than 5/HPF regardless of symptoms. At 12 weeks, there were 3-4-fold decreases from baseline in mean daily frequency of UI for onabotulinumtoxinA 100 $U$ vs. placebo (-2.65 vs. $-0.87 ; \mathrm{p}<0.001) ; 57.5 \%$ of patients treated with onabotuliumtoxinA $100 \mathrm{U}$ achieved a $50 \%$ or greater reduction in UI episodes and $22.9 \%$ were continent compared to $28.9 \%$ and $6.5 \%$, respectively, for those treated with placebo. A majority of $60.8 \%$ of onabotulinumtoxinA patients reported a positive treatment response on TBS compared to $29.2 \%$ of those who received placebo $(p<0.001)$. All secondary efficacy outcomes were significantly different between groups favouring onabotulinumtoxinA, including mean decreases in number of micturitions $(-2.15$ vs. -0.91 ; $\mathrm{p}<0.001)$, urgency $(-2.92$ vs. $-1.21 ; p<0.001)$, and nocturia $(-0.45$ vs. $-0.24 ; p<0.05)$ per 24 hours. The most frequently reported adverse event was uncomplicated UTI occurring in $15.5 \%$ of onabotulinumtoxinA- and $5.9 \%$ of placebo-treated patients. Dysuria $(12.2 \%)$, bacteriuria $(5 \%)$, and urinary retention $(5.4 \%)$ occurred at a higher rate in those patients treated with onabotulinumtoxinA. The proportion of patients who initiated $\mathrm{CIC}$ was $6.1 \%$ in the onabotulinumtoxinA group vs. $0 \%$ in the placebo group. The duration of $\mathrm{CIC}$ was six weeks or fewer for more than half of those who required it.

Chapple et al performed a similarly large, phase 3, multicentre, randomized, double-blind, placebo-controlled study (Level of evidence 1b, Grade A). ${ }^{281}$ Eligible patients included those with idiopathic $\mathrm{OAB}$ inadequately managed by anticholinergic therapy with urinary incontinence; $>3$ UUI episodes and an average of $>8$ micturitions per day in a three-day bladder diary; and a PVR urine volume $<100 \mathrm{ml}$. A total of 548 patients were randomized to receive either onabotulinumtoxinA or placebo. The co-primary efficacy end points were change from baseline in number of UI episodes and proportion of patients with a positive treatment response on TBS at 12 weeks. OAB symptoms were assessed via three-day voiding diary and health-related QOL was assessed using I-QOL and KHQ. Safety measurements included adverse events and 
PVR urine. OnabotulinumtoxinA significantly decreased the co-primary endpoint of UI compared to placebo (-2.95 vs. -1.03; $p<0.001)$. The patient's perception of positive change in their condition demonstrated a large and significant difference between onabotulinumtoxinA and placebo groups $(62.8 \%$ vs. $26.8 \% ; p<0.001)$. Significant reductions in all other OAB symptoms and improvement in health-related QOL measures were found following treatment with onabotulinumtoxinA $100 \mathrm{U}$. Uncomplicated UTI was the most frequently reported adverse event and occurred in $20.4 \%$ and $5.2 \%$ of the onabotulinumtoxinA and placebo groups, respectively. The proportion of patients requiring $\mathrm{CIC}$ was $6.9 \%$ in the onabotulinumtoxinA group vs. $0.7 \%$ in the placebo group.

Observational studies provide insight into the efficacy and adverse events in specific populations with refractory idiopathic $O A B$ treated with onabotulinumtoxinA.

Liao and Kuo evaluated the efficacy and safety of intradetrusor onabotulinumtoxinA (100 U) in 166 patients, including 61 frail elderly, 63 elderly, and 42 younger patients with idiopathic, refractory DO (Level of evidence $2 \boldsymbol{b}$, Grade $\boldsymbol{B}$ ). ${ }^{282}$ Frailty was defined as age $>65$ years and three or more of any of unintentional weight loss of $4.54 \mathrm{~kg}$ in the last year, selfreported exhaustion, weakness (grip strength), slow walking speed, and/or low physical activity. All patients were closely monitored at 1-2 weeks, one and three months, and every three months thereafter until the response to onabotulinumtoxinA disappeared. Videourodynamics, seven-day bladder diary, and the International Prostate Symptom Score (IPSS) QOL index were obtained at baseline and at three months. The primary efficacy outcome was change in the Patient Perception of Bladder Condition (PPBC) with a decrease in PPBC of two considered successful. Procedure-related adverse events were recorded and included acute urinary retention (post-void greater than $350 \mathrm{ml}$, necessitating catheterization), gross hematuria, generalized weakness, large PVR (>150 ml), straining to void, and UTI. The primary outcome was similar between groups at three months (frail elderly $83.4 \%$; elderly $91.2 \%$; younger $88.9 \%$ ) and at six months (frail elderly $49.4 \%$; elderly $52.1 \%$, younger $49.4 \%$ ); however at 12 months, success rates were significantly lower for the frail elderly compared to elderly and younger groups (frail elderly $6.28 \%$; elderly $22.3 \%$; younger $23.1 \%$ ). The rates of acute urinary retention, straining to void, and hematuria were similar across groups; however, the frail elderly were more likely to have a large PCR (frail elderly $60.7 \%$; elderly $39.7 \%$, younger $35.7 \%$ ) and to report generalized weakness (frail elderly $6.6 \%$, elderly $0 \%$, younger $0 \%$ ).

Wang et al retrospectively compared 48 patients with type II diabetes mellitus and refractory DO who received intravesical onabotulinumtoxinA $100 \cup$ to 48 age-matched, nondiabetic, controls (Level of evidence $2 \boldsymbol{b}$, Grade B). ${ }^{283}$ Success rates, defined as at least a two-point decrease in PPBC score, were similar between groups during the six-month followup period. Improvements in all OAB symptoms, as measured by seven-day bladder diary and urodynamic parameters, were comparable between the two groups. Diabetic patients had significantly greater incidence of large PVRs $(60.4 \%$ vs. $33.3 \% ; \mathrm{p}<0.007)$ and generalized weakness $(10.4 \%$ vs. $0 \%$; $\mathrm{p}<0.028)$ compared to non-diabetic patients. Acute urinary retention $(10.4 \%$ vs. $6.3 \%$; $p=0.357$, straining to void ( $54.2 \%$ vs. $41.7 \%$; $p=0.154)$, hematuria $(8.3 \%$ vs. $10.4 \%$; $\mathrm{p}=0.500)$, and UTI ( $12.5 \%$ vs. $12.5 \% ; \mathrm{p}=0.621)$ were similar.

\section{Long-term followup}

Patients who completed either of the two aforementioned phase 3 trials were eligible to enter a three-year extension and continue treatment with onabotulinumtoxinA $100 \mathrm{U}$ as needed for management of OAB symptoms. ${ }^{284}$ Prespecified re-treatment criteria included 12 weeks or more since previous treatment, two or more UUI episodes on a three-day bladder diary, and PVR $<200 \mathrm{ml}$. A total of 839 patients entered the open-label extension study, with 430 (51.3\%) completing the 3.5-year study period. The median duration of effect of onabotulinumtoxinA was 7.6 months. The median duration of effect was six months or less in $34.2 \%, 6-12$ months in $37.2 \%$, and greater than 12 months in $28.5 \%$. The rate of discontinuation due to lack of efficacy or adverse events was $5.7 \%$ and $5.1 \%$, respectively. Only $0.5 \%$ discontinued due to treatment-related adverse events, including $\mathrm{UTI}$, urinary retention, dysuria, and bladder pain. Therefore, the majority of patients discontinued treatment for other reasons (personal reasons, loss to followup, and study burden). Reductions in number of UI episodes per day remained constant throughout treatment and consistently high proportions of patients reported improvement or great improvement on the TBS across all treatments (Level of evidence $\mathbf{2 b}$, Grade B). Reductions in other OAB symptoms and improvements in health-related QOL were sustained with long-term onabotulinumtoxinA treatment. Importantly, long-term treatment with onabotulinumtoxinA was well-tolerated, with no evidence of increasing occurrence of adverse events with repeat onabotulinumtoxin $A$ treatments. De novo $\mathrm{CIC}$ incidence decreased from $4 \%$ after the first treatment to less the $2 \%$ for all subsequent treatment cycles. There was no incidence of onabotulinumtoxinA neutralizing antibody formation in those receiving the approved $100 \mathrm{U}$ doses.

Summary and recommendations: OnabotulinumtoxinA (100 U) may be offered as long-term therapy to carefully selected patients with symptoms of frequency, urgency, and urgency incontinence who have had an inadequate response to or are intolerant of $O A B$ pharmacotherapy (Evidence strength Grade A). Patients considering onabotulinumtoxinA must be carefully counselled regarding the need for close followup, the possible need for catheteriza- 


\section{tion (indwelling or CIC), and likelihood of repeat injections to maintain symptom improvement.}

\section{Third-line treatment: PTNS, SNM}

Along with onabotulinumtoxinA injections, third-line treatment for $\mathrm{OAB}$ includes peripheral tibial nerve stimulation (PTNS) and sacral neuromodulation (SNM). Unlike the pharmacological management, onabotulinumtoxinA and SNM are considered invasive, with side effect profiles that may not be immediately reversible or may be permanently irreversible. Both PTNS and SNM are supported by Grade $B$ evidence due to the observational nature of the majority of available studies, small sample sizes, disparate inclusion criteria, and short followup periods. The lack of long-term followup continues to be the main weakness in studies..$^{285-288}$

\section{PTNS}

From the available literature, 18 studies and six systematic reviews were reviewed in consideration of PTNS. Compared to AMs, the treatment effect of PTNS is similar, but with a more tolerable side effect profile. The majority of studies demonstrated improvements in incontinence, frequency, nocturia, and QOL, and minimal side effects (bleeding at insertion site and inconsequential sensation of pain during stimulation) (Level of evidence $2 \boldsymbol{a}$, Grade $\boldsymbol{B}$ ). The general PTNS protocol included stimulation for 30 minutes, once a week, for three months, with followup periods from four weeks to 36 months. Baseline incontinence was typically $>3$ episodes/day (2.2-9.8) and was reduced by $1-3$ episodes/ day. Frequency of 11.8-16.5 episodes/day was reduced by 2-5 episodes/day. Nocturia episodes were reduced by 1-2 episodes/night. ${ }^{289-298}$ Furthermore, when PTNS was compared to a sham-PTNS, improvements were only seen in the active treatment group (Level of evidence $\mathbf{1 b}$, Grade B). ${ }^{293}$

On its own and combined with tolterodine $2-4 \mathrm{mg}$ daily, the use of PTNS appears to improve baseline symptoms when compared to tolterodine alone (Level of evidence 2b, Grade B). ${ }^{289,290}$ Studies with 44-52 weeks of followup showed that improvements were sustained when therapy was continued (Level of evidence 2b, Grade B). ${ }^{289,291-293}$

In one double-blind, randomized, controlled trial, Finazzi et al showed that patients in the PTNS group $(71 \%$ experienced $>50 \%$ reduction in UUI episodes) achieved statistically significantly improved incontinence, frequency, voided volumes, and I-QOL scores (Level of evidence $2 \boldsymbol{b}$, Grade B). ${ }^{299}$ In another randomized trial, three groups, PTNS, oxybutynin ER $10 \mathrm{mg} /$ day, and PTNS + oxybutynin ER $10 \mathrm{mg} /$ day, showed similar improvements over 12 weeks (Level of evidence $2 \boldsymbol{b}$, Grade B). ${ }^{300}$ At 24 weeks, the oxybutynin only group demonstrated worsening of response rate when compared to the PTNS groups.
In line with the duration of treatment effects seen above, some studies showed sustained benefit from PTNS up to 4-6 months following end of treatment, despite varying treatment regimens (Level of evidence $2 \boldsymbol{b}$, Grade B). ${ }^{301-303}$ In studies involving maintenance treatment regimens for patients who initially responded to PTNS, statistically significant improvements were sustained through 24-36 months following varying protocols. ${ }^{293,304}$ Analyzing six prospective non-randomized trials, subjective and objective success rates in PTNS patients were $61.4 \%$ and $60.6 \%$, respectively, though the definitions of success varied. ${ }^{305}$ In a meta-analysis of RCTs in which the control comprised either placebo or sham groups, PTNS patients were more likely to consider treatment a success with a relative risk of $7.02(95 \%$ Cl 1.69-29.17) (Level of evidence 1a, Grade B). ${ }^{286}$

Of note, PTNS does require a system capable of providing frequent clinic appointments, typically lasting 30 minutes to one hour in length, and patients must be compliant and able to continue frequent followup. Therefore, attention must be paid to the patient's level of motivation and travel resources.

Summary and recommendations: Physicians and patients should consider PTNS safe and effective as third-line treatment in a carefully selected population (Evidence strength Grade B).

\section{SNM}

SNM has been widely available since the late 1990s. It has been supported by predominantly observational data and few rigorous studies, including four RCTs, in a review of 23 studies in the recent literature. The treatment effects duration for SNM responders is similar to the pattern of PTNS in that maintenance of symptom improvement occurs only with continued use of the intervention. Separating SNM from PTNS and onabotulinumtoxinA injections is the different adverse event profile, including the need for surgical re-intervention in up to $39.5 \%$ of patients, with up a third of patients in the majority of studies requiring revision. SNM was also complicated by pain at the stimulator site $(3.3-19.8 \%)$, pain at the lead site $(4.5-19.1 \%)$, lead migration $(2.2-8.6 \%)$, electric shock (5.5-7.9\%), and infection/ irritation (2.2-14.3\%). ${ }^{306}$ Positive bacterial colonization of the connector or lead site, measured at the time of the Stage II implant, occurred in $24 \%$ of patients (9/32). ${ }^{307}$ One third of colonized patients went on to develop infection of the device requiring explantation. Only one patient who was not colonized developed infection. When the Stage I period was $>14$ days, $50 \%$ of patients showed colonization; when Stage I was $\leq 14$ days, $14 \%$ developed colonization. ${ }^{307}$ Furthermore, SNM is complicated by the preclusion of pelvic or abdomen MRI studies while the device is in place.

In review, typical study patients were characterized by the following: baseline incontinence 5.0-11.6 episodes per day, 
or $>4$ pads per day, and frequency typically $>13$ episodes per day. ${ }^{308-318}$ The success rate of Stage I implants, the testing phase, in patients who previously failed standard medical therapy or stopped due to medication side effects was found to be about $70 \%$ (Level of evidence $\mathbf{3} \boldsymbol{b}$, Grade $\boldsymbol{B}$ ). ${ }^{319}$ Patients with worse incontinence ( $>10$ episodes/day) fared better than patients with less severe incontinence $(<5$ episodes/ day) (Level of evidence 3b, Grade C). ${ }^{320}$ In patients who had previously tried onabotulinumtoxinA injection, 79\% (11/14 patients) were satisfied with treatment. ${ }^{321}$ Obesity does not affect the chance of success. ${ }^{322}$

In Stage II implants, the treatment phase, respectable followup periods of up to five years were reported. When treatment success was defined as $\geq 50 \%$ decrease in the number of daily incontinence episodes or pads used, the initial $87 \%$ success rate one month post-procedure decreased to $62 \%$ five years post-procedure (Level of evidence $3 \boldsymbol{b}$, Grade $\boldsymbol{C}$ ). ${ }^{309}$ Several studies in a cohort of patients comprised of urgencyfrequency patients compared to urgency-incontinence patients reflect this trend, demonstrating 56\% success in the urgencyfrequency group and $68 \%$ success in the urgency-incontinence group at five years (Level of evidence $2 \boldsymbol{b}$, Grade $\boldsymbol{C}$ ). ${ }^{311,316}$ Long-term patient satisfaction was surveyed to be $90 \%$ at a median post-implant interval 6.4 years. ${ }^{313}$ Older patients, with mean age of 76 years, reported improvement $(27.8 \%)$ and complete success with cessation of UUI episodes (55.5\%). ${ }^{323}$ Banakhar et al evaluated the effects on female sexual function and its impact on QOL in 23 sexually active women using the Female Sexual Function Index (FSFI) and Short-Form Health Survey (SF-36). At four months, statistically significant improvements were found in desire and orgasm categories, as well as in QOL in: physical function, energy, emotional well-being, social functioning, and general health (Level of evidence 3b, Grade C). ${ }^{324}$ Twelve-month outcomes in sexual function using the FSFI were also significantly improved. ${ }^{325}$

Two notable RCTs include the In-site Trial and the Rosetta Trial. ${ }^{326,327}$ The In-site Trial was a prospective, multicentre, FDA-mandated approval study evaluating the safety of the tined lead at six months and included a subset of patients with mild OAB symptoms randomized to SNM or standard medical therapy (SMT). ${ }^{326}$ Of the initial 147 patients, 130 completed six months of therapy, 59 in the SNM group and 71 in the SMT group. At the six-month mark, $61 \%$ of the SNM group and $42 \%$ of the SMT group $(p=0.02)$ achieved $\geq 50 \%$ improvement in average incontinence episodes/day or voids/day or a return to normal voiding frequency of $<8$ voids/day. Additionally, the SNM group responded significantly better in OAB QOL, improvement of sexual function, and improvement in depression (Level of evidence $\mathbf{1 b}$, Grade $\boldsymbol{B})$. The major limitations of this study include the mild nature of symptoms (SNM: mean 11.9 voids/day; mean 2.4 incontinence episodes/day; mean 1.1 pads/day; SMT: mean 11.9 voids/day, mean 2.7 incontinence episodes/day, and mean 1.1 pads/day), and the relatively undefined $O A B$ medication regimen. The Rosetta Trial was a randomized, open-label, active-control trial comparing the effectiveness of $200 \mathrm{U}$ of onabotulinumtoxinA vs. sacral neuromodulation therapy for refractory UUI at six months. ${ }^{327}$ Of the initial 386 patients, 190 in the onabotulinumtoxinA group and 174 in the SNM group both completed the six-month followup and were fit for primary analysis. The primary outcome was change from baseline in mean number of daily episodes of UUI averaged over six months, as recorded over three consecutive days in monthly bladder diaries. In the intention-totreat population, patients treated with onabotulinumtoxinA had a greater six-month mean decrease of 3.9 episodes of UUI per day than did the SNM group of 3.3 (mean difference $0.63 ; 95 \% \mathrm{Cl} 0.13-1.14 ; \mathrm{p}=0.01)$. This difference is small and may not be clinically relevant. In secondary outcome analysis, patients in the onabotulinumtoxinA group experienced greater improvement in symptom bother and treatment satisfaction, but there was no significant difference in QOL, treatment preference, convenience, or adverse effects (Level of evidence $\mathbf{1 b}$, Grade B). The major limitations of this study are the exclusion of varying onabotulinumtoxinA injection techniques and the exclusion of men.

Summary and recommendations: Physicians and patients should consider SNM as more invasive and higher-risk than other third-line treatment, but a suitable option for patients with $O A B$ symptoms refractory to preferred treatment options (Evidence strength Grade B).

\section{Additional treatment (indwelling catheters, augmentation cystoplasty, urinary diversion)}

Beyond the behavioural, lifestyle, and medical/interventional management provided in second- and third-line treatment of $\mathrm{OAB}$, the adult, non-neurogenic population has few options supported by current literature. In the patient with contraindications to other treatment options, including intolerance to medications, allergy, severe debilitation or immobility, and cognitive deficit or expected cognitive decline, indwelling or intermittent catheterization may be tried. However, this carries a high risk of catheter-associated UTIs, long-term issues of urethral erosion (indwelling urethral catheters), and development of bladder calculi, and comes at the requirement of patient compliance and/or caregiver support. The use of catheterization in any form will require ongoing symptom evaluation and close, conscious followup, often by primary care physicians, for adverse effects/calculi. Though rare, malignancy has been described as a complication of enterocystoplasty, mostly in case reports. The majority of malignant tumours were adenocarcinomas, but urothelial carcinoma, carcinoid, and sarcomata have been seen. ${ }^{328}$

In very rare cases, surgery is an option, including augmentation cystoplasty or urinary diversion (Level of evidence 
5, Grade D). Most case series documenting the use of these surgical options do so in the treatment of neurogenic and paediatric patient populations, and are not suitable from which to draw conclusions for the adult, non-neurogenic patient. Furthermore, the patient's perceived benefit from treatment earlier in the treatment algorithm is primarily assessed in terms of QOL. Surgical intervention should probably be reserved for patients in whom other treatments either fail or result in an unacceptable QOL. The severity of potential adverse effects of surgical intervention must be weighed against the likely benefit in QOL.

Summary and recommendations: Indwelling catheterization, augmentation cystoplasty, or other urinary diversions are rare long-term management strategies for $O A B$ and should only be considered after all other medical and surgical options have been exhausted and only after careful consideration of the likely benefits and risks. (Evidence strength Grade D)

\section{Followup}

The intent of followup is to ascertain compliance and efficacy, and to assess for adverse events. Ideally, measurements using validated $O A B$-specific instruments should be obtained and repeated at each subsequent visit. Therefore, the International Consortium for Health Outcomes Measurement proposed the Standard Set for OAB. ${ }^{329}$ Followup schedules should be individualized according to the prescribed treatment and level of concern for patient safety.

Clinicians should be aware of the differences between $\mathrm{OAB}$ treatments with respect to expected efficacy and probability and type of adverse event. For example, the potential of AM agents to improve OAB symptoms may not be fully realized for a period of 12 weeks, whereas side effects, such as dry mouth, constipation, and central nervous system effects, may present earlier with varying degrees of severity. Thus, patients and their caregivers (in the case of elderly or frail elderly) should be informed of these nuances to promote compliance and patient safety and should be subsequently queried at all followup visits. Information gathered at each visit will help the clinician and patient decide on next management steps, particularly if the patient either does not respond or experiences untoward side effects. Initially, patients who have received intradetrusor onabotulinumtoxinA must be followed closely, with assessment of PVR for the possibility of acute urinary retention and need for catheterization. If onabotulinumtoxin $A$ is deemed effective and safe, a repeat injection can be offered at six months and adjusted according to individual response. Neuromodulation, including PTNS and SNM, should be assessed pre- and post-treatment and after any setting adjustment with appropriate instruments, such as a bladder diary. Adverse events unique to neuromodulation should be routinely assessed including wound complications, persistent nerve pain, and collateral stimulation. Patients with urinary diversion, including indwelling catheterization, or lower urinary tract reconstructive surgery should be followed regularly for symptom control and potential complications.

Summary and recommendations: Patient followup should be routinely offered and individualized based on current treatment(s) and concern for patient safety. At each followup visit, the clinician should assess for compliance, efficacy, and potential side effects. If management is deemed ineffective or intolerable, then alternative treatment options should be presented, including drug dosemodification, change within drug class, change or addition of drug class, or consideration of third- or, rarely, additional $O A B$ therapies (Expert Opinion).

\section{Required research and future trends}

Future research in $O A B$ should further investigate all discussed areas, in particular pathophysiology, epidemiology, and clinical practice, including diagnosis and treatment options.

\section{Pathophysiology research and further implications}

New discoveries in the pathophysiology of $\mathrm{OAB}$ are warranted. Nowadays, alterations have been observed in the cholinergic, purinergic, adrenergic, serotonergic, glycinergic, GABAergic, and nitrergic pathways, as well as in production levels of different specific and non-specific transmitters like nerve growth factor, rho-kinase, and prostaglandins. ${ }^{330}$ Emerging roles of ion and transient receptor potential channels have been observed lately. ${ }^{331}$ Recent advances in cell-depended mechanism of bladder contraction have demonstrated the presence of the interstitial cells of Cajal in bladder suburothelium and detrusor muscle compartments. ${ }^{332}$ It should be noted that new research findings do not only lead to an understanding of the pathophysiology of $O A B$, but can also contribute to new diagnostic methods and proper drug development. Each of these functional units expresses a distinct pattern of sensor and effector mechanisms that are potential diagnostic and therapeutic targets.

In the research for a reliable and non-invasive test for $\mathrm{OAB}$ patients, much interest has focused on biomarkers, with their potential for bedside testing. Markers of high- or low-grade infection or inflammation detectable both in urine and blood have now been noted to be raised in $O A B$, including serum C-reactive protein and different cytokines, with the greatest concern on nerve growth factor and prostaglandin E2. ${ }^{333}$

Drugs preventing acetylcholine-mediated involuntary detrusor contractions are the mainstay of $\mathrm{OAB}$ treatment and have the largest scientific background. Nevertheless, there are now several alternative therapeutic options available. Modernization of presently used drugs and designing new 
compounds are intended to specifically target the urothelium and afferent nerves involved in pathophysiology of OAB. Moreover, future studies should also be aimed at determining the need for long-term chronic administration and its potential impact of an individual patient's health.

New AM molecules, novel modes of drug delivery, and even new combinations of existing treatments are presently studied; however newly developed AM agents, imidafenacin and tarafenacin, did not show any difference in terms of efficacy or side effect profile in comparison to currently used drugs. ${ }^{334}$ To minimize systemic absorption and related side effects, vaginal and intravesical routes of oxybutynin delivery have been developed. ${ }^{335,336}$ Intravesical instillation therapy using biodegradable devices have also been studied, as these could represent a good alternative to existing treatment for OAB.

The recent success of mirabegron as a new targeted drug for beta-3-adrenoceptors has moved to further studies on this signalling pathway. While use of mirabegron avoids many of the unwanted AM effects, it has a similar rate of adverse events and there remains concern about cardiac events, despite a recent meta-analysis. ${ }^{337}$ The beta- 3 agonist solabegron showed a statistically significant improvement in the number of incontinence episodes, with side effects rates and vital signs recordings similar to placebo. In view of these positive findings, solabegron is in the final phases of research. ${ }^{338}$ Other beta-3-adrenoceptor agonists (aryloxypropanolamine h, Trk-380, AJ-9677, CL 316,243) are currently under investigation. ${ }^{334}$

New insight into pathophysiology of OAB resulted in possible new treatment objectives. Presently, the most promising targets seem to be the purinergic and cannabinoid systems, with different members of the transient receptor potential channel family. ${ }^{331}$

The underlying pathophysiology associated with idiopathic $\mathrm{OAB}$ is widely acknowledged to be multifactorial. Thus, phenotyping/profiling of patients with different underlying defects originating in the urothelial/mucosal layer of the bladder, the detrusor muscle cell layer, and the central nervous system could potentially improve the clinical problem of failed treatment. ${ }^{339} \mathrm{~A}$ major challenge in profiling patients with subtypes of idiopathic OAB is the lack of a validated list of screening strategies or phenotypic markers to identify trial participants with different underlying pathophysiologies. Such phenotyping markers would need to indicate specific pathophysiological situations in which a disturbance in the urothelial/suburothelial/mucosal layer of the bladder, the detrusor muscle cell layer of the bladder, or the central nervous system could lead to the genesis of OAB symptoms. To overcome these issues, all future clinical trials should include patient profiling classifications based on suspected underlying pathophysiology.

\section{Epidemiological research and further implications}

No appropriate management could be implemented without reliable epidemiological data. Information on development and natural history of $O A B$ is scant. Associated comorbidities and $O A B$ related risk factors have not been sufficiently studied. Even though $\mathrm{OAB}$ has a significant effect on a patients' QOL, it is not clear whether this issue has an impact on outcomes of treatment. Well-conducted epidemiological studies could help in development of potential preventive interventions.

Reports on prevalence and incidence of OAB consistently identify it as a highly prevalent condition in both men and women; ${ }^{9}$ however, many people with OAB do not seek medical attention and opt to suffer in silence, possibly without realising that treatments are available. ${ }^{340}$ These serious issues may lead to major limits in patients' social and professional lives implicating further emotional distress, depression, and social isolation. Thus, the emerging role of social media in medicine should also be exploited in urology, particularly in OAB patients. ${ }^{341}$

\section{Clinical research and further implications}

To this day, disparities exist among $\mathrm{OAB}$ treatment-response assessment in clinical trials and different multidimensional PROs were used as primary or secondary endpoints in clinical research. ${ }^{342}$ Given the heterogeneity of symptoms and multifaceted impact of $O A B$, measurement of outcomes in clinical trials is complicated. Researchers are confronted with the problem of balancing between objective findings in assessment and subjective outcomes reported by patients. ${ }^{343}$ Moreover, this significant heterogeneity even exists between the response and non-response definitions in terms of symptom-based and patient-reported outcomes. ${ }^{344}$ No consensus exists when it comes to measuring treatment outcomes with bladder diaries and PRO questionnaires. The usefulness of voiding diaries in OAB clinical trials is limited, mainly due to lack of validation/ variations of content, format, and duration of data capture. OAB studies report a high level of placebo effect and the placebo response is poorly understood. ${ }^{345}$ The symptom-based definition of $\mathrm{OAB}$ is useful to enter patients into treatment process; however, it fails to address what is most important to patients and doesn't allow investigation of underlying patholphysiology. Thus, it is clear that a new, simpler approach, with incorporated symptoms and health-related QOL evaluation should be employed to provide a more comprehensive and standardized approach to $\mathrm{OAB}$ assessment.

Population aging has emerged as a major worldwide demographic trend, both in developed countries and the developing world. It is known that $\mathrm{OAB}$ symptoms become increasingly prevalent with aging. ${ }^{12}$ Furthermore, older persons are less likely to receive evidence-based care ${ }^{346}$ and are more reluctant 
to seek assistance ${ }^{347}$ than younger people, thus $\mathrm{OAB}$ often remains undiagnosed and untreated. Clinical presentation and management of $\mathrm{OAB}$ are complicated in the vulnerable elderly by the presence of baseline frailty and multiple coexisting chronic conditions. Urological symptoms, incontinence in particular, are significantly connected with increased risk of falls, fractures, ${ }^{348}$ and hospitalization. ${ }^{349}$ Currently available drug treatments for $\mathrm{OAB}$ are usually poorly tolerated and often discontinued. ${ }^{350}$ Needless to say, there is a dearth of evidence from clinical studies relating to the frail elderly, as clinical trials rarely include this population. Future clinical trials and research studies should focus on this group of patients to improve their prognosis and health-related QOL. Treatment outcomes must be tailored and individualized and should be coordinated with other medical care providers.

\section{Conclusion}

To summarize, our knowledge of the $\mathrm{OAB}$ syndrome has increased immensely over recent years. New OAB discoveries might help us make an earlier diagnosis, prevent progression, predict treatment response, and obtain better outcomes. As researchers begin to systematically explore both the genome and the metabolome of the urinary tract, with a special attention to transitional studies and clinical research, we will probably expect great improvement of our practice and in $\mathrm{OAB}$ patients' relief in the future.

Competing interests: Dr. Corcos is an advisor for Allergan, Astellas, Pfizer; a speaker for Allergan and Duchesnay; has received payments/grants/honoraria from Astellas; and has participated in clinical trials supported by Allergan and Ipsen. Dr. Przydacz has participated in clinical trials supported by Bristol-Myers Squibb. Dr. Campeau is an advisor for Astellas and Pfizer; a speaker for Astellas, Duchesnay, and Pfizer; has received payments/grants/honoraria from Astella and Pfizer; and has participated in clinical trials supported by Pfizer. Dr. Gray is an advisor for Astellas; a speaker for Astellas, Merus, and Pfizer; has received grants/honoraria from Astellas, Merus, and Pfizer; and has participated in clinical trials supported by Biones. Dr. Hickling is an advisor for Astellas and Pfizer; a speaker for Allergan and Pfizer; has received grants/honoraria from Boston Scientific; and has participated in clinical trials supported by Astellas. Dr. Radomski is an advisor for Allergan, Astellas, Duchesnay, Lilly, Merus, and Pfizer; a speaker for Astellas, Olympus, and Pfizer; and has participated in clinical trials supported by Allergan, Astellas, and Pfizer. Dr. Wagg is an advisor for Astellas and Pfizer; has received payment/grants/honoraria from Astellas, Duchesnay, Pfizer, and SCA AB; and has participated in clinical trials supported by Astellas and Pfizer. Dr. Stothers and Ms. Honeine report no competing personal or financial interests.

Acknowledgments: The following residents/fellows have participated in the preparation of these guidelines: Marwa Abdulaziz, MSc, Dr. Andrew Macnab, and Dr. Jonathan L. Witten.

\section{References}

1. University of Oxford, Graduate School in EBM and Research Methods, Centre for Evidence-Based Medicine [Internet]; Oxford Centre for Evidence-based Medicine - Levels of Evidence and Grades of Recommendation, Published 2009; Cited December 2016. Available from: http://www.cebm.net/ oxford-centre-evidence-based-medicine-levels-evidence-march-2009/. Accessed March 23, 2017.

2. Haylen BT, de Ridder D, Freeman RM, et al. An International Urogynecological Association (IUGA)/ International Continence Society (ICS) joint report on the terminology for female pelvic floor dysfunction. Neurourol Urodyn 2010;29:4-20. https://doi.org/10.3109/9781439807217-111

3. Abrams $P$, Cardozo L, Fall M, et al. The standardization of terminology of lower urinary tract function: Report from the Standardization Subcommittee of the International Continence Society. Neurourol Urodyn 2002;21:167-78. https://doi.org/10.1002/nau.10052

4. Fitzgerald MP, Brubaker L. Variability of 24-hour voiding diary variables among asymptomatic women. J Urol 2003;169:207-9. https://doi.org/10.1016/S0022-5347(05)64069-4

5. Irwin DE, Abrams $P$, Milsom I, et al. Understanding the elements of overactive bladder: Questions raised by the EPIC study. BJU Int 2008;101:1381-7. https://doi.org/10.1111/j.1464-410X.2008.07573.x

6. Link CL, Steers WD, Kusek JW, et al. The association of adiposity and overactive bladder appears to differ by gender: Results from the Boston Area Community Health survey. J Urol 2011;185:955-63. https://doi.org/10.1016/i.juro.2010.10.048

7. Patra PB, Patra $S$. Sex differences in the physiology and pharmacology of the lower urinary tract. Curr Urol 2013;6:179-88. https://doi.org/10.1159/000343536

8. Choo MS, Ku JH, Lee JB, et al. Cross-cultural differences for adapting overactive bladder symptoms: Results of an epidemiologic survey in Korea. World J Uro 2007;25:505-11. https://doi.org/10.1007/ s00345-007-0183-6

9. Corcos J, Schick E. Prevalence of overactive bladder and incontinence in Canada. Can J Urol 2004;11:227884.

10. Coyne KS, Sexton $C C$, Vats $\mathrm{V}$, et al. National community prevalence of overactive bladder in the United States stratified by sex and age. Urology 2011;77:1081-7. https://doi.org/10.1016/j.urology.2010.08.039

11. Tikkinen $K A$, Auvinen $A$, Tiitinen A, et al. Reproductive factors associated with nocturia and urinary urgency in women: A population-based study in Finland. Am J Obstet Gynecol 2008:199:153e l-12.

12. Irwin DE, Milsom I, Hunskaar S, et al. Population-based survey of urinary incontinence, overactive bladder, and other lower urinary tract symptoms in five countries: Results of the EPIC study. Eur Urol 2006;50:130615. https://doi.org/10.1016/j.eururo.2006.09.019

13. Stewart WF, Van Rooyen JB, Cundiff GW, et al. Prevalence and burden of overactive bladder in the United States. World J Urol 2003;20:327-36.

14. Herschorn S, Gajewski J, Schulz J, et al. A population-based study of urinary symptoms and incontinence: The Canadian Urinary Bladder Survey. BJU Int 2008;101:52-8.

15. Milsom I, Abrams P, Cardozo L, et al. How widespread are the symptoms of an overactive bladder and how are they managed? A population-based prevalence study. BJU Int 2001;87:760-6. https://doi.org/10.1046/i.1464-410x.2001.02228.x

16. Donaldson MM, Thompson JR, Matthews RJ et al. The natural history of overactive bladder and stress urinary incontinence in older women in the community: A three-year prospective cohort study. Neurourol Urodyn 2006;25:709-16. https://doi.org/10.1002/nau.20235

17. Moller $L A$, Lose $G$, Jorgensen $T$. The prevalence and bothersomeness of lower urinary tract symptoms in women 40-60 years of age. Acta Obstet Gynecol Scand 2000;79:298-305. https://doi.org/10.1080/ j.1600-0412.2000.079004298.x

18. Nitti VW, Rosenberg S, Mitcheson DH, et al. Urodynamics and safety of the $\beta 3$-adrenoceptor agonist mirabegron in males with lower urinary tract symptoms and bladder outlet obstruction. J Urol 2013;190:13207. https://doi.org/10.1016/i.juro.2013.05.062

19. Lee JY, Kim HW, Lee SJ, et al. Comparison of doxazosin with or without tolterodine in men with symptomatic bladder outlet obstruction and an overactive bladder. BJU Int 2004;94:817-20. https://doi.org/10.1111/i.1464-410X.2004.05039.x

20. Kaplan SA, Roehrborn CG, Gong J, et al. Add-on fesoterodine for residual storage symptoms suggestive of overactive bladder in men receiving -blocker treatment for lower urinary tract symptoms. BJU Int 2012;109:1831-40. https://doi.org/10.1111/j.1464-410X.2011.10624.x

21. Vuichoud C, Loughlin K. Benign prostatic hyperplasia: Epidemiology, economics, and evaluation. Can J Urol 2015;22(Suppl 1):1-6.

22. Chapple CR, Herschorn S, Abrams P, et al. Efficacy and safety of tolterodine extended-release in men with overactive bladder symptoms treated with an -blocker: Effect of baseline prostate-specific antigen concentration. BJU Int 2010;106:1332-8. https://doi.org/10.1111/i.1464-410X.2010.09359.x 
Corcos et al.

23. de Nunzio C, Franco $G$, Rocchegiani $A$, et al. The evolution of detrusor overactivity after watchful waiting, medical therapy, and surgery in patients with bladder outlet obstruction. J Urol 2003;169:535-9. https://doi.org/10.1016/S0022-5347(05)63949-3

24. Cotteril, N. Quality of life issues in continence care. Nurs Stand 2011;26:51-8. https://doi.org/10.7748/ ns.26.8.51.s51

25. Avery KN, Bosch IL, Gotoh M, et al. Questionnaires to assess urinary and anal incontinence: Review and recommendations. J Urol 2007;177:39-49. hitps://doi.org/10.1016/i.juro.2006.08.075

26. Riss P, Kargl J. Quality of life and urinary incontinence in women. Maturitas 2011;68:137-42. https://doi.org/10.1016/i.maturitas.2010.11.006

27. Irwin DE, Milsom I, Chancellor MB, et al. Dynamic progression of overactive bladder and urinary incontinence symptoms: A systematic review. Eur Urol 2010;58:532-43. https://doi.org/10.1016/i. eururo.2010.06.007

28. Capelini MV, Riccetto CL, Dambros M, et al. Pelvic floor exercises with biofeedback for stress urinary incontinence. Int Braz I Urol 2006;32:462-8; discussion 9. https://doi.org/10.1590/S167755382006000400015

29. Oh SJ, Ku JH, Choo MS, et al. Health-related quality of life and sexual function in women with stress urinary incontinence and overactive bladder. Int J Urol 2008;15:62-7; discussion 7. https://doi. org/10.1111/i.1442-2042.2007.01905.x

30. Ko Y, Lin SJ, Salmon JW, et al. The impact of urinary incontinence on quality of life of the elderly. Am J Manag Care 2005;11:S103-11.

31. Higa R, Lopes MH. The impact of urinary incontinence on female nursing personnel. Rev Bras Enferm 2007;60:213-6. https://doi.org/10.1590/S0034-71672007000200016

32. Salvatore $S$, Serati $M$, Laterza $R$, et al. The impact of urinary stress incontinence in young and middle-age women practicing recreational sports activity: An epidemiological study. Br I Sports Med 2009;43:1115-8. https://doi.org/10.1136/bism.2008.049072

33. Melville JL, Walker E, Katon W, et al. Prevalence of comorbid psychiatric illness and its impact on symptom perception, quality of life, and functional status in women with urinary incontinence. Am J Obstet Gynecol 2002;187:80-7. https://doi.org/10.1067/mob.2002.124839

34. Stach-Lempinen B, Hakala AL, Laippala $P$, et al. Severe depression determines quality of life in urinary incontinent women. Neurourol Urodyn 2003;22:563-8. https://doi.org/10.1002/nau.10137

35. Perry S, McGrother CW, Turner K, et al. An investigation of the relationship between anxiety and depression and urge incontinence in women: Development of a psychological model. Br J Health Psychol 2006;11:463-82. https://doi.org/10.1348/135910705×60742

36. Nygaard I, Turvey C, Burns TL, et al. Urinary incontinence and depression in middle-aged United States women. Obstet Gynecol 2003;101:149-56. https://doi.org/10.1097/00006250-200301000-00028

37. Lai HH, Shen B, Rawal A, et al. The relationship between depression and overactive bladder/urinary incontinence symptoms in the clinical OAB population. BMC Urol 2016;16:60. https://doi.org/10.1186/ s12894-016-0179-x

38. Nicolson P, Kopp Z, Chapple CR, et al. It's just the worry about not being able to control it! A qualitative study of living with overactive bladder. Br J Health Psychol 2008;13:343-59. https://doi.org/10.1348/135910707X187786

39. Giuseppe PG, Pace G, Vicentini C. Sexual function in women with urinary incontinence treated by pelvic floor transvaginal electrical stimulation. J Sex Med 2007;4:702-7. https://doi.org/10.1111/j.17436109.2006.00318.x

40. Aslan E, Beii NK, Gungor I, et al. Prevalence and risk factors for low sexual function in women: A study of 1009 women in an outpatient clinic of a university hospital in Istanbul. J Sex Med 2008;5:2044-52. https://doi.org/10.1111/i.1743-6109.2008.00873.x

41. Coyne $\mathrm{KS}$, Sexton $\mathrm{CC}$, Thompson $\mathrm{CL}$, et al. Impact of overactive bladder on work productivity. Urology 2012;80:97-103. https://doi.org/10.1016/j.urology.2012.03.039

42. Sexton CC, Coyne KS, Vats V, et al. Impact of overactive bladder on work productivity in the United States: Results from EpilUTS. Am J Manag Care 2009;15:S98-S107.

43. Hewison A, McCaughan D, Watt I. An evaluative review of questionnaires recommended for the assessment of quality of life and symptom severity in women with urinary incontinence. I Clin Nurs 2014;23:29983011. https://doi.org/10.1111/jocn.12503

44. Nelson R, Norton N, Cautley E, et al. Community-based prevalence of anal incontinence. JAMA 1995;274:559-561. https://doi.org/10.1001/jama.1995.03530070057030

45. Pretlove SJ, Radley S, Toozs-Hobson PM, et al. Prevalence of anal incontinence according to age and gender: A systematic review and meta-regression analysis. Int Urogynecol I Pelvic Floor Dysfunct 2006;17:407-17. https://doi.org/10.1007/s00192-005-0014-5

46. Irwin DE, Kopp ZS, Agatep B, et al. Worldwide prevalence estimates of lower urinary tract symptoms, overactive bladder, urinary incontinence, and bladder outlet obstruction. BJU Int 2011;108:1132-8. https://doi.org/10.1111/i.1464-410X.2010.09993.x
47. Sharma A, Marshjall RJ, MacMillan AK, et al. Determining levels of fecal incontinence in the community: A New Zealand cross-sectional study. Dis Colon Rectum 2011;54:1381-7. https://doi.org/10.1097/ DCR.0b013e31822ddOfo

48. Milsom I, Altman D, Cartwright $R$, et al. Epidemiology of urinary incontinence (UI) and other lower urinary tract symptoms (LUTS), pelvic organ prolapse (POP) and anal (Al) incontinence. In: Abrams P, Cardozo L, Khoury S, Wein A, eds. Incontinence: 5th International Consultation on Incontinence, Paris February 2012. 5th ed. Paris: Health Publications Ltd.; 2013.

49. Milsom I, Coyne KS, Nicholson S, et al. Global prevalence and economic burden of urgency urinary incontinence: A systematic review. Eur Urol 2014;65:79-95. https://doi.org/10.1016/i.eururo.2013.08.031

50. Zarowitz BJ, Allen C, O'Shea T, et al. Clinical burden and non-pharmacologic management of nursing facility residents with overactive bladder and/or urinary incontinence. Consult Pharm 2015;30:533-42. https://doi.org/10.4140/TCP.n.2015.533

51. Elstad EA, Taubenberger SP, Botelho EM, et al. Beyond incontinence: The stigma of other urinary symptoms. J Adv Nurs 2010;66:2460-70. https://doi.org/10.1111/j.1365-2648.2010.05422.x

52. Teunissen $D$, van Weel $C$, Lagro-Janssen $T$. Urinary incontinence in older people living in the community: Examining help-seeking behaviour. Br J Gen Pract 2005;55:776-82.

53. Horrocks $S$, Somerset $M$, Stoddart $H$, et al. What prevents older people from seeking treatment for urinary incontinence? A qualitative exploration of barriers to the use of community continence services. Fam Pract 2004;21:689-96. htrps://doi.org/10.1093/fampra/cmh622

54. Strickland R. Reasons for not seeking care for urinary incontinence in older community-dwelling women: A contemporary review. Urologic Nursing 2014;34:63-8.

55. Thomas $P$, Ingrand $P$, Lalloue $F$, et al. Reasons of informal caregivers for institutionalizing dementia patients previously living at home:The Pixel study. Int I Geriatr Psychiatry 2004;19:127-35. https://doi.org/10.1002/gps. 1039

56. Holroyd-Leduc JM, Mehta KM, Covinsky KE. Urinary incontinence and its association with death, nursing home admission, and functional decline. J Am Geriatr Soc 2004;52:712-8. https://doi.org/10.1111/ j.1532-5415.2004.52207.x

57. Tang DH, Colayco D, Piercy J, et al. Impact of urinary incontinence on health-related quality of life, daily activities, and healthcare resource utilization in patients with neurogenic detrusor overactivity. BMC Neurology 2014;14:74. https://doi.org/10.1186/1471-2377-14-74

58. Sexton $\mathrm{CC}$, Coyne $\mathrm{KS}$, Thompson C, et al. Prevalence and effect on health-related quality of life of overactive bladder in older Americans: Results from the epidemiology of lower urinary tract symptoms study. J Am Geriatr Soc 2011;59:1465-70. https://doi.org/10.1111/i.1532-5415.2011.03492.x

59. Coyne KS, Kvasz M, Ireland AM, et al. Urinary incontinence and its relationship to mental health and health-related quality of life in men and women in Sweden, the United Kingdom, and the United States. Eur Urol 2012;61:88-95. https://doi.org/10.1016/i.eururo.2011.07.049

60. Coyne KS, Wein A, Nicholson S, et al. Comorbidities and personal burden of urgency urinary incontinence: a systematic review. Int I Clin Pract 2013;67:1015-33. https://doi.org/10.1111/iicp.12164

61. Irwin DE, Milsom I, Kopp $Z$, et al. Prevalence, severity, and symptom bother of lower urinary tract symptoms among men in the EPIC study: Impact of overactive bladder. Eur Urol 2009;56:14-20. https://doi.org/10.1016/i.eururo.2009.02.026

62. Gotoh M, Kobayashi T, Sogabe K. Characterization of symptom bother and health-related quality of life in Japanese female patients with overactive bladder. Neurourol Urodyn 2015;34:730-5. https://doi.org/10.1002/nau.22663

63. Wehrberger $C$, Madersbacher $S$, Jungwirth $S$, et al. Lower urinary tract symptoms and urinary incontinence in a geriatric cohort - a population-based analysis. BJU Int 2012;110:1516-21. https://doi.org/10.1111/i.1464-410X.2012.11022.x

64. Dubeau CE, Simon SE, et al. The effect of urinary incontinence on quality of life in older nursing home residents. J Am Geriatt Soc 2006;54:1325-33. https://doi.org/10.1111/i.1532-5415.2006.00861.x

65. MacDonald CD, Butler L. Silent no more: Elderly women's stories of living with urinary incontinence in long-term care. J Gerontol Nurs 2007;33:14-20.

66. Farage MA, Miller KW, Berardesca E, et al. Psychosocial and societal burden of incontinence in the aged population: A review. Arch Gynecol Obstet 2008;277:285-90. https://doi.org/10.1007/s00404-007-0505-3

67. Kuiper JS, Zuidersma M, Oude Voshaar RC, et al. Social relationships and risk of dementia: A systematic review and meta-analysis of longitudinal cohort studies. Ageing Res Rev 2015;22:39-57. https://doi. org/10.1016/i.arr.2015.04.006

68. Milsom I, Kaplan SA, Coyne KS, et al. Effect of bothersome overactive bladder symptoms on health-related quality of life, anxiety, depression, and treatment seeking in the United States: Results from EpiLUTS. Urology 2012;80:90-6. https://doi.org/10.1016/j.urology.2012.04.004

69. Ikeda Y, Nakagawa H, Ohmori-Matsuda K, et al. Risk factors for overactive bladder in the elderly population: A community-based study with face-to-face interview. Int I Urol 201 1;18:212-8. https://doi. org/10.1111/.1.1442-2042.2010.02696.x 
70. Cartwright $R$, Srikrishna $S$, Cardozo $L$, et al. Validity and reliability of the patient's perception of intensity of urgency scale in overactive bladder. BJU Int 2011;107:1612-7. https://doi.org/10.1111/j.1464410X.2010.09684.x

71. Yun JH, Kim JH, Kim JH, et al. Can we decide the optimal initial treatment for male lower urinary tract symptoms patients with overactive bladder by the most bothersome symptom? A randomized, prospective, open-label study. Urol Int 2014;93:338-43. https://doi.org/10.1159/000365335

72. Willis-Gray MG, Dieter AA, Geller EJ. Evaluation and management of overactive bladder: Strategies for optimizing care. Res Rep Urol 2016;8:113-22. https://doi.org/10.2147/RRU.S93636

73. Fan YH, Lin AT, Chen KK. Defining causes for overactive bladder symptoms in women. Low Urin Tract Symptoms 2012;4:73-6. https://doi.org/10.1111/i.1757-5672.2011.00139.x

74. Garnett $S$, Abrams $P$. The natural history of the overactive bladder and detrusor overactivity. A review of the evidence regarding the long-term outcome of the overactive bladder. J Urol 2003;169:843-8. https://doi.org/10.1097/01.ju.0000050305.05345.40

75. Chapple C, Khullar V, Nitti VW, et al. Efficacy of the 3-adrenoceptor agonist mirabegron for the treatment of overactive bladder by severity of incontinence at baseline: A posthoc analysis of pooled data from three randomized, phase 3 trials. Eur Urol 2015;67:1 1-4. https://doi.org/10.1016/i.eururo.2014.06.052

76. Brubaker L, Chapple C, Coyne KS, et al. Patient-reported outcomes in overactive bladder: Importance for determining clinical effectiveness of treatment. Urology 2006;68(2 Suppl):3-8. https://doi.org/10.1016/i.urology.2006.05.045

77. Jura YH, Townsend MK, Curhan GC, et al. Caffeine intake, and the risk of stress, urgency, and mixed urinary incontinence. J Urol 2011;185:1775-80. https://doi.org/10.1016/i.juro.2011.01.003

78. Dallosso HM, McGrother CW, Matthews RJ, et al. The association of diet and other lifestyle factors with overactive bladder and stress incontinence: A longitudinal study in women. BJU Int 2003;92:69-77. https://doi.org/10.1046/j.1464-410X.2003.04271.x

79. Cartwright R, Srikrishna S, Cardozo L, et al. Does diet coke cause overactive bladder? A four-way crossover trial investigating the effect of carbonated soft drinks on overactive bladder symptoms in normal volunteers. 37th annual meeting of the International Continence Society Neurourol Urodyn 2007;26:626-7.

80. Wells MJ, Jamieson K, Markham TC, et al. The effect of caffeinated versus decaffeinated drinks on overactive bladder: A double-blind, randomized, crossover study. J Wound Ostomy Continence Nurs 2014;41:371-8. https://doi.org/10.1097/WON.0000000000000040

81. Masereijan NN, Wager CG, Giovannucci EL, et al. Intake of caffeinated, carbonated, or citrus beverage types and development of lower urinary tract symptoms in men and women. Am J Epidemiol 2013;177:1399410. https://doi.org/10.1093/aje/kws411

82. Kim MS, Lee $\mathrm{GH}, \mathrm{Na} E \mathrm{E}$, et al. The association of pelvic organ prolapse severity and improvement in overactive bladder symptoms after surgery for pelvic organ prolapse. Obstet Gynecol Sci 2016;59:214-9. https://doi.org/10.5468/ogs.2016.59.3.214

83. Kerr-Wilson RH, Thompson SW, Orr JW Jr, et al. Effect of labor on the postpartum bladder. Obstet Gynecol 1984;64:115-8.

84. Kerr-Wilson RH, McNally S. Bladder drainage for caesarean section under epidural analgesia. Br J Obstet Gynaecol 1986;93:28-30. https://doi.org/10.1111/i.1471-0528.1986.tb07808.x

85. Humburg J, Troeger C, Holzgreve W, et al. Risk factors in prolonged postpartum urinary retention: An analysis of six cases. Arch Gynecol Obstet 201 1;283:179-83. https://doi.org/10.1007/s00404-009-1320-9

86. Yip SK, Hin LY, Chung TK. Effect of the duration of labour on postpartum post-void residual bladder volume. Gynecol Obstet Invest 1998;45:177-80. https://doi.org/10.1159/000009951

87. Golabek T, Skalski M, Przydacz M, et al. Lower urinary tract symptoms, nocturia, and overactive bladder in patients with depression and anxiety. Psychiatr Pol 2016;50:417-30.

88. Ekundayo 0J. The association between overactive bladder and diuretic use in the elderly. Curr Urol Rep 2009;10:434-40. https://doi.org/10.1007/s11934-009-0069-9

89. Wagg A. Treating overactive bladder in the elderly. Can Urol Assoc J 2011;5:S149-51. https://doi.org/10.5489/cuaj.11188

90. Zullo MA, Plotti F, Calcagno M, et al. Vaginal estrogen therapy and overactive bladder symptoms in postmenopausal patients after a tension-free vaginal tape procedure: A randomized clinical trial. Menopause 2005;12:421-7. https://doi.org/10.1097/01.GME.0000148645.93603.62

91. Cheng $\mathrm{CL}$, Li JR, Lin $\mathrm{CH}$, et al. Positive association of female overactive bladder symptoms and estrogen deprivation: A nationwide population-based cohort study in Taiwan. Medicine (Baltimore) 2016;95:e4107. https://doi.org/10.1097/MD.0000000000004107

92. Steele SR, Varma MG, Prichard D, et al. The evolution of evaluation and management of urinary or fecal incontinence and pelvic organ prolapse. Curr Probl Surg 2015;52:17-75. https://doi.org/10.1067/i. cpsurg.2015.01.001

93. Lugo Salcedo F, Sánchez Borrego R; G.U.I.A.S Group. Assessment of female prevalence of overactive bladder $(O A B)$ in Barcelona using a self-administered screening questionnaire: The Cuestionario de Autoevaluación del Control de la Vejiga (CACV). Int Urogynecol J 2013;24:1559-66. https://doi.org/10.1007/s00192-013-2067-1
94. Hikita KS, Honda M, Hirano S, et al. Comparison of the overactive bladder symptom score and the overactive bladder symptom score derived from the bladder diaries. Neurourol Urodyn 2016;35:349-53. https://doi.org/10.1002/nau.22719

95. Kelleher R, Staskin D, Cherian P, et al., Committee 5B. Patient reported outcome assessment. In: Abrams P, Cardozo L, Khoury S, et al. 5th International Consultation on Incontinence, Paris February 2012.

96. Shy M, Fletcher SG. Objective evaluation of overactive bladder: Which surveys should I use? Curr Bladder Dysfunct Rep 2013;8:45. https://doi.org/10.1007/s1 1884-012-0167-2

97. Amundsen $\mathrm{CL}$, Parsons $\mathrm{M}$, Tissot $\mathrm{B}$, et al. Bladder diary measurements in asymptomatic females: functional bladder capacity, frequency, and 24-hr volume. Neurourol Urodyn 2007:26:341-9. https://doi.org/10.1002/nau.20241

98. Stav K, Dwyer PL, Rosamilia A. Women overestimate daytime urinary frequency: The importance of the bladder diary. J Urol 2009;181:2176-80. https://doi.org/10.1016/i.juro.2009.01.042

99. Zimmern P, Litman $\mathrm{HJ}$, Mueller $\mathrm{E}$, et al. Effect of fluid management on fluid intake and urge incontinence in a trial for overactive bladder in women. BJU Int 2010;105:1680-5. https://doi.org/10.1111/j.1464410X.2009.09055.x

100. Honjo H, Kawauchi A, Ukimura 0 , et al. Analysis of bladder diary with urinary perception to assess overactive bladder symptoms in community-dwelling women. Neurourol Urodyn 2009;28:982-5. https://doi.org/10.1002/nau.20704

101. Fitzgerald MP, Ayuste D, Brubaker L. How do urinary diaries of women with an overactive bladder differ from those of asymptomatic controls? BJU Int 2005;96:365-7. https://doi.org/10.1111/i.1464410X.2005.05632.x

102. Brown JS, McNaughton KS, Wyman JF, et al. Measurement characteristics of a voiding diary for use by men and women with overactive bladder. Urology 2003;61:802-9. https://doi.org/10.1016/ S0090-4295(02)02505-0

103. Nygaard I, Holcomb R. Reproducibility of the seven-day voiding diary in women with stress urinary incontinence. Int Urogynecol J Pelvic Floor Dysfunct 2000;11:15-7. https://doi.org/10.1007/PL00004021

104. Ertberg P, Møller LA, Lose G. A comparison of three methods to evaluate maximum bladder capacity: cystometry, uroflowmetry and a 24 -h voiding diary in women with urinary incontinence. Acta Obstet Gynecol Scand 2003;82:374-7. https://doi.org/10.1034/i.1600-0412.2003.00076.x

105. Jimenez-Cidre MA, Lopez-Fando L, Esteban-Fuertes $M$, et al. The three-day bladder diary is a feasible, reliable, and valid tool to evaluate the lower urinary tract symptoms in women. Neurourol Urodyn 2015;34:128-32. https://doi.org/10.1002/nau.22530

106. Fayyad AM, Hill SR, Jones G. Urine production and bladder diary measurements in women with type 2 diabetes mellitus and their relation to lower urinary tract symptoms and voiding dysfunction. Neurourol Urodyn 2010;29:354-8

107. Homma Y, Kakizaki H, Yamaguchi 0, et al. Assessment of overactive bladder symptoms: Comparison of three-day bladder diary and the overactive bladder symptoms score. Urology 2011;77:60-4. https://doi.org/10.1016/i.urology.2010.06.044

108. Bright $\mathrm{E}$, Cotterill N, Drake $\mathrm{M}$, et al. Developing and validating the International Consultation on Incontinence Questionnaire bladder diary. Eur Urol 2014;66:294-300. https://doi.org/10.1016/j. eururo.2014.02.057

109. van Brummen $\mathrm{HJ}$, Heintz AP, van der Vaart $\mathrm{CH}$. The association between overactive bladder symptoms and objective parameters from bladder diary and filling cystometry. Neurourol Urodyn 2004;23:38-42. https://doi.org/10.1002/nau.10162

110. Buchsbaum GM, Albushies DT, Guzick DS. Utility of urine reagent strip in screening women with incontinence for urinary tract infection. Int Urogynecol J Pelvic Floor Dysfunct 2004;15:391-3. https://doi.org/10.1007/s00192-004-1192-2

111. Arinzon Z, Shabat S, Peisakh A, et al. Clinical presentation of urinary tract infection (UTI) differs with aging in women. Arch Gerontol Geriatr 2012;55:145-7. https://doi.org/10.1016/..archger.2011.07.012

112. Moore EE, Jackson SL, Boyko EJ, et al. Urinary incontinence and urinary tract infection: Temporal relationships in postmenopausal women. Obstet Gynecol 2008;111: 317-23. https://doi.org/10.1097/ AOG.0b013e318160d64a

113. Sorrentino F, Cartwright R, Digesu GA, et al. Associations between individual lower urinary tract symptoms and bacteriuria in random urine samples in women. Neurourol Urodyn 2015; 34:429-33. https://doi.org/10.1002/nau.22607

114. Grabe M, Bartoletti R, Bierklund Johansen TE. EAU guidelines on urological infections 2015. Available at: httrp://uroweb.org/wp-content/uploads/EAU-Guidelines-Urological-nfections-v2.pdf. Accessed April 7, 2017.

115. Widmer $M$, Lopez I, Gülmezoglu AM, et al. Duration of treatment for asymptomatic bacteriuria during pregnancy. Cochrane Database Syst Rev 2015; 11:CD000491. https://doi.org/10.1002/14651858. cd000491.pub3

116. Cai T, Verze P, Palmieri A, et al. Is preoperative assessment and treatment of asymptomatic bacteriuria necessary for reducing the risk of postoperative symptomatic urinary tract infections after urological surgical procedures? Urology 2017;99:100-5. https://doi.org/10.1016/j.urology.2016.10.016 
Corcos et al.

117. May M, Brookman-Amissah S, Hoschke B, et al. Post-void residual urine as a predictor of urinary tract infection — is there a cutoff value in asymptomatic men? J Urol 2009;181:2540-4. https://doi.org/10.1016/i.juro.2009.01.103

118. Milleman M, Langenstroer P, Guralnick ML. Post-void residual urine volume in women with overactive bladder symptoms. J Urol 2004;172:1911-4. htrps://doi.org/10.1097/01.ju.0000140502.34334.75

119. Park J, Lavelle JP, Palmer MH. Voiding dysfunction in older women with overactive bladder symptoms: A comparison of urodynamic parameters between women with normal and elevated post-void residual urine. Neurourol Urodyn 2016;35:95-9. https://doi.org/10.1002/nau.22689

120. Drake MJ, Nixon PM, Crew JP. Drug-induced bladder and urinary disorders. Incidence, prevention and management. Drug Safety 1998;19:45-55. htrps://doi.org/10.2165/00002018-199819010-00004

121. Goode PS, Locher JL, Bryant RL, et al. Measurement of post-void residual urine with portable transabdominal bladder ultrasound scanner and urethral catheterization. Int Urogynecol J Pelvic Floor Dysfunct 2000;11:296-300. https://doi.org/10.1007/s001920070020

122. Griffiths DJ, Harrison G, Moore K, et al. Variability of post-void residual urine volume in the elderly. Urol Res 1996;24:23-6. hitps://doi.org/10.1007/BF00296729

123. Marks LS, Dorey FJ, Macairan ML, et al. Three-dimensional ultrasound device for rapid determination of bladder volume. Urology 1997;50:341-8. https://doi.org/10.1016/S0090-4295(97)00293-8

124. Nygaard IE. Post-void residual volume cannot be accurately estimated by bimanual examination. Int Urogynecol J Pelvic Floor Dysfunct 1996;7:74-6. https://doi.org/10.1007/BF01902376

125. Ouslander JG, Simmons $S$, Tuico $E$, et al. Use of a portable ultrasound device to measure post-void residual volume among incontinent nursing home residents. J Am Geriatr Soc 1994; 42:1189-92. https://doi.org/10.1111/j.1532-5415.1994.tb06987.x

126. McVary KT, Roehrborn CG, Avins AL et al. American Urological Association Guideline: Management of benign prostatic hyperplasia (BPH) revised, 2010. American Urological Association Education and Research, Inc. 2010. Available at: https://www.auanet.org/education/guidelines/benign-prostatic-hyperplasia.cfm. Accessed April 7, 2017

127. Robinson D, Oelke M, Khullar $V$, et al. Bladder wall thickness in women with symptoms of overactive bladder and detrusor overactivity: Results from the randomized, placebo-controlled shrink study. Neurourol Urodyn 2016;35:819-25. hitps://doi.org/10.1002/nau.22808

128. Rachaneni S, McCooty S, Middleton L, et al. Bladder ultrasonography for diagnosing detrusor overactivity: Test accuracy study and economic evaluation. Health Technol Assess 2016;20:1-150. https://doi.org/10.3310/hta20070

129. Oelke M. International Consultation on Incontinence-Research Society (ICI-RS) report on non-invasive urodynamics: The need of standardization of ultrasound bladder and detrusor wall thickness measurements to quantify bladder wall hypertrophy. Neurourol Urodyn 2010;29:634-9. https://doi.org/10.1002/ nau.20834

130. Antunes-Lopes T, Cruz CD, Cruz F, et al. Biomarkers in lower urinary tract symptoms/overactive bladder: A critical overview. Curr Opin Urol 2014;24:352-7. https://doi.org/10.1097/MOU.0000000000000064

131. Nitti VW, Rovner ES, Bavendam T. Response to fesoterodine in patients with an overactive bladder and urgency urinary incontinence is independent of the urodynamic finding of detrusor overactivity. BJU Int 2010;105:1268-75. https://doi.org/10.1111/i.1464-410X.2009.09037.x

132. Malone-Lee JG, Al-Buheissi S. Does urodynamic verification of overactive bladder determine treat ment success? Results from a randomized, placebo-controlled study. BJU Int 2009; 103:931-7. https://doi.org/10.1111/i.1464-410X.2009.08361.x

133. Amir B, Farrell SA. SOGC Committee opinion on urodynamics testing. J Obstet Gynaecol Can 2008;30:71727. https://doi.org/10.1016/S1701-2163(16)32921-8

134. Lin LY, Yeh NH, Lin CY, et al. Comparisons of urodynamic characteristics between female patients with overactive bladder and overactive bladder plus stress urinary incontinence. Urology 2004;64:945-9. https://doi.org/10.1016/i.urology.2004.06.023

135. Al-Zahrani AA, Gajewski J. Urodynamic findings in women with refractory overactive bladder symptoms. Int J Urol 2016;23:75-9. hitps://doi.org/10.1111/iju. 12954

136. Rovner ES, Goudelocke CM. Urodynamics in the evaluation of overactive bladder. Curr Urol Rep 2010;11:343-7. https://doi.org/10.1007/s1 1934-010-0130-8

137. de Boer TA, Salvatore S, Cardozo L, et al. Pelvic organ prolapse and overactive bladder. Neurourol Urodyn 2010;29:30-9. https://doi.org/10.1002/nau.20858

138. Winters JC, Dmochowski RR, Goldman HB, et al. Urodynamic studies in adults: AUA/SUFU guideline. J Urol 2012;188(6 Suppl):2464-72. https://doi.org/10.1016/i.juro.2012.09.081

139. Rovner E, Kennelly M, Schulte-Baukloh H, et al. Urodynamic results and clinical outcomes with intravesical botulinum toxin a (onabotuliumtoxina) in a randomized, placebo-controlled, dose-finding study in idiopathic overactive bladder. J Urol 2010;183:e591-2. https://doi.org/10.1016/i.juro.2010.02.1284

140. Anding R, Rosier P, Smith P, et al. When should video be added to conventional urodynamics in adults and is it justified by the evidence? ICI-RS 2014. Neurourol Urodyn 2016;35:324-9. https://doi.org/10.1002/nau.22865
141. Borello-France D, Burgio KL, Goode PS, et al. Urinary incontinence treatment: Adherence to behavioural interventions for urge incontinence when combined with drug therapy: Adherence rates, barriers, and predictors. Physical Therapy 2010;90:1493-1505. https://doi.org/10.2522/pti.20080387

142. Gormley EA, Lightner DJ, Burgio KL, et al. Diagnosis and treatment of overactive bladder (non-neurogenic) in adults: AUA/SUFU guideline 2014. Available at: htrps://www.auanet.org/common/pdf/education/ clinical-guidance/Overactive-Bladder.pdf. Accessed March 23, 2017

143. Fantl JA, Wyman JF, McClish DK et al. Efficacy of bladder training in older women with urinary incontinence. JAMA 1991;265:609-13. https://doi.org/10.1001/jama.1991.03460050063021

144. Jarvis $\mathrm{GJ}$. A controlled trial of bladder drill and drug therapy in the management of detrusor instability. BJU 1981;53:565-6. https://doi.org/10.1111/i.1464-410X.1981.tb03261.x

145. Burgio KL, Locher JL, Goode PS, et al. Behavioural vs. drug treatment for urge urinary incontinence in older women: A randomized, controlled trial. JAMA 1998;280:1995-2000. https://doi.org/10.1001/ jama.280.23.1995

146. Burgio KL, Goode PS, Johnson TM 2nd, et al. Behavioural vs. drug treatment for overactive bladder in men: The male overactive bladder treatment in veterans (MOTIVE) trial. J Am Geriatr Soc 2011;59:2209-16. https://doi.org/10.1111/i.1532-5415.2011.03724.x

147. Goode PS, Burgio KL, Locher JL et al. Urodynamic changes associated with behavioural and drug treatment of urge incontinence in older women. J Am Geriatr Soc 2002;50:808-16. https://doi.org/10.1046/ j.1532-5415.2002.50204.x

148. Kaya S, Akbayrak T, Beksac S. Comparison of different treatment protocols in the treatment of idiopathic detrusor overactivity: A randomized, controlled trial. Clin Rehabil 2011;25:327- 38. https://doi.org/10.1177/0269215510385481

149. Wyman JF, Fantl JA, McClish DK, et al. Comparative efficacy of behavioural interventions in the management of female urinary incontinence. Continence Program for Women Research Group. Am I Obstet Gynecol 1998;179:999-1007. https://doi.org/10.1016/S0002-9378(98)70206-6

150. Arruda RM, Castro RA, Sousa GC, et al. Prospective randomized comparison of oxybutynin, functional electrostimulation, and pelvic floor training for treatment of detrusor overactivity in women. Int Urogynecol J Pelvic Floor Dysfunct 2008;19:1055-61. https://doi.org/10.1007/s00192-008-0586-y

151. Colombo M, Zanetta $G$, Scalambrino $S$, et al. Oxybutynin and bladder training in the management of female urge urinary incontinence: a randomized study. Int Urogynecol J 1995;6:63-7. https://doi. org/10.1007/BF01962573

152. Song C, Park JT, Heo KO, et al. Effects of bladder training and/or tolterodine in female patients with overactive bladder syndrome: A prospective, randomized study. J Korean Med Sci 2006;21:1060-3. https://doi.org/10.3346/ikms.2006.21.6.1060

153. Kafri $R$, Langer $R$, Dvir $Z$, et al. Rehabilitation vs. drug therapy for urge urinary incontinence: Shortterm outcome Int. Urogynecol J Pelvic Floor Dysfunct 2007;18:407-11. https://doi.org/10.1007/ s00192-006-0163-1

154. Flanagan L, Roe B, Jack B, et al. Systematic review of care intervention studies for the management of incontinence and promotion of continence in older people in care homes with urinary incontinence as the primary focus (1966-2010). Geriatr Gerontol Int 2012;12:600-11. https://doi.org/10.1111/i.14470594.2012.00875.x

155. Subak LL, Wing R, West DS, et al. Weight loss to treat urinary incontinence in overweight and obese women. N Engl J Med 2009;360:481-90. htrps://doi.org/10.1056/NEJMoa0806375

156. Hashim H, Abrams P. How should patients with an overactive bladder manipulate their fluid intake? BJU Int 2008;102:62-6. https://doi.org/10.1111/i.1464-410X.2008.07463.x

157. Bryant CM, Dowell CJ, Fairbrother G. Caffeine reduction education to improve urinary symptoms. $B r J$ Nurs 2002;11:560-5. https://doi.org/10.12968/bjon.2002.11.8.10165

158. Gleason JL, Richter HE, Redden DT, et al. Caffeine and urinary incontinence in US women. Int Urogynecol J 2013;24:295-302. https://doi.org/10.1007/s00192-012-1829-5

159. Sarma AV, Kanaya A, Nyberg $L M$, et al. Risk factors for urinary incontinence among women with type 1 diabetes: Findings from the epidemiology of diabetes interventions and complications study. Urology 2009;73:1203-9. https://doi.org/10.1016/j.urology.2008.11.009

160. Lucas MG, Bedretdinova D, Bosch JLHR, et al. EUA Guidelines on Urinary Incontinence, 2014.Avaialble at: http://Uroweb.org/wp-content/uploads/20-Urinary-Incontinence_LR.pdf; Accessed April 7, 2017.

161. Chiu AF, Liao CH, Wang CC, et al. High classification of chronic heart failure increases risk of overactive bladder syndrome and lower urinary tract symptoms. Urology 2012;79:260-5. https://doi.org/10.1016/i. urology.2011.10.020

162. Tuncer $\mathrm{M}$, Yazici 0 , Kafkasli A, et al. Critical evaluation of the overactive bladder and urgency urinary incontinence association with obstructive sleep apnea syndrome in a relatively young adult male population. Neurourol Urodyn 2016 Dec 6 [Epub ahead of print]. https://doi.org/10.1002/nau.23184

163. Miyazato $M$, Tohyama $K$, Touyama $M$, et al. Effect of continuous positive airway pressure on nocturnal urine production in patients with obstructive sleep apnea syndrome. Neurourol Urodyn 2017;36:376-9. https://doi.org/10.1002/nau.22936 
164. Miyauchi Y, Okazoe H, Okujyo M, et al. Effect of the continuous positive airway pressure on the nocturnal urine volume or night-time frequency in patients with obstructive sleep apnea syndrome. Urology 2015;85:333-6. https://doi.org/10.1016/i.urology.2014.11.002

165. Spence-Jones C, Kamm MA, Henry MM, et al. Bowel dysfunction: A pathogenic factor in uterovaginal prolapse and urinary stress incontinence. Br J Obstet Gynaecol 1994;101:147-52. https://doi.org/10.1111/j.1471-0528.1994.tb13081.x

166. Coyne KS, Cash B, Kopp Z, et al. The prevalence of chronic constipation and fecal incontinence among men and women with symptoms of overactive bladder. BJU Int 2011;107:254-61. https://doi. org/10.1111/.1.1464-410X.2010.09446.x

167. Alling Moller L, Lose G, Jorgensen T. Risk factors for lower urinary tract symptoms in women 40-60 years of age. Obstet Gynecol 2000;96:446-51. https://doi.org/10.1016/S0029-7844(00)00915-7

168. Byles J, Millar CJ, Sibbritt DW, et al. Living with urinary incontinence: A longitudinal study of older women. Age Ageing 2009:38:333-8. https://doi.org/10.1093/ageing/afp013

169. Charach G, Greenstein A, Rabinovich P, et al. Alleviating constipation in the elderly improves lower urinary tract symptoms. Gerontology 2001;47:72-6. https://doi.org/10.1159/000052776

170. Burkhard FC, Lucas MG, Berghmans LC, et al. Urinary Incontinence in Adults. EAU Guidelines 2016. Available at: http://uroweb.org/guideline/urinary-incontinence/. Accessed April 17, 2017.

171. Newman DK, Giovannini D. The overactive bladder: A nursing perspective. Am J Nurs 2002;102:36-46 https://doi.org/10.1097/00000446-200206000-00042

172. Kobelt G, Kirchberger I, Malone-Lee J. Quality-of-life aspects of the overactive bladder and the eVect of treatment with tolterodine. BJU Int 1999;83:583-90. https://doi.org/10.1046/i.1464410x.1999.00004.x

173. Kobelt-Nguyen $G$, Johanesson M, Mattiasson A. Correlations between symptoms of urge incontinence and scores of a generic quality of life instrument (SF36) and health status measurements (EuroQoL) and between changes in symptoms and QoL scores. In Abstract: 27th Annual Meeting of international Continence Society 1997 Sep 23.

174. Milne JL. Behavioural therapies for overactive bladder: Making sense of the evidence. J Wound Ostomy Continence Nurs 2008:35:93-101. https://doi.org/10.1097/01.WON.0000308624.68582.19

175. Schabert VF, Bavendam T, Goldberg EL, et al. Challenges for managing overactive bladder and guidance for patient support. Am J Manag Care 2009;15:S118-22.

176. Wyman JF, Burgio KL, Newman DK. Practical aspects of lifestyle modifications and behavioural interventions in the treatment of overactive bladder and urgency urinary incontinence. Int J Clin Pract 2009;63:1177-91. https://doi.org/10.1111/i.1742-1241.2009.02078.x

177. NICE: Urinary Incontinence: The management of Urinary Incontinence in Women. October 2006. Available at: https://www.nice.org.uk/guidance/cg171. Accessed April 7, 2017.

178. Dallosso HM, McGrother CW, Matthews RJ, et al. The association of diet and other lifestyle factors with overactive bladder and stress incontinence: a longitudinal study in women. BJU Int 2003;92:69-77. hitps://doi.org/10.1046/i.1464-410X.2003.04271.x

179. Muscatello DJ, Rissel C, Szonyi G. Urinary symptoms and incontinence in an urban community: Prevalence and associated factors in older men and women. Intern Med J 2001;31:151-60. https://doi.org/10.1046/i.1445-5994.2001.00035.x

180. Bump RC, Sugerman HJ, Fantl JA, et al. Obesity and lower urinary tract function in women: Effect of surgically induced weight loss. Am J Obstet Gynecol 1992;167:392-9. https://doi.org/10.1016/ S0002-9378(11)91418-5

181. Subak LL, Whitcomb E, Shen HU, et al. Weight loss: A novel and effective treatment for urinary incontinence. J Urol 2005;174:190-5. hitps://doi.org/10.1097/01.ju.0000162056.30326.83

182. Auwad W, Steggles P, Bombieri L, et al. Moderate weight loss in obese women with urinary incontinence: A prospective longitudinal study. Int Urogynecol J Pelvic Floor Dysfunct 2008;19:1251-9. hitps://doi.org/10.1007/s00192-008-0616-9

183. Newman DK. Lifestyle interventions. Pelvic floor disorders. Philadelphia: Elsevier Saunders. 2004:269-76.

184. Swithinbank L, Hashim H, Abrams P. The effect of fluid intake on urinary symptoms in women. J Urol 2005;174:187-9. https://doi.org/10.1097/01.ju.0000162020.10447.31

185. Coyne KS, Sexton CC, Irwin DE, et al. The impact of overactive bladder, incontinence, and other lower urinary tract symptoms on quality of life, work productivity, sexuality, and emotional well-being in men and women: Results from the EPIC study. BJU Int 2008;101:1388-95. https://doi.org/10.1111/j.1464410X.2008.07601.X

186. Snooks SJ, Barnes PR, Swash M, et al. Damage to the innervation of the pelvic floor musculature in chronic constipation. Gastroenterology 1985;89:977-81. https://doi.org/10.1016/0016-5085(85)90196-9

187. Hannestad YS, Rortveit G, Daltveit AK, et al. Are smoking and other lifestyle factors associated with female urinary incontinence? The Norwegian EPINCONT Study. Int I Obstet Gynaecol 2003;1 10:247-54. hitps://doi.org/10.1046/i.1471-0528.2003.02327.x

188. Jorgensen S, Hein HO, Gyntelberg F. Heavy liffing at work and risk of genital prolapse and herniated lumbar disc in assistant nurses. Occup Med 1994;44:47-9. https://doi.org/10.1093/occmed/44.1.47
189. Nygaard I, DeLancey Jo, Arnsdorf L, et al. Exercise and incontinence. Obstet Gynecol1990;75:848-51. https://doi.org/10.1016/0020-7292(90)90554-x

190. Nygaard IE, Thompson FL, Svengalis SL, et al. Urinary incontinence in elite nulliparous athletes. Obstet Gynecol 1994;84:183-7.

191. Eliasson K, Nordlander I, Larson B, et al. Influence of physical activity on urinary leakage in primiparous women. Scand J Med Sci Sports 2005;15:87-94. https://doi.org/10.1111/i.1600-0838.2004.407.x

192. Kikuchi A, Niu K, lkeda Y, et al. Association between physical activity and urinary incontinence in a community-based elderly population aged 70 years and over. Eur Urol 2007;52:868-75. https://doi. org/10.1016/i.eururo.2007.03.041

193. Bump RC, McClish DK. Cigarette smoking and urinary incontinence in women. Am J Obstet Gynecol 1992;167:1213-8. https://doi.org/10.1016/S0002-9378(11)91691-3

194. Imamura M, Abrams P, Bain C, et al. Systematic review and economic modelling of the effectiveness and cost-effectiveness of non-surgical treatments for women with stress urinary incontinence. Health Technol Assess 2010;14:1-188. https://doi.org/10.3310/hta14400

195. Health Canada, Healthy Canadians, Benefits of quitting smoking. Available at: http://www.healthycanadians.gc.ca/healthy-living-vie-saine/tobacco-tabac/quit-cesser/quit-now-cesser-maintenant/benefitsavantages-eng.php. Accessed March 23, 2017.

196. Eustice S, Roe B, Paterson J. Prompted voiding for the management of urinary incontinence in adults. The Cochrane Library 2000: CD002113. https://doi.org/10.1002/14651858.cd002113

197. Ostaszkiewicz J, Johnston L, Roe B. Habit retraining for the management of urinary incontinence in adults. The Cochrane Library 2004:CD002801. htrps://doi.org/10.1002/14651858.cd002801.pub2

198. Wyman JF, Fantl JA. Bladder training in ambulatory care management of urinary incontinence. Urol Nurs 1991;11:11-7.

199. Shafik A, Shafik IA. Overactive bladder inhibition in response to pelvic floor muscle exercises. World I Urol 2003;20:374-7.

200. Shamliyan T, Wyman J, Kane RL. Nonsurgical treatments for urinary incontinence in adult women: Diagnosis and comparative effectiveness. Rockville (MD): Agency for Healthcare Research and Quality (US); 2012 Apr.

201. Berghmans B, van Doorn EV, Nieman F, et al. Efficacy of physical therapeutic modalities in women with proven bladder overactivity. Eur Urol 2002;41:581-7. https://doi.org/10.1016/S03022838(02)00178-1

202. Burgio KL, Goode PS, Locher JL, et al. Behavioural training with and without biofeedback in the treatment of urge incontinence in older women: A randomized, controlled trial. JAMA 2002;288:2293-9. hitps://doi.org/10.1001/jama.288.18.2293

203. Hines SH, Seng IS, Messer KL, et al. Adherence to a behavioural program to prevent incontinence. West J Nurs Res 2007;29:36-56. https://doi.org/10.1177/0193945906293793

204. Hay-Smith EJ, Herderschee R, Dumoulin C, et al. Comparisons of approaches to pelvic floor muscle training for urinary incontinence in women. The Cochrane Library 2011; Dec 7:CD009508. https://doi.org/10.1002/14651858.cd009508

205. Madhuvrata $P$, Cody JD, Ellis $G$, et al. Which anticholinergic drug for overactive bladder symptoms in adults. Cochrane Database Syst Rev 2012;1:CD005429. https://doi.org/10.1002/14651858. cd005429.pub2

206. Khullar V, Chapple C, Gabriel Z, et al. The effects of antimuscarinics on health-related quality of life in overactive bladder: A systematic review and meta-analysis. Urology 2006; 68:38-48. https://doi.org/10.1016/i.urology.2006.05.043

207. Chapple CR, Khullar V, Gabriel Z, et al. The effects of antimuscarinic treatments in overactive bladder: An update of a systematic review and meta-analysis. Eur Urol 2008:54: 543-62. https://doi.org/10.1016/i.eururo.2008.06.047

208. Visco AG, Fraser MO, Newgreen D, et al. What is the role of combination drug therapy in the treatment of overactive bladder? ICI-RS 2014. Neurourol Urodyn 2016;35:288-92. https://doi.org/10.1002/ nau.22795

209. Buser N, Ivic S, Kessler TM, et al. Efficacy and adverse events of antimuscarinics for treating overactive bladder: Network meta-analyses. Eur Urol 2012;62:1040-60. https://doi.org/10.1016/i. eururo.2012.08.060

210. Kessler $T M$, Bachmann $L M$, Minder $C$, et al. Adverse event assessment of antimuscarinics for treating overactive bladder: A network meta-analytic approach. PLoS One 2011;6: e16718. https://doi.org/10.1371/journal.pone.0016718

211. Kosilov KV, Loparev S, Kuzina I, et al. Treatment compliance of working persons to highdose antimuscarinic therapies: A randomized trial. Ther Adv Urol 2016;8: 239-48. https://doi.org/10.1177/1756287216652030

212. $\mathrm{Ng} \mathrm{DB}$, McCart $M$, Klein $C$, et al. Evaluating outcomes in patients with overactive bladder within an integrated healthcare delivery system using a treatment patterns analyzer. Am Health Drug Benefits 2016;9:343-53 
Corcos et al.

213. Wagg A, Compion G, Fahey A, et al. Persistence with prescribed antimuscarinic therapy for overactive bladder: A UK experience. BJU Int 2012;110: 1767-74. https://doi.org/10.1111/i.1464410X.2012.11023.x

214. Tripathi RC, Tripathi BJ, Haggerty C. Drug-induced glaucomas. Drug Safety 2003;26:749-67 https://doi.org/10.2165/00002018-200326110-00002

215. Gray SL, Anderson ML, Dublin S, et al. Cumulative use of strong anticholinergic medications and incident dementia. JAMA Intern Med 2015;175:401-7. https://doi.org/10.1001/iamainternmed.2014.7663

216. Myint PK, Fox C, Kwok CS, et al. Total anticholinergic burden and risk of mortality and cardiovascular disease over 10 years in 21636 middle-aged and older men and women of EPIC-Norfolk prospective population study. Age Ageing 2015;44:219-25. https://doi.org/10.1093/ageing/afu185

217. Cui Y, Zong H, Yang C, et al. The efficacy and safety of mirabegron in treating OAB: A systematic review and meta-analysis of phase 3 trials. Int Urol Nephrol 2014;46:275-84. https://doi.org/10.1007/ s1 1255-013-0509-9

218. Khullar V, Amarenco G, Angulo JC, et al. Efficacy and tolerability of mirabegron, a $\beta 3$-adrenoceptor agonist, in patients with overactive bladder: Results from a randomized European-Australian phase 3 trial. Eur Urol 2013;63: 283-95. htrps://doi.org/10.1016/i.eururo.2012.10.016

219. Nitti VW, Auerbach S, Martin N, et al. Results of a randomized, phase 3 trial of mirabegron in patients with overactive bladder. J Urol 2013;189:1388-95. https://doi.org/10.1016/i.juro.2012.10.017

220. Herschorn S, Barkin J, Castro-Diaz D, et al. A phase 3, randomized, double-blind, parallel-group, placebocontrolled, multicentre study to assess the efficacy and safety of the $\beta 3$ adrenoceptor agonist, mirabegron, in patients with symptoms of overactive bladder. Urology 2013;82:313-20. https://doi.org/10.1016/i urology.2013.02.077

221. Clinical study report: Phase 3 study of YM178: A double-blind group comparison study in patients with overactive bladder (protocol no. 178-CL-048) [CONFIDENTIAL internal manufacturer's report]. Tokyo: Astellas Pharma Inc, 2010.

222. Nitti VW, Khullar V, van Kerrebroeck $P$, et al. Mirabegron for the treatment of overactive bladder: A prespecified pooled efficacy analysis and pooled safety analysis of three randomized, double-blind, placebocontrolled, phase 3 studies. Int I Clin Pract 2013;67:619-32. https://doi.org/10.1111/iicp.12194

223. Mirabegron for treating symptoms of overactive bladder. 2013, National Institute for Health and Care Excellence: London, UK.

224. Castro-Diaz D, Chapple CR, Hakimi Z, et al. The effect of mirabegron on patient-related outcomes in patients with overactive bladder: The results of post hoc correlation and responder analyses using pooled date from three randomized, phase 3 trials. Qual Life Res 2015;24:1719-27. https://doi.org/10.1007/ s11136-014-0904-4

225. Khullar V, Cambronero J, Angulo JC, et al. Efficacy of mirabegron in patients with and without prior antimuscarinic therapy for overactive bladder: A post-hoc analysis of a randomized European-Australian phase 3 trial. BMC Urol 2013;13:45. htrps://doi.org/10.1186/1471-2490-13-45

226. Yamaguchi 0, Marui E, Kakizaki H, et al. Phase 3, randomized, double-blind, placebo-controlled study of the $\beta 3$-adrenoceptor agonist mirabegron, $50 \mathrm{mg}$ once daily, in Japanese patients with overactive bladder. BJU Int 2014;113:951-60. https://doi.org/10.1111/bju.12649

227. Chapple CR, Kaplan SA, Mitcheson D, et al. Randomized, double-blind, active-controlled, phase 3 study to assess 12-month safety and efficacy of mirabegron, a $\beta 3$-adrenoceptor agonist, in overactive bladder. Eur Urol 2013;63:296-305. https://doi.org/10.1016/j.eururo.2012.10.048

228. Abrams P, Kelleher C, Staskin D, et al. Combination treatment with mirabegron and solifenacin in patients with overactive bladder: Exploratory responder analyses of efficacy and evaluation of patient-reported outcomes from a randomized, double-blind, factorial, dose-ranging, phase 2 study (SYMPHONY). World $J$ Urol 2016 [Epub ahead of print]. https://doi.org/10.1007/s00345-016-1908-1

229. Drake MJ, Chapple C, Esen AA, et al. Efficacy and safety of mirabegron add-on therapy to solifenacin in incontinent overactive bladder patients with an inadequate response to initial four-week solifenacin monotherapy: A randomized, double-blind, multicentre, phase 3B study (BESIDE). Eur Urol 2016;70:13645. https://doi.org/10.1016/i.eururo.2016.02.030

230. Nitti VW, Chapple CR, Walters C, et al. Safety and tolerability of the $\beta 3$-adrenoceptor agonist mirabegron, for the treatment of overactive bladder: Results of a prospective pooled analysis of three 12-week, randomized, phase 3 trials and of a one-year, randomized phase 3 trial. Int I of Clin Pract 2014;68:972-85. https://doi.org/10.1111/iicp.12433

231. Wagg A, Franks B, Ramos B, et al. Persistence and adherence with the new beta-3 receptor agonist, mirabegron, vs. antimuscarinics in overactive bladder: Early experience in Canada. Can Urol Assoc J 2015; 9:343-50. https://doi.org/10.5489/cuaj.3098

232. Kinjo M, Sekiguchi Y, Yoshimura Y, et al. Long-term persistence with mirabegron vs. solifenacin in women with overactive bladder: Prospective, randomized trial. Low Urin Tract Symptoms 2016 [Epub ahead of print]. https://doi.org/10.1111/luts.12151

233. Maman K, Aballea S, Nazir J, et al. Comparative efficacy and safety of medical treatments for the management of overactive bladder: A systematic literature review and mixed treatment comparison. Eu Urol 2014;65:755-65. https://doi.org/10.1016/i.eururo.2013.11.010
234. Rochon PA, Anderson GM, Tu JV, et al. Age- and gender-related use of low-dose drug therapy: The need to manufacture low-dose therapy and evaluate the minimum effective dose. J Am Geriatr Soc 1999;47:954-9. https://doi.org/10.1111/.i.1532-5415.1999.tb01290.x

235. Bemelmans BL, Kiemeney LA, Debruyne FM. Low-dose oxybutynin for the treatment of urge incontinence: Good efficacy and few side effects. Eur Urol 2000;37:709-13. htrps://doi.org/10.1159/000020222

236. Malone-Lee J, Lubel D, Szonyi G. Low dose oxybutynin for the unstable bladder. BMJ 1992;304:1053. htrps://doi.org/10.1136/bmi.304.6833.1053

237. Kosilov KV, Loparev SA, Ivanovskaya MA, et al. Comparative effectiveness of combined low- and standarddose trospium and solifenacin for moderate overactive bladder symptoms in elderly men and women. Urol Int 2014;93:470-3. https://doi.org/10.1159/000363658

238. Qato DM, Wilder J, Schumm LP, et al. Changes in prescription and over-the-counter medication and dietary supplement use among older adults in the U.S., 2005 vs. 2011. JAMA Intern Med 2016;176:473-82. https://doi.org/10.1001/jamainternmed.2015.8581

239. Cresswell KM, Fernando B, McKinstry B, et al. Adverse drug events in the elderly. Br Med Bull 2007;83:259-74. https://doi.org/10.1093/bmb/ldm016

240. Hofer-Dueckelmann C, Prinz E, Beindl W, et al. Adverse drug reactions (ADRs) associated with hospital admissions — elderly female patients are at highest risk. Int I Clin Pharmacol Ther 2011;49:577-86. https://doi.org/10.5414/CP201514

241. Rodenburg EM, Stricker BH, Visser LE. Sex differences in cardiovascular drug induced adverse reactions causing hospital admissions. Br J Clin Pharmacol 2012;74:1045-52. https://doi.org/10.1111/i.13652125.2012.04310.x

242. Feinberg M. The problems of anticholinergic adverse effects in older patients. Drugs Aging 1993;3:335-48. https://doi.org/10.2165/00002512-199303040-00004

243. Hopcraft MS, Tan C. Xerostomia: An update for clinicians. Aust Dent J 2010;55:238-44; quiz 353. https://doi.org/10.1111/i.1834-7819.2010.01229.x

244. Herschorn S, Pommerville P, Stothers L, et al. Tolerability of solifenacin and oxybutynin immediate release in older ( $>65$ years) and younger ( $\leq 65$ years) patients with overactive bladder: Sub-analysis from a Canadian, randomized, double-blind study. Curr Med Res Opin 2011;27:375-82. https://doi.org/10. $1185 / 03007995.2010 .541433$

245. Kraus SR, Ruiz-Cerda JL, Martire D, et al. Efficacy and tolerability of fesoterodine in older and younger subjects with overactive bladder. Urology 2010;76:1350-7. https://doi.org/10.1016/i.urology.2010.03.097

246. Wagg A, Khullar V, Marschall-Kehrel D, et al. Flexible-dose fesoterodine in elderly adults with overactive bladder: Results of the randomized, double-blind, placebo-controlled study of fesoterodine in an aging population trial. J Am Geriatr Soc 2013;61:185-93. https://doi.org/10.1111/igs.12088

247. Chapple CR, Nilvebrant L. Tolterodine: selectivity for the urinary bladder over the eye (as measured by visual accommodation) in healthy volunteers. Drugs R D 2002;3:75-81. htrps://doi.org/10.2165/00126839200203020-00001

248. Altan-Yaycioglu R, Yaycioglu 0, Aydin Akova Y, et al. Ocular side-effects of tolterodine and oxybutynin, a single-blind, prospective, randomized trial. Br J Clin Pharmacol 2005;59:588-92. htrps://doi.org/10.1111/i.1365-2125.2005.02356.x

249. Fox C, Richardson K, Maidment ID, et al. Anticholinergic medication use and cognitive impairment in the older population: The medical research council cognitive function and ageing study. J Am Geriatr Soc 2011;59:1477-83. https://doi.org/10.1111/i.1532-5415.2011.03491.x

250. Carriere I, Fourrier-Reglat A, Dartigues JF, et al. Drugs with anticholinergic properties, cognitive decline, and dementia in an elderly general population: The three-city study. Arch Intern Med 2009;169:1317-24. https://doi.org/10.1001/archinternmed.2009.229

251. Sumukadas D, McMurdo ME, Mangoni AA, et al. Temporal trends in anticholinergic medication prescription in older people: Repeated cross-sectional analysis of population prescribing data. Age Ageing 2014;43:51521. https://doi.org/10.1093/ageing/aft199

252. Kay GG, Abou-Donia MB, Messer WS Jr, et al. Antimuscarinic drugs for overactive bladder and their potential effects on cognitive function in older patients. J Am Geriatr Soc 2005;53:2195-2201. https://doi.org/10.1111/i.1532-5415.2005.00537.x

253. Wagg A. The cognitive burden of anticholinergics in the elderly — implications for the treatment of overactive bladder. Eur Urol Rev 2012;7:42-9.

254. Fox C, Livingston G, Maidment ID, et al. The impact of anticholinergic burden in Alzheimer's dementia-the LASER-AD study. Age and Ageing 2011;40:730-5. https://doi.org/10.1093/ageing/afr102

255. Laroche ML, Charmes JP, Nouaille Y, et al. Is inappropriate medication use a major cause of adverse drug reactions in the elderly? Br J Clin Pharmacol 2007;63:177-86. https://doi.org/10.1111/j.13652125.2006.02831.x

256. Colucci VJ, Rivey MP. Tolterodine-warfarin drug interaction. Ann Pharmacother 1999:33:1173-6. https://doi.org/10.1345/aph.19025

257. Hashimoto M, Imamura T, Tanimukai S, et al. Urinary incontinence: An unrecognized adverse effect with donepezil. Lancet 2000;356:568. https://doi.org/10.1016/S0140-6736(00)02588-5 
258. Starr JM. Cholinesterase inhibitor treatment and urinary incontinence in Alzheimer's disease. J Am Geriatr Soc 2007;55:800-1. https://doi.org/10.1111/i.1532-5415.2007.01143.x

259. Kroger E, Van Marum R, Souverein P, et al. Treatment with rivastigmine or galantamine and risk of urinary incontinence: Results from a Dutch database study. Pharmacoepidemiol Drug Saf 2015;24:276-85. https://doi.org/10.1002/pds.3741

260. Sink KM, Thomas J 3rd, Xu H, et al. Dual use of bladder anticholinergics and cholinesterase inhibitors: Long-term functional and cognitive outcomes. J Am Geriatr Soc 2008;56:847-53. https://doi.org/10.1111/i.1532-5415.2008.01681.x

261. Isik AT, Celik T, Bozoglu E, et al. Trospium and cognition in patients with late onset Alzheimer disease. J Nutr Health Aging 2009;13:672-6. https://doi.org/10.1007/s12603-009-0196-5

262. Sakakibara R, Ogata T, Uchiyama T, et al. How to manage overactive bladder in elderly individuals with dementia? A combined use of donepezil, a central acetylcholinesterase inhibitor, and propiverine, a peripheral muscarine receptor antagonist. J Am Geriatr Soc 2009;57:1515-7. https://doi.org/10.1111/ j.1532-5415.2009.02369.x

263. Panel. AGSBCUE. American Geriatrics Society 2015 updated Beers criteria for potentially inappropriate medication use in older adults. J Am Geriatr Soc 2015;63:2227-46. https://doi.org/10.1111/igs.13702

264. Oelke M, Becher K, Castro-Diaz D, et al. Appropriateness of oral drugs for long-term treatment of lower urinary tract symptoms in older persons: Results of a systematic literature review and international consensus validation process (LUTS-FORTA 2014). Age Ageing 2015;44:745-55. https://doi.org/10.1093/ ageing/afv077

265. Lee PG, Cigolle C, Blaum C. The co-occurrence of chronic diseases and geriatric syndromes: The health and retirement study. J Am Geriatr Soc 2009;57:511-6. https://doi.org/10.1111/i.15325415.2008.02150.x

266. Resnick NM, Yalla SV, Laurino E. The pathophysiology of urinary incontinence among institutionalized elderly persons. N Engl J Med 1989;320:1-7. https://doi.org/10.1056/NEJM198901053200101

267. Johnson TM 2nd, Kincade JE, Bernard SL, et al. Self-care practices used by older men and women to manage urinary incontinence: Results from the national follow-up survey on self-care and aging. J Am Geriatr Soc 2000;48:894-902. https://doi.org/10.1111/i.1532-5415.2000.tb06885.x

268. Teunissen TA, Lagro-Janssen AL. Sex differences in the use of absorbent (incontinence) pads in independently living elderly people: Do men receive less care? Int I Clin Pract 2009;63:869-73. https://doi.org/10.1111/i.1742-1241.2008.01975.x

269. Rogers MA, Mody L, Kaufman SR, et al. Use of urinary collection devices in skilled nursing facilities in five states. J Am Geriatr Soc 2008;56:854-61. https://doi.org/10.1111/j.1532-5415.2008.01675.x

270. Gage $\mathrm{H}$, Avery M, Flannery C, et al. Community prevalence of long-term urinary catheters use in England. Neurourol Urodyn 2017;36:293-6. https://doi.org/10.1002/nau.22961

271. Wullnera U, Schmitz-Hubscha T, Antonyb G, et al. Autonomic dysfunction in 3414 Parkinson's disease patients enrolled in the German Network on Parkinson's disease (KNP e.V.): The effect of ageing. Eur $J$ Neurol 2007;14:1405-8. https://doi.org/10.1111/j.1468-1331.2007.01982.x

272. Szonyi G, Collas DM, Ding YY, et al. Oxybutynin with bladder retraining for detrusor instability in elderly people: A randomized, controlled trial. Age Ageing 1995;24:287-91. https://doi.org/10.1093/ageing/24.4.287

273. Kay GG, Staskin DR, Macdiarmid S, et al. Cognitive effects of oxybutynin chloride topical gel in older healthy subjects: A one-week, randomized, double-blind, placebo- and active-controlled study. Clin Drug Invest 2012;32:707-14. https://doi.org/10.1007/BF03261924

274. Kay G, Kardiasmenos K, Crook T. Differential effects of the antimuscarinic agents tolterodine tartrate ER and oxybutynin chloride ER on recent memory in older subjects. Proceedings of the 36th meeting of the International Continence Society. 2006;25:P087.

275. Kay GG, Ebinger U. Preserving cognitive function for patients with overactive bladder: Evidence for a differential effect with darifenacin. Int J Clin Pract 2008;62:1792-1800. https://doi.org/10.1111/j.17421241.2008.01849.x

276. Staskin D, Kay G, Tannenbaum C, et al. Trospium chloride has no effect on memory testing and is assay undetectable in the central nervous system of older patients with overactive bladder. Int I Clin Pract 2010;64:1294-1300. https://doi.org/10.1111/i.1742-1241.2010.02433.x

277. Wagg A, Dale M, Tretter R, et al. Randomized, multicentre, placebo-controlled, double-blind crossover study investigating the effect of solifenacin and oxybutynin in elderly people with mild cognitive impairment: The SENIOR study. Eur Urol 2013;64:74-81. https://doi.org/10.1016/i.eururo.2013.01.002

278. Kay GG, Maruff P, Scholfield D, et al. Evaluation of cognitive function in healthy older subjects treated with fesoterodine. Postgrad Med 2012;124:7-15. https://doi.org/10.3810/pgm.2012.05.2543

279. Dorschner W, Stolzenburg JU, Griebenow R, et al. Efficacy and cardiac safety of propiverine in elderly patients — a double-blind, placebo-controlled clinical study. Eur Urol 2000;37:702-8. https://doi.org/10.1159/000020221

280. Nitti VW, Dmochowski R, Herschorn S, et al. OnabotulinumtoxinA for the treatment of patients with overactive bladder and urinary incontinence: Results of a phase 3 , randomized, placebo-controlled trial. J Urol 2013;189:2186-93. https://doi.org/10.1016/i.uro.2012.12.022
281. Chapple C, Sievert K-D, MacDiarmid S, et al. OnabotulinumtoxinA $100 \mathrm{U}$ significantly improves all idiopathic overactive bladder symptoms and quality of life in patients with overactive bladder and urinary incontinence: A randomized, double-blind, placebo-controlled trial. Eur Urol 2013;64:249-56. https://doi.org/10.1016/i.eururo.2013.04.001

282. Liao $\mathrm{CH}$, Kuo $\mathrm{HC}$. Increased risk of large post-void residual urine and decreased long-term success rate after intravesical onabotulinumtoxinA injection for refractory idiopathic detrusor overactivity. I Urol 2013;189:1804-10. https://doi.org/10.1016/i.juro.2012.11.089

283. Wang $\mathrm{CC}$, Liao $\mathrm{CH}$, Kuo HC. Diabetes mellitus does not affect the efficacy and safety of intravesical onabotulinumtoxinA injection in patients with refractory detrusor overactivity. Neurourol Urodyn 2014;33:1235-9. https://doi.org/10.1002/nau.22494

284. Nitti VW, Sievert K-D, Sussman D, et al. Voiding dysfunction durable efficacy and safety of long-term onabotulinumtoxinA treatment in patients with overactive bladder syndrome: Final results of a 3.5-year study. J Urol 2016;196:791-800. https://doi.org/10.1016/i.juro.2016.03.146

285. Biemans JM, van Balken MR. Efficacy and effectiveness of percutaneous tibial nerve stimulation in the treatment of pelvic organ disorders: A systematic review. Neuromodulation 2013;16:25-33. https:// doi.org/10.1111/i.1525-1403.2012.00504.x

286. Burton C, Saija A, Latthe PM. Effectiveness of percutaneous posterior tibial nerve stimulation for overactive bladder: A systematic review and meta-analysis. Neurourol Urodyn 2012; 31:1206-13. https://doi.org/10.1002/nau.22251

287. Gaziev G, Topazio L, lacovelli V, et al. Percutaneous tibial nerve stimulation (PTNS) efficacy in the treatment of lower urinary tract dysfunctions: A systematic review. BMC Urol 2013;13:61. https://doi.org/10.1186/1471-2490-13-61

288. Levin PJ, Wu JM, Kawasaki A, et al. The efficacy of posterior tibial nerve stimulation for the treatment of overactive bladder in women: A systematic review. Int Urogynecol J 2012;11:1591-7. https://doi.org/10.1007/s00192-012-1712-4

289. Peters KM, MacDiarmid SA, Wooldridge LS, et al. Randomized trial of percutaneous tibial nerve stimulation vs. extended-release tolterodine: Results from the overactive bladder innovative therapy trial. J Urol 2009:182:1055-61. https://doi.org/10.1016/i.juro.2009.05.045

290. Sancaktar M, Ceyhan ST, Akyol I, et al. The outcome of adding peripheral neuromodulation (Stoller afferent neuro-stimulation) to antimuscarinic therapy in women with severe overactive bladder. Gynecol Endocrinol 2010;26:729-32. https://doi.org/10.3109/09513591003649815

291. Klingler HC, Pycha A, Schmidbauer J, et al. Use of peripheral neuromodulation of the S3 region for treatment of detrusor overactivity: A urodynamic-based study. Urology 2000;56:766-71. https://doi.org/10.1016/S0090-4295(00)00727-5

292. MacDiarmid SA, Peters KM, Shobeiri SA, et al. Long-term durability of percutaneous tibial nerve stimulation for the treatment of overactive bladder. J Urol 2010;183:234-40. https://doi.org/10.1016/i. juro.2009.08.160

293. Peters KM, Carrico DJ, Perez-Marrero RA, et al. Randomized trial of percutaneous tibial nerve stimulation vs. sham efficacy in the treatment of overactive bladder syndrome: Results from the SUmiT trial. J Urol 2010;183:1438-43. https://doi.org/10.1016/i.juro.2009.12.036

294. van Balken MR, Vandoninck V, Gisolf KW, et al. Posterior tibial nerve stimulation as neuromodulative treatment of lower urinary tract dysfunction. J Urol 2001;166:914-8. https://doi.org/10.1016/ S0022-5347(05)65863-6

295. Vandoninck $V$, van Balken MR, Finazzi Agrò $E$, et al. Percutaneous tibial nerve stimulation in the treatment of overactive bladder: Urodynamic data. Neurourol Urodyn 2003;22:227-32. https://doi.org/10.1002/ nau. 10111

296. Vandoninck V, van Balken MR, Finazzi Agró E, et al. Posterior tibial nerve stimulation in the treatment urge incontinence. Neurourol and Urodyn 2003;22:17-23. https://doi.org/10.1002/nau.10036

297. Wooldridge LS. Percutaneous tibial nerve stimulation for the treatment of urinary frequency, urinary urgency, and urge incontinence: Results from a community-based clinic. Urol Nurs 2009;29:177-85.

298. Yoong W, Ridout AE, Damodaram M, et al. Neuromodulative treatment with percutaneous tibial nerve stimulation for intractable detrusor instability: Outcomes following a shortened six-week protocol. BJU Int 2010;106:1673-6. https://doi.org/10.1111/i.1464-410X.2010.09461.x

299. Finazzi-Agro E, Petta F, Sciobica F, et al. Percutaneous tibial nerve stimulation effects on detrusor overactivity incontinence are not due to a placebo effect: A randomized, double-blind, placebo-controlled trial. J Urol 2010:184:2001-6. https://doi.org/10.1016/i.uro.2010.06.113

300. Souto SC, Reis LO, Palma T, et al. Prospective and randomized comparison of electrical stimulation of the posterior tibial nerve vs. oxybutynin versus their combination for treatment of women with overactive bladder syndrome. World J Urol 2013;32:179-84.

301. Marchal C, Herrera B, Antuna F, et al. Percutaneous tibial nerve stimulation in treatment of overactive bladder: When should retreatment be started? Urology 2011;78:1046-50. htrps://doi.org/10.1016/j. urology.2011.07.1394

302. Sherif $\mathrm{H}$, Abdelwahab 0. Posterior tibial nerve stimulation as treatment for the overactive bladder. Arab J Urol 2013;11:131-5. https://doi.org/10.1016/i.aju.2013.04.007 
Corcos et al.

303. Arrabal-Polo MA, Palao-Yago F, Campon-Pacheco I, et al. Clinical efficacy in the treatment of overactive bladder refractory to anticholinergics by posterior tibial nerve stimulation. Korean I Urol 2012;53:483-6. https://doi.org/10.4111/kju.2012.53.7.483

304. Yoong W, Shah P, Dadswell R, et al. Sustained effectiveness of percutaneous tibial nerve stimulation for overactive bladder syndrome: Two-year followup of positive responders. Int Urogynecol J 2013;24:795-9. https://doi.org/10.1007/s00192-012-1936-3

305. Moossdorff-Steinhauser HF, Berghmans B. Effects of percutaneous tibial nerve stimulation on adult patients with overactive bladder syndrome: A systematic review. Neurourol Urodyn 2013:32:206-14. https://doi.org/10.1002/nau.22296

306. van Kerrebroeck PE, van Voskuilen AC, Heesakkers JP, et al. Results of sacral neuromodulation therapy for urinary voiding dysfunction: Outcomes of a prospective, worldwide clinical study. J Urol 2007;178:202934. https://doi.org/10.1016/i.juro.2007.07.032

307. Lai HH, Grewal S. Bacterial colonization rate of interstim and infection outcome with staged testing. Urology 2013;82:1255-60. https://doi.org/10.1016/i.urology.2013.08.034

308. Aboseif S, Tamaddon K, Chalfin S, et al. Sacral neuromodulation as an effective treatment for refractory pelvic floor dysfunction. Urology 2002;60:52-5. https://doi.org/10.1016/S0090-4295(02)01630-8

309. Groen J, Blok BF, Bosch JL. Sacral neuromodulation as treatment for refractory idiopathic urge urinary incontinence: Five-year results of a longitudinal study in 60 women. J Urol 2011;186:954-9. https://doi.org/10.1016/i.juro.2011.04.059

310. Hassouna MM, Siegel SW, Nyeholt AA, et al. Sacral neuromodulation in the treatment of urgencyfrequency symptoms: A multicentre study on efficacy and safety. J Urol 2000;163:1849-54. https://doi.org/10.1016/S0022-5347(05)67558-1

311. Janknegt RA, Hassouna MM, Siegel SW, et al. Long-term effectiveness of sacral nerve stimulation for refractory urge incontinence. Eur Urol 2001;39:101-6. https://doi.org/10.1159/000052420

312. Kessler $T M$, Buchser $E$, Meyer $S$, et al. Sacral neuromodulation for refractory lower urinary tract dysfunction: Results of a nationwide registry in Switzerland. Eur Urol 2007;51:1357-63. https://doi.org/10.1016/i. eururo.2006.11.011

313. Leong RK, Marcelissen TA, Nieman FH, et al. Satisfaction and patient experience with sacral neuromodulation: Results of a single-centre sample survey. J Urol 2011;185:588-92. https://doi.org/10.1016/i juro.2010.09.090

314. Oerlemans DJ, van Voskuilen AC, Marcelissen T, et al. Is on-demand sacral neuromodulation in patients with OAB syndrome a feasible therapy regime? Neurourol Urodyn 2011;30:1493-6. https://doi.org/10.1002/nau.21070

315. Schmidt RA, Jonas U, Oleson KA, et al. Sacral nerve stimulation for treatment of refractory urinary urge incontinence. Sacral Nerve Stimulation Study Group. J Urol 1999;162:352-7. https://doi.org/10.1016/ S0022-5347(05)68558-8

316. Siegel SW, Catanzaro F, Dijkema HE, et al. Long- term results of a multicentre study on sacral nerve stimulation for treatment of urinary urge incontinence, urgency-frequency, and retention. Urology 2000;56:87-91. https://doi.org/10.1016/S0090-4295(00)00597-5

317. Cameron AP, Anger JT, Madison R, et al. Battery explantation after sacral neuromodulation in the Medicare population. Neurourol Urodyn 2013;32:238-41. ttps://doi.org/10.1002/nau.22294

318. Boyle P, Robertson C, Mazzetta C, et al. The prevalence of male urinary incontinence in four centres: The UREPIK Study. BJU Int 2003;92:943-7. https://doi.org/10.1111/i.1464-410x.2003.04526.x

319. Davis T, Makovey I, Guralnick ML, et al. Sacral neuromodulation outcomes for the treatment of refractory idiopathic detrusor overactivity stratified by indication: Lack of anticholinergic efficacy vs. intolerability. Can Urol Assoc J 2013;7:176-8. https://doi.org/10.5489/cuaj.1346

320. Yazdany T, Bhatia N, Nguyen J. Determining outcomes, adverse events, and predictors of success after sacral neuromodulation for lower urinary disorders in women. Int Urogynecol J 2011;22:1549-54. https://doi.org/10.1007/s00192-011-1512-2

321. Smits MA, Oerlemans D, Marcelissen TA, et al. Sacral neuromodulation in patients with idiopathic overactive bladder after initial botulinum toxin therapy. J Urol 2013;190:2148-52. htrps://doi.org/10.1016/i. juro.2013.07.017

322. Shih C, Miller JL, Fialkow M, et al. Reoperation after sacral neuromodulation therapy: A single-institution experience. Female Pelvic Med Reconstr Surg 2013;19:175-8. https://doi.org/10.1097/ SPV.0b013e31828ab3c9

323. Angioli R, Montera R, Plotti F, et al. Success rates, quality of life, and feasibility of sacral nerve stimulation in elderly patients: One-year followup. Int Urogynecol J 2013;24:789-94. https://doi.org/10.1007/ s00192-012-1928-3

324. Banakhar $M$, Gazwani $Y$, Kelini $M$, et al. Effect of sacral neuromodulation on female sexual function and quality of life: Are they correlated? Can Urol Assoc J 2014;8:E762-7. https://doi.org/10.5489/ cuai.2300

325. Yih JM, Killinger KA, Boura JA, et al. Changes in sexual functioning in women after neuromodulation for voiding dysfunction. J Sex Med 2013;10:2477-83. https://doi.org/10.1111/ism.12085

326. Siegel S, Noblett K, Mangel J, et al. Results of a prospective, randomized, multicentre study evaluating sacral neuromodulation with InterStim therapy compared to standard medical therapy at six months in subjects with mild symptoms of overactive bladder. Neurourol Urodynam 2015;34:224-30. https://doi.org/10.1002/nau.22544

327. Amundsen C, Richter H, Menefee S, et al. OnabotulinumtoxinA vs. sacral neuromodulation on refractory urgency urinary incontinence in women: A randomized clinical trial. JAMA 2016;316:1366-74. https://doi.org/10.1001/jama.2016.14617

328. Gilbert SM, Hensle TW. Metabolic consequences and long-term complications of enterocystoplasty in children. J Urol 2005;173:1080-6. https://doi.org/10.1097/01.ju.0000155248.57049.4e

329. International Consortium for Health Outcomes Measurement, the Standard Set for OAB. Available at: http://www.ichom.org/medical-conditions/overactive-bladder/. Accessed on March 23, 2017.

330. Patra PB, Patra S. Research findings on overactive bladder. Curr Urol 2015;8:1-21. https://doi.org/10.1159/000365682

331. Andersson KE. Potential future pharmacological treatment of bladder dysfunction. Basic Clin Pharmacol Toxicol 2016;119:75-85. https://doi.org/10.1111/bcpt.12577

332. McCloskey KD. Interstitial cells in the urinary bladder - localization and function. Neurourol Urodyn 2010;29:82-7. https://doi.org/10.1002/nau.20739

333. Cartwright R, Afshan I, Derpapas A, et al. Novel biomarkers for overactive bladder. Nat Rev Urol 2011;8:139-45. https://doi.org/10.1038/nrurol.2011.7

334. Thiagamoorthy G, Cardozo L, Robinson D. Current and future pharmacotherapy for treating overactive bladder. Expert Opin Pharmacother 2016;17:1317-25. https://doi.org/10.1080/14656566.201 6.1186645

335. Gittelman M, Weiss H, Seidman L. A phase 2, randomized, double-blind, efficacy and safety study of oxybutynin vaginal ring for alleviation of overactive bladder symptoms in women. J Urol 2014;191:101421. https://doi.org/10.1016/i.juro.2013.11.019

336. Krause P, Fuhr U, Schnitker J, et al. Pharmacokinetics of intravesical vs. oral oxybutynin in healthy adults: Results of an open-label, randomized, prospective clinical study. J Urol 2013;190:1791-7. https://doi.org/10.1016/i.juro.2013.05.011

337. Rosa GM, Ferrero $S$, Nitti VW, et al. Cardiovascular safety of 3-adrenoceptor agonists for the treatment of patients with overactive bladder syndrome. Eur Urol 2016;69:311-23. https://doi.org/10.1016/i. eururo.2015.09.007

338. Ohlstein EH, von Keitz A, Michel MC. A multicentre, double-blind, randomized, placebo-controlled trial of the 3-adrenoceptor agonist solabegron for overactive bladder. Eur Urol 2012;62:834-40. https://doi.org/10.1016/i.eururo.2012.05.053

339. Hanna-Mitchell AT, Kashyap M, Chan WV, et al. Pathophysiology of idiopathic overactive bladder and the success of treatment: A systematic review from ICI-RS 2013. Neurourol Urodyn 2014;33:611-7. https://doi.org/10.1002/nau.22582

340. Wagg A, Majumdar A, Toozs-Hobson P, et al. Current and future trends in the management of overactive bladder. Int Urogynecol J Pelvic Floor Dysfunct 2007;18:81-94. https://doi.org/10.1007/s00192006-0229-0

341. Gómez Rivas J, Rodríguez Socarrás M, Tortolero Blanco L. Social media in urology: Opportunities, applications, appropriate use, and new horizons. Cent European I Urol 2016;69:293-8.

342. Chapple CR, Kelleher CJ, Evans CJ, et al. A narrative review of patient-reported outcomes in overactive bladder: What is the way of the future? Eur Urol 2016; 70:799-805. https://doi.org/10.1016/j. eururo.2016.04.033

343. Cotterill N, Goldman H, Kelleher C, et al. What are the best outcome measures when assessing treatment for LUTD? Achieving the most out of outcome evaluation: ICI-RS 2011. Neurourol Urodyn 2012;31:400-3. htrps://doi.org/10.1002/nau.22210

344. Goldman HB, Wyndaele JJ, Kaplan SA, et al. Defining response and non-response to treatment in patients with overactive bladder: A systematic review. Curr Med Res Opin 2014;30:509-26. https://doi.org/1 $0.1185 / 03007995.2013 .860021$

345. Mangera A, Chapple CR, Kopp ZS, et al. The placebo effect in overactive bladder syndrome. Nat Rev Urol 2011;8:495-503. https://doi.org/10.1038/nrurol.2011.99

346. Wagg A, Duckett J, McClurg D, et al. To what extent are national guidelines for the management of urinary incontinence in women adhered? Data from a national audit. BJOG 2011;118:1592-600. https://doi.org/10.1111/i.1471-0528.2011.03100.x

347. Irwin DE, Milsom I, Kopp Z, et al. Symptom bother and healthcare-seeking behaviour among individuals with overactive bladder. Eur Urol 2008;53:1029-37. https://doi.org/10.1016/i.eururo.2008.01.027

348. Brown JS, Vittinghoff E, Wyman JF, et al. Urinary incontinence: Does it increase risk for falls and fractures? Study of Osteoporotic Fractures Research Group. J Am Geriatr Soc 2000;48:721-5. https://doi. org/10.1111/j.1532-5415.2000.tb04744.x 
Guideline: Adult overactive bladder

349. Thom DH, Haan MN, Van Den Eeden SK. Medically recognized urinary incontinence and risks of hospitalization, nursing home admission, and mortality. Age Ageing 1997;26:367-74. https://doi.org/10.1093/ ageing/26.5.367

350. Gibson W, Wagg A. New horizons: Urinary incontinence in older people. Age Ageing 2014;43:157-63. https://doi.org/10.1093/ageing/aft214
Correspondence: Dr. Jacques Corcos, Department of Urology, Jewish General Hospital, Montreal, QC, Canada; icorcos@uro.jgh.mcgill.ca 